\title{
An evaluation of current West Virginia specifications and construction methods regarding the density of hot mix asphalt
}

Andrew Rudolph

West Virginia University

Follow this and additional works at: https://researchrepository.wvu.edu/etd

\section{Recommended Citation}

Rudolph, Andrew, "An evaluation of current West Virginia specifications and construction methods regarding the density of hot mix asphalt" (2006). Graduate Theses, Dissertations, and Problem Reports. 3267.

https://researchrepository.wvu.edu/etd/3267

This Thesis is protected by copyright and/or related rights. It has been brought to you by the The Research Repository @ WVU with permission from the rights-holder(s). You are free to use this Thesis in any way that is permitted by the copyright and related rights legislation that applies to your use. For other uses you must obtain permission from the rights-holder(s) directly, unless additional rights are indicated by a Creative Commons license in the record and/ or on the work itself. This Thesis has been accepted for inclusion in WVU Graduate Theses, Dissertations, and Problem Reports collection by an authorized administrator of The Research Repository @ WVU. For more information, please contact researchrepository@mail.wvu.edu. 


\title{
An Evaluation of Current West Virginia Specifications and Construction Methods Regarding the Density of Hot Mix Asphalt
}

\section{Andrew Rudolph}

Thesis submitted to the College of Engineering and Mineral Resources at West Virginia University in partial fulfillment of the requirements for the degree of

\author{
Master of Science \\ In \\ Civil Engineering
}

\author{
Dr. John P. Zaniewski, Chair \\ Dr. Ronald W. Eck \\ Mr. Thomas Medvick \\ Department of Civil Engineering \\ Morgantown, West Virginia \\ 2006
}

Keywords: Density, Compaction, Longitudinal Joints, Quality Control, West Virginia Specifications 


\title{
ABSTRACT \\ An Evaluation of Current West Virginia Specifications and Construction Methods Regarding the Density of Hot Mix Asphalt
}

\begin{abstract}
Andrew Rudolph
Pavement performance depends on the quality of the material, the mix design, and construction. The objectives of pavement construction are to place the material with a smooth surface, and compacted to the target density. Inadequate density permits water to enter the pavement leading to premature distress. It also can contribute to rutting as the pavement densify. A surface that is too dense is also prone to rutting.

This research evaluated methods for: measuring density, quality control, and longitudinal joint construction. Density specifications for West Virginia and surrounding states were reviewed to assess the compaction requirements for hot mix asphalt (HMA).

This research proposes several changes to West Virginia's construction specifications, including the use of the nuclear gauge and a minimum density requirement for longitudinal joint. Some state-of-the-art construction techniques are presented to aid the contractor in obtaining the target density. Recommendations are also made for further research.
\end{abstract}




\section{ACKNOWLEDGMENTS}

I would like to express my gratitude to Dr. John Zaniewski, my advisor, for his help, support, and patience during the pursuit of my Master of Science in Civil Engineering degree. Dr. Zaniewski’s insight and advice was particularly helpful during my research. I would like to thank Mr. Thomas Medvick for his time and assistance during this research endeavor, and for his willingness to serve on my committee. I would also like to thank Dr. Ronald Eck for his time and willingness to serve on my committee.

The support shown by my brothers Jay, Bryan, and Jeremy, my sister Aimee, my uncle Mike, my aunt Becky, my nephews Taylor and Heath, and the rest of my family is greatly appreciated. I would also like to thank my close friends Thomas Sheets and Amanda Hedrick for their love and support. Most of all, I would like to thank my father Jack Rudolph. Your confidence in me is my source of motivation. 


\section{TABLE OF CONTENTS}

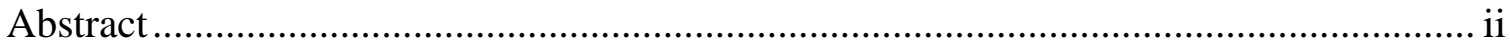

Acknowledgments................................................................................................. iii

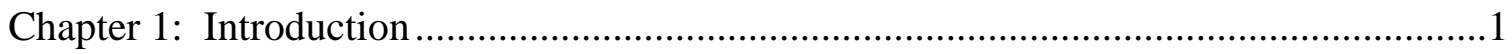

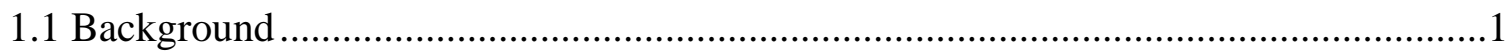

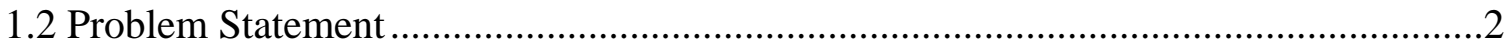

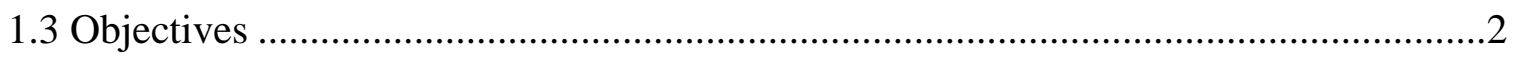

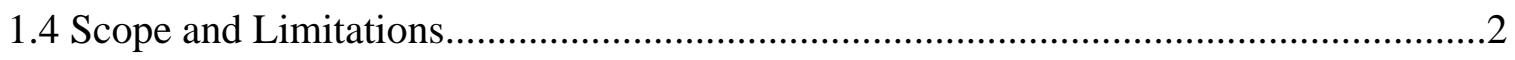

1.5 Thesis Organization ...................................................................................................

Chapter 2: Literature Review....................................................................................

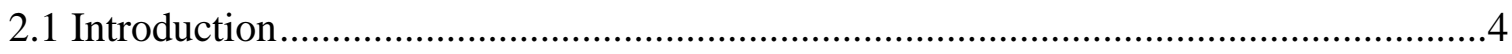

2.2 Description of Joints and Lanes .............................................................................

2.3 Rollers and Compaction..........................................................................................

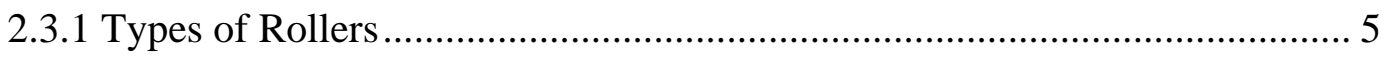

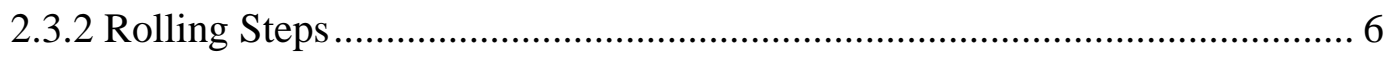

2.3.3 Techniques for Rolling Longitudinal Joints ................................................ 7

2.4 Joint Placement Techniques....................................................................................

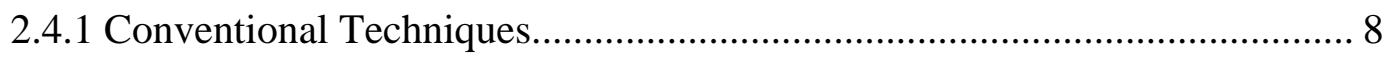

2.4.2 Michigan Wedge .................................................................................. 9

2.4.3 New Jersey Wedge (3:1) ................................................................... 9

2.4.4 Tapered 3:1 with 1" Offset ........................................................................... 10

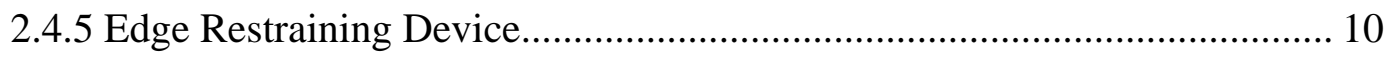

2.4.6 Cutting Wheel (or Joint Trimming) ............................................................. 10

2.4.7 Cutting Wheel with Tack Coat ................................................................... 11 
2.4.8 Rubberized Asphalt Tack Coat ........................................................................ 11

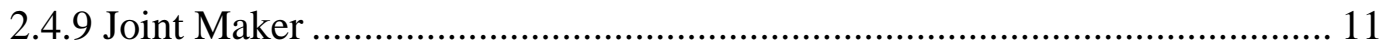

2.4.10 Joint Heating ......................................................................................... 11

2.4.11 Summary of Joint Placement Techniques.................................................. 13

2.5 Joint Density Measurement....................................................................................13

2.5.1 Quality Control ....................................................................................... 13

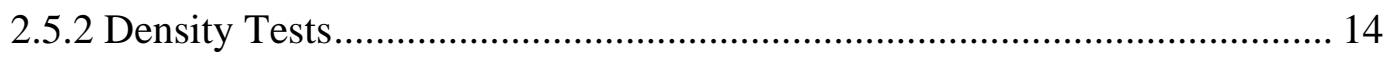

2.5.2.1 Laboratory Methods ................................................................................14

2.5.2.2 Nuclear Density Gauges ......................................................................14

2.5.2.3 Dielectric Devices for Measuring Density....................................................17

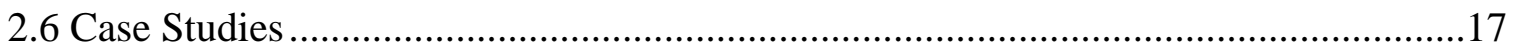

2.6.1 Wisconsin Department of Transportation.................................................... 17

2.6.2 National Center for Asphalt Technology ……………………........................ 20

2.6.3 Kentucky Transportation Center............................................................... 22

2.7 Review of Current Specifications for Density …………………………………........23

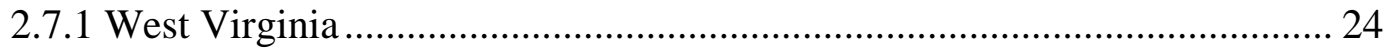

2.7.2 Pennsylvania ........................................................................................... 26

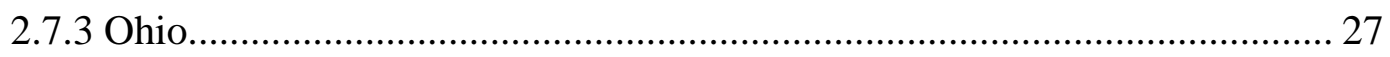

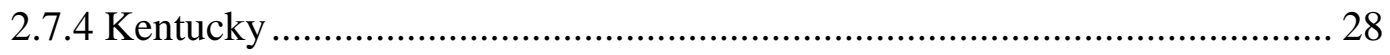

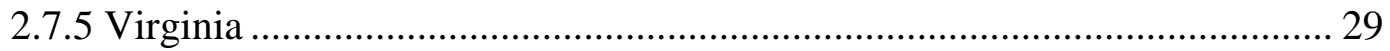

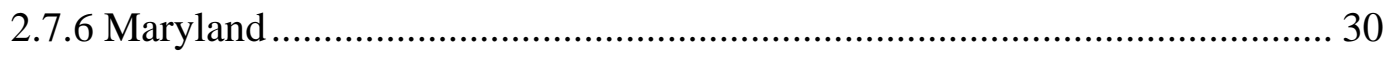

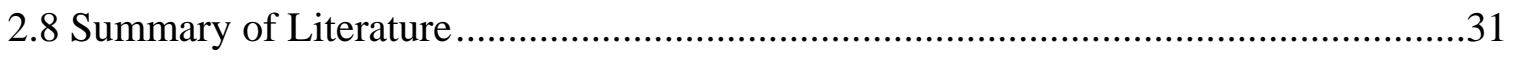

Chapter 3: Research Methodology..............................................................................33

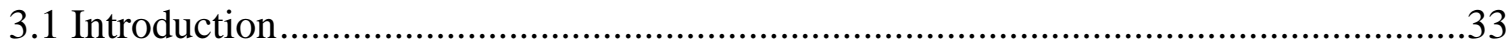


3.2 Field Density Measurement ...........................................................................................33

3.3 Lab Density Procedure...............................................................................................35

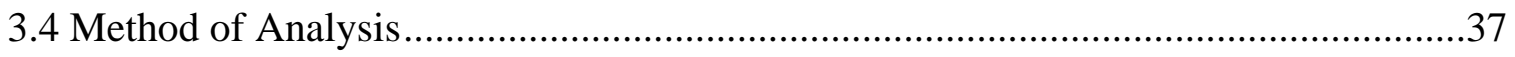

Chapter 4: Results and Analysis ..................................................................................40

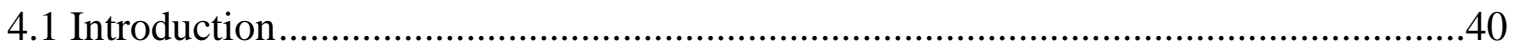

4.2 Visual Inspection of Longitudinal Joints .....................................................................40

4.3 Comparison of Mat and Joint Densities......................................................................4

4.4 Rollerpass and Lot Methods for Quality Control …………….....................................44

4.5 Corrections to Nuclear Density Gauge Readings .........................................................49

4.6 Methods for Measuring Specific Gravity ………………………………….............49

4.6.1 Comparing the SSD and Paraffin Methods................................................... 52

4.6.2 Comparing the Nuclear Density Gauge to the Thin-lift Gauge .................... 56

4.6.3 Comparing Paraffin Method to the Nuclear Density Gauge.......................... 58

4.6.4 Comparing SSD Method to the Thin-lift Density Gauge ............................. 61

4.6.5 Comparing the SSD Method to the Nuclear Density Gauge ........................ 63

4.6.6 Comparing the Thin lift Gauge to the Paraffin Method................................ 68

Chapter 5: Conclusions and Recommendations ..............................................................70

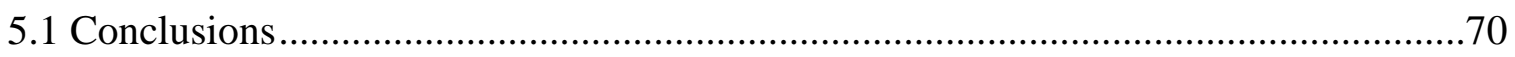

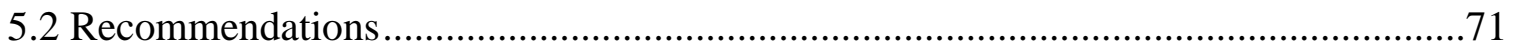

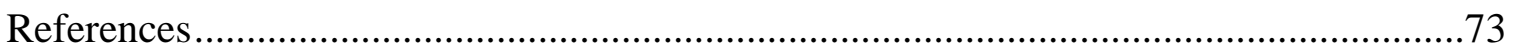

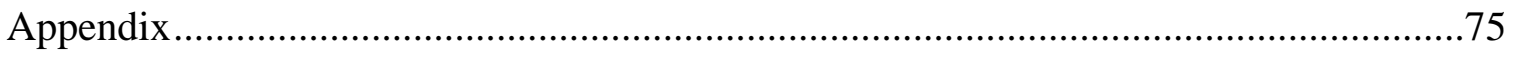




\section{LIST OF FIGURES}

Figure 2.1: Vibratory Roller Drum ..........................................................................

Figure 2.2: Oscillatory Roller Drum...........................................................................6

Figure 2.3: Rolling from the Hot Side ..........................................................................

Figure 2.4: Rolling from the Cold Side ..........................................................................

Figure 2.5: Rolling from the Hot Side 6" Away from the Joint ...........................................8

Figure 2.6: (a) Hot Lane Overlapping the Cold Lane, (b) Lanes without Overlap .............9

Figure 2.7: Basic Wedge Configuration with an Offset ...................................................

Figure 2.8: Edge Restraining Device .........................................................................10

Figure 2.9: Schematic of a Joint Maker ...........................................................................11

Figure 2.10: Joint Maker Attached to the End Gate of a Paver ..........................................12

Figure 2.11: (a) Infrared Heater; (b) Infrared Heater Attached to the Side of the Paver

Screed; (c) Effect that the Infrared Heater has on Pavement Temperature ...........12

Figure 2.12: Nuclear Density Gauge ............................................................................15

Figure 2.13: Thin-lift Nuclear Gauge .......................................................................16

Figure 2.14: Operating Principle of Pavement Quality Indicator ......................................17

Figure 2.15: WSDOT Test Section Layout...................................................................18

Figure 3.1: Placement of Nuclear Density Gauge with Respect to the Core Sample.......34

Figure 3.2: Orientation of the Nuclear Density Gauge for each Reading with Respect to the Core Sample ..........................................................................................................35

Figure 4.1: Visually Good Joints ...............................................................................

Figure 4.2: Visually Bad Joints....................................................................................42

Figure 4.3: Comparison Between Visually Good and Bad Joints using SSD Data..........42

Figure 4.4: Comparison Between Visually Good and Bad Joints using Paraffin Data ....43

Figure 4.5: Comparison of Mat and Joint Densities using the Paraffin Data for I-77 ......45 
Figure 4.6: Comparison of Mat and Joint Densities using the Paraffin Data for I-79

(Elkview).

Figure 4.7: Comparison of Mat and Joint Densities using the Paraffin Data for US-60 ..46

Figure 4.8: Comparison of Mat and Joint Specific Gravities using Paraffin Data for

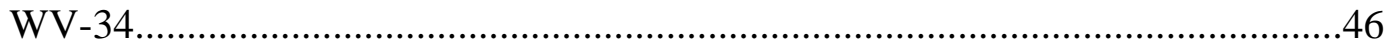

Figure 4.9: Comparison of Mat and Joint Specific Gravities using the SSD Data..........48

Figure 4.10: Comparison of Rollerpass and Lot Methods using SSD Data ....................48

Figure 4.11: Comparison of Rollerpass and Lot Methods using Nuclear Gauge Data.....49

Figure 4.12: Nuclear Density Gauge Measurements Corrected for Base Density ...........51

Figure 4.13: SSD and Paraffin Data for I-77 Project...................................................52

Figure 4.14: SSD and Paraffin Data for I-79 (Elkview) Project....................................53

Figure 4.15: SSD and Paraffin Data for US-60 Project..............................................53

Figure 4.16: SSD and Paraffin Data for WV-622 Project ..........................................54

Figure 4.17: SSD and Paraffin Data for WV-114 Project ..........................................54

Figure 4.18: SSD and Paraffin Data for CR-39 Project..............................................55

Figure 4.19: SSD and Paraffin Data for WV-34 Project ............................................56

Figure 4.20: Nuclear Gauge and Thin-lift Gauge Data for WV-622 Project....................57

Figure 4.21: Nuclear Gauge and Thin-lift Gauge Data for US-60 project ......................57

Figure 4.22: Nuclear Gauge and Paraffin Data for US-60 Project .................................58

Figure 4.23: Nuclear Gauge and Paraffin Data for WV-622 Project...............................59

Figure 4.24: Nuclear Gauge and Paraffin Data for CR-39 Project .................................59

Figure 4.25: Nuclear Gauge and Paraffin Data for WV-34 Project................................60

Figure 4.26: Nuclear Gauge and Paraffin Data for WV-114 Project..............................61

Figure 4.27: SSD and Thin-lift Gauge Data for WV-622 Project .................................62

Figure 4.28: SSD and Thin-lift Gauge Data for US-60 Project....................................62 
Figure 4.29: SSD and Nuclear Gauge Data for I-64 Project.......................................63

Figure 4.30: SSD and Nuclear Gauge Data for I-79 (Big Otter) Project........................64

Figure 4.31: SSD and Nuclear Gauge Data for CR-39 Project.....................................64

Figure 4.32: SSD and Nuclear Gauge Data for US-60 Project...................................65

Figure 4.33: SSD and Nuclear Gauge Data for WV-622 Project .................................65

Figure 4.34: SSD and Adjusted Nuclear Gauge Data for the WV-34 Project.................66

Figure 4.35: SSD and Adjusted Nuclear Gauge Data for the WV-16 Project.................67

Figure 4.36: SSD and Adjusted Nuclear Gauge Data for the WV-114 Project...............67

Figure 4.37: Thin-lift Gauge and Paraffin Data for the WV-622 Project........................68

Figure 4.38: Thin-lift Gauge and Paraffin Data for the US-60 Project ..........................69 


\section{LIST OF TABLES}

Table 2.1: Summary of Joint Placement Techniques.................................................13

Table 2.2: Section Stations and Lengths ..................................................................18

Table 2.3: Percent Maximum Density ….................................................................19

Table 2.4: Percent of Longitudinal Cracking after Ten Years.......................................19

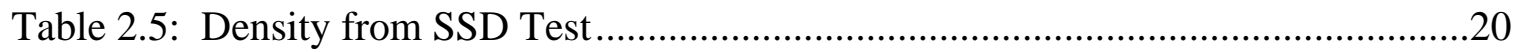

Table 2.6: Density from Nuclear Density Gauge......................................................20

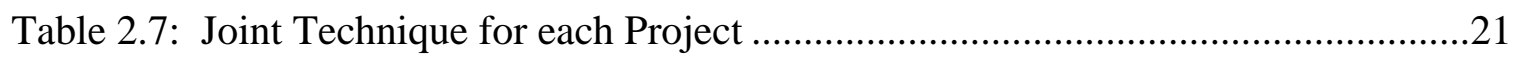

Table 2.8: Density Requirements Specified by KDOT ….........................................29

Table 2.9: Compaction Procedures Governed by State Specifications............................32

Table 3.1: Summary of the Density Measurements Recorded .....................................39

Table 3.2: Projects Used in Various Comparisons ....................................................39

Table 4.1: t-Test Comparing Good and Bad Joint Density ...........................................43

Table 4.2: t-Test Comparing Mat and Joint Specific Gravities using Paraffin and SSD

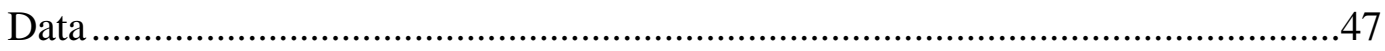

Table 4.3: t-Test Comparing Mat and Joint Specific Gravities using SSD Data..............48

Table 4.4: t-Test Comparing Rollerpass to Lot Method .............................................49

Table 4.5: Project Data Available for each Comparison .............................................50

Table 4.6: Comparison of SSD and Paraffin Methods using the t-Test..........................55

Table 4.7: Comparison of SSD and Paraffin Tests using the $\mathrm{z}-$ Test...............................56

Table 4.8: t-Test Comparing Thin-lift Gauge to Nuclear Gauge ...................................58

Table 4.9: t-Test Comparing Paraffin Data to Unadjusted Nuclear Density Gauge Data 60

Table 4.10: t-Test Comparing Paraffin Data to Adjusted Nuclear Density Gauge Data..61

Table 4.11: t-test Comparing SSD and Thin-lift Density Gauge Data ...........................63 
Table 4.12: t-Test Comparing SSD and Nuclear Density Gauge Data...........................66

Table 4.13: t-test Comparing SSD Data to Adjusted Nuclear Density Gauge Data.........68

Table 4.14: t-Test Comparing Paraffin and Thin-lift Gauge Data.................................69

Table 5.15: Results of Comparison Between Testing Methods.....................................70

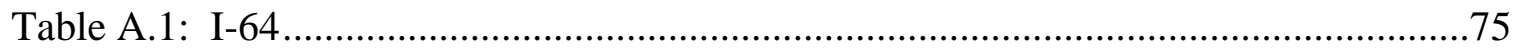

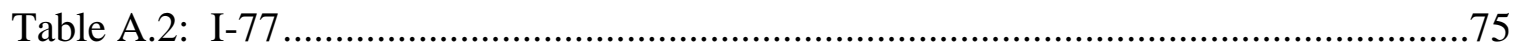

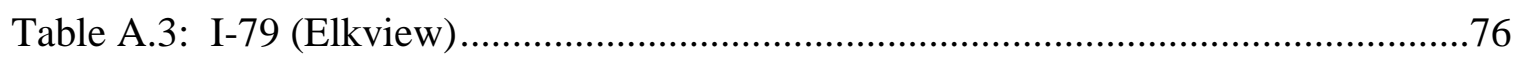

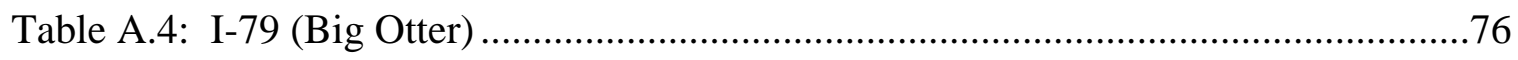

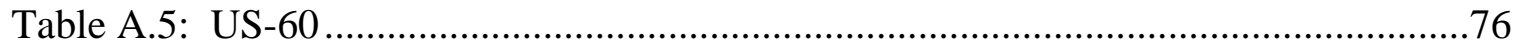

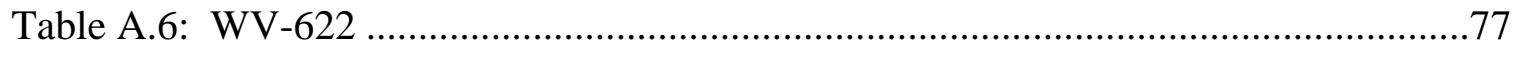

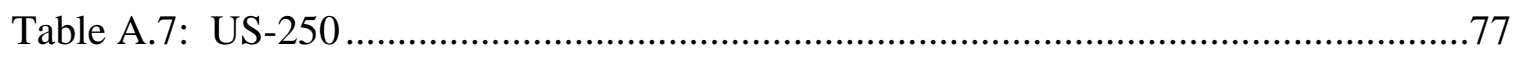

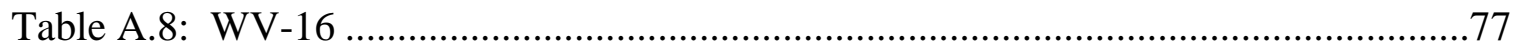

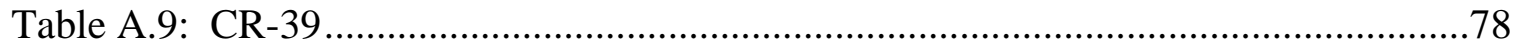

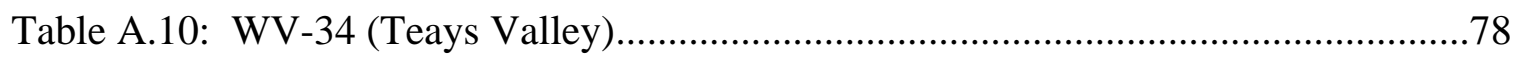

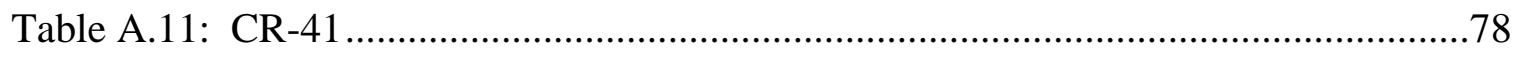

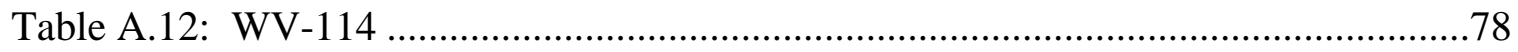

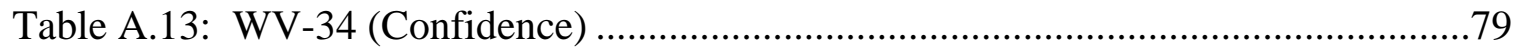




\section{CHAPTER 1: INTRODUCTION}

\subsection{BACKGROUND}

When constructing a bituminous pavement structure, a great emphasis is placed on achieving the target density. If the density is too low, the pavement is permeable and susceptible to damage from freeze-thaw and other effects caused by the presence of water in the structure. If the density is too high, the pavement has a higher potential for premature rutting, pushing, and shoving (Brown 1990).

Rollers are a common tool used to compact hot mix asphalt (HMA). The roller exerts force on the pavement surface causing the aggregate in the mix to reorient into a denser configuration. The liquid asphalt aides the compaction process by acting as a lubricant while hot.

The ability to quickly and effectively measure density during the pavement construction process is crucial to ensuring that the pavement structure has the proper density. Until the late 1960's, most agencies did not impose density requirements (Caterpillar 2003). Specifications governing the method of placement were used until distresses began to occur in pavement structures. Specifications were then changed to govern the end result instead of the method of placement.

Initially, core samples were used to determine the density of a pavement structure. Coring is slow, expensive, and destructive; so a new method was needed to quickly determine the density at the job site. The nuclear density gauge is often used since it can determine the density within minutes, which can allow for further compacting after testing. But the nuclear density gauge has limitations. The Caterpillar Compaction Manual lists these limitations for the nuclear density gauge:

- The gauge reading for the standard thick-lift nuclear gauge is influenced by the density of all material within 4” of the surface.

- The accuracy of the gauge reading is compromised if the surface of the test area is rough and allows for an air gap between the material and the gauge. 
- The reading can be influenced by the chemical composition of the aggregate in the mix. A siliceous aggregate and a calcareous aggregate could differ by as much as $5 \mathrm{lb} / \mathrm{ft}^{3}$.

- The precision of the nuclear gauge is often questioned.

With modern technology, contractors can compact the mat to the target density without many complications. But there are many problems when compacting the joint. As a result, in 1992 the National Center for Asphalt Technology (NCAT) coordinated a research project to study various methods for placing the joint (Kandhal and Mallick, 1997). Many state highway agencies have conducted studies of their own since that study.

The standard nuclear gauge and the thin-lift nuclear gauge will be used in this report. The term "nuclear gauge" will refer to the standard nuclear gauge that is not designed specifically for thin overlays.

\subsection{PROBLEM STATEMENT}

Great emphasis is put on density during the construction of a flexible pavement structure. West Virginia has specifications to help ensure that compaction is performed properly in order to get a pavement with high quality. These specifications are assessed in order to determine the effectiveness of the specifications and how West Virginia's specifications compare to the specifications of the surrounding states.

\subsection{OBJECTIVES}

The objective of this research is to evaluate the effectiveness of West Virginia's density specifications. With this information, recommendations for changing the specifications can be made.

\subsection{SCOPE AND LIMITATIONS}

This research focused on density practices used in West Virginia. Methods for measuring the field density, including the nuclear gauge and the thin-lift nuclear gauge, are assessed and compared along with the SSD and paraffin methods for testing cores. 
The effectiveness of the rollerpass method of quality control is compared to the lot method.

An emphasis is placed on the density at the longitudinal joint. Various longitudinal joint placement techniques are studied and compared. Methods for operating the roller at the joint are also reviewed.

Some of the data used in this experiment was provided by the contractor and the West Virginia Division of Highways (WVDOH). As a result, this research was designed around that given data. The data provided were not structured using proper experimental design techniques. As a result, only tentative conclusions can be formulated based on this data set.

\subsection{THESIS ORGANIZATION}

Chapter 2 reviews various types of rollers along with rolling techniques for the joint. Joint placement techniques are then studied. A description of the nuclear gauge and thin-lift nuclear gauge is provided. Some case studies and an overview of the specifications used by West Virginia and the surrounding states are also reviewed.

Chapter 3 discusses the experimental plan and explains the field and lab test procedures followed during the process of this research.

Chapter 4 compares the specific gravity of visually good and poor looking joints. A comparison between the mat and joint specific gravities is made followed by a comparison between the rollerpass and lot methods of quality control. Comparisons are then made between the various lab and field techniques for testing density.

Chapter 5 presents conclusions from this research and recommendations for further research.

Data assembled during the research are presented in the appendix. 


\section{CHAPTER 2: LITERATURE REVIEW}

\subsection{INTRODUCTION}

Various joint compaction techniques have been tested and studied since 1990. Information on these studies and their results is well documented by credible agencies such as the National Center for Asphalt Technology (NCAT) and Department of Transportation organizations from various states. Several studies have also been conducted comparing various techniques for measuring the field density of thin asphalt overlays. The information available from these sources forms the basis for planning this research.

Knowledge of the terminology and definitions of the various compaction techniques is necessary for this study. Once this is reviewed, studies performed by the above mentioned organizations are described. The current hot mix asphalt concrete (HMAC) compaction specifications used by West Virginia and the surrounding states are reviewed and compared. Conclusions are made as to whether or not each specification is adequate in order to ensure proper compaction.

\subsection{DESCRIPTION OF JOINTS AND LANES}

There are three longitudinal joint types used in the construction of flexible pavements. Foster, et al. (1964) defined these joints as:

Hot Joint - A hot joint is produced with pavers operating in echelon spaced close enough together so that the lane placed first does not cool significantly before the second lane is placed.

Semi-Hot Joint - A semi-hot joint is produced when there is a restriction on the distance a paver may proceed before paving the adjacent lane to match the first lane. The material in the first lane cools to about $120^{\circ} \mathrm{F}$ to $140^{\circ} \mathrm{F}$ before the adjacent lane is placed.

Cold Joint - A cold joint occurs where the first lane has cooled overnight or longer before the next lane is placed or where the first lane is carried so far ahead that the face has cooled to well below $120^{\circ} \mathrm{F}$.

The lanes are described in a similar manner: 
Hot Lane - The most recently paved lane.

Cold Lane - The lane has already been placed and compacted with a roller.

\subsection{ROLLERS AND COMPACTION}

\subsubsection{Types of Rollers}

The most commonly used rollers can be classified as static or dynamic. Some common static rollers include:

Static Steel Wheel Roller - Rollers with static drums use the effective dead weight of the machine to apply pressure on the surface. This is commonly referred to as a three wheel roller.

Pneumatic Roller - Rollers with a series of rubber tires used in place of a steel drum.

Dynamic rollers include:

Vibratory Roller - The shaft of the drum is attached to a mass, as shown in

Figure 2.1. This mass spins rapidly around the shaft to produce the vibrations exerted by the drum. Compaction is achieved mainly by the series of compression waves penetrating the soil or the asphalt in combination with the effective static weight of the drum. The resulting compaction force is almost vertical (Briaud and Seo, 2003). Vibratory rollers can also be operated in static mode for finish passes.

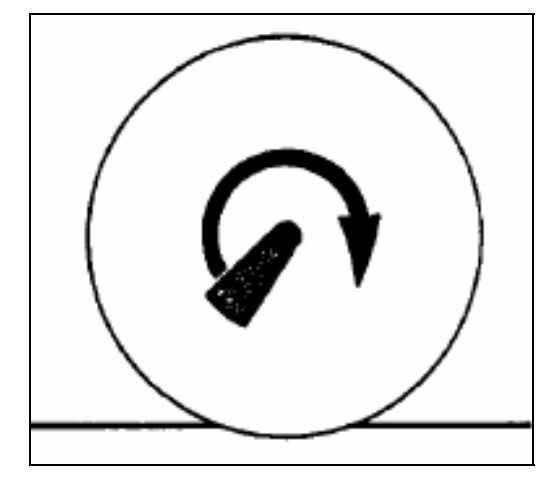

Figure 2.1: Vibratory Roller Drum 
The frequency and amplitude of the vibrations can be controlled. Generally, thicker lifts require higher amplitude and a lower frequency compared to thin lifts (Roberts, et al., 1996). The compaction force comes from the weight of the roller and the force generated from the centrifugal weight.

Oscillatory Roller - A new development in roller technology, this roller uses two opposite rotating eccentric masses as shown in Figure 2.2. This causes movement in the horizontal and vertical directions. Compaction is achieved mainly by transmitted shear waves through the material (Briaud and Seo, 2003).

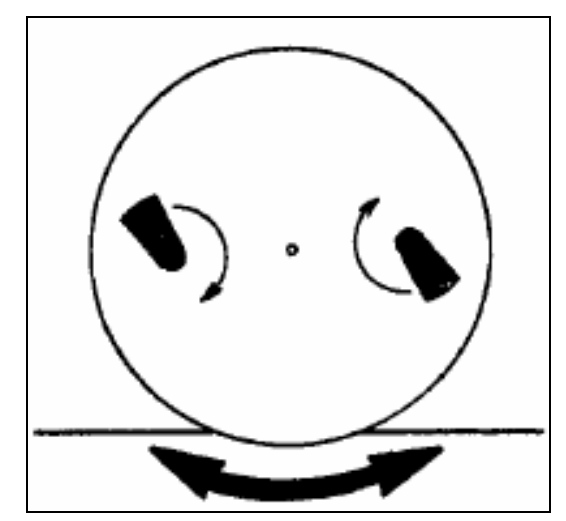

Figure 2.2: Oscillatory Roller Drum

\subsubsection{Rolling Steps}

Compaction of asphalt is done in three steps:

Breakdown rolling - Rolling is done while the mat is still soft (mat temperature is higher than $175^{\circ} \mathrm{F}$ ) with a static or vibratory roller. The mat is rolled in order to achieve the required density.

Intermediate rolling - If the required density cannot be achieved with a single roller, an intermediate static or dynamic roller can be used in addition to the breakdown roller. 
Finish rolling - The purpose of finish rolling is to remove marks that may have been left by the previous rollers or by the paver, and to make the surface as smooth as possible. A static roller must be used.

\subsubsection{Techniques for Rolling Longitudinal Joints}

The three different rolling techniques used to compact the joint are:

Rolling from the hot side - When rolling from the hot side, the roller is operated over the hot lane in the vibratory mode while maintaining a 6” (152mm) overlap onto the cold side, as demonstrated in Figure 2.3. This overlap prevents the lanes from being uneven.

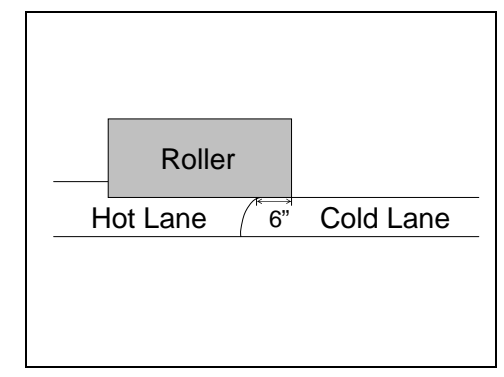

Figure 2.3: Rolling from the Hot Side

Rolling from the cold side - The roller is operated in static mode over the cold lane with a 6” (152mm) overlap on the hot lane, as shown in Figure 2.4. The idea behind this method is that this has a "pinching” effect on the joint (Kandhal, Ramirez, and Ingram, 2001).

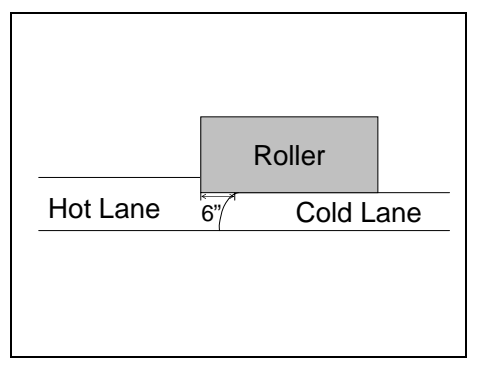

Figure 2.4: Rolling from the Cold Side 
Rolling from the hot side 6” (152mm) away from the joint - The roller is operated in vibratory mode over the hot lane while maintaining a distance of 6” (152mm) from the joint, as displayed in Figure 2.5. This pushes the asphalt laterally toward the joint. After the initial pass is completed, the joint is rolled from the hot side to "pinch" the material at the joint.

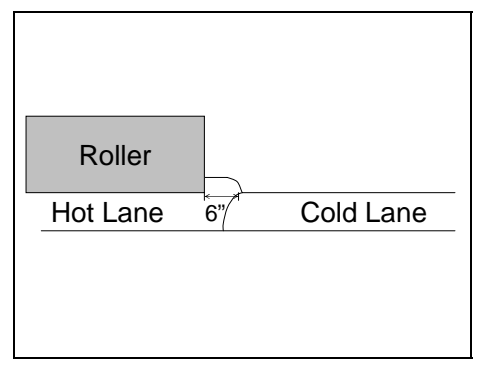

Figure 2.5: Rolling from the Hot Side 6” Away from the Joint

\subsection{JOINT PLACEMENT TECHNIQUES}

Most contractors prefer to roll from the hot side when compacting the material at the joint. The colder, stiffer pavement in the cold lane can prevent the material on the hot side of the joint from receiving the full compactive effort. If the roller does not use the 6” overlap when rolling from the hot side and operates the roller edge along the joint, then the pavement may shear at the joint.

This section describes various techniques and machines that are designed to compact the material at the joint to achieve high density and low permeability.

\subsubsection{Conventional Techniques}

This method calls for no special joint treatment. The first lane is placed and compacted. If the material at the edge of the lane is not restrained there may not be sufficient resistance to the compaction effort resulting in low density at the joints.

When the second lane is placed, paver screed is typically operated with a 6" overlap on the cold lane as shown in Figure 2.6. When the overlap material is compacted, the density of the material in the cold side of the joint is increased. The 6" overlap is not required, but is preferred by contractors since it does not require as much operator skill (Kandhal and Mallick, 1997). 


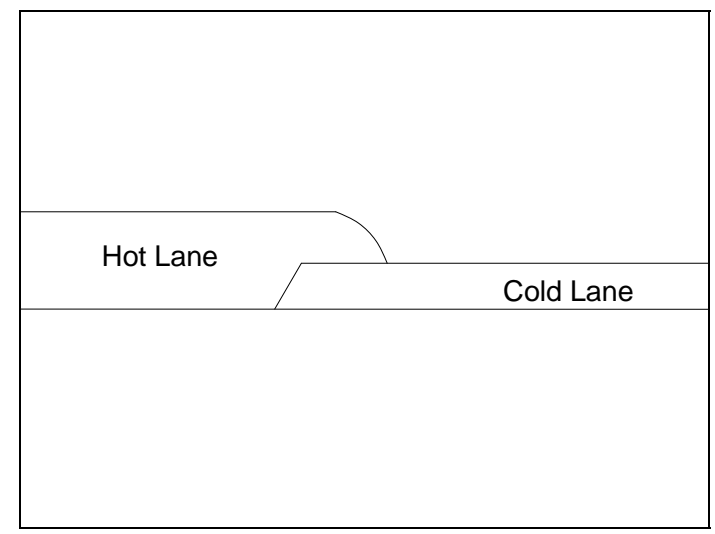

(a)

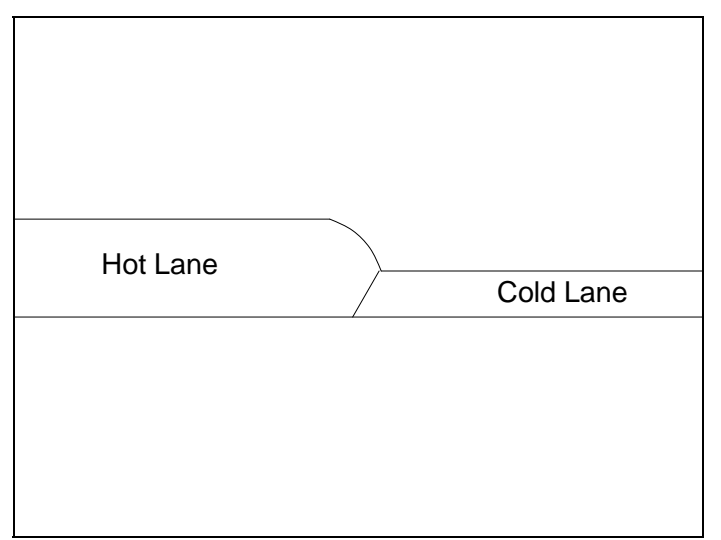

(b)

Figure 2.6: (a) Hot Lane Overlapping the Cold Lane, (b) Lanes without Overlap

\subsubsection{Michigan Wedge}

This joint uses a slope of 12:1 (horizontal/vertical) for the taper and no offset. Figure 2.7 shows this configuration with an offset, which is $1 / 2$ ” for the Michigan wedge. The wedge is formed by attaching a steel plate to the paver screed. The unconfined edge is then compacted with a small roller that is attached to the paver. This method should be limited to pavements with a lift thickness of 1.5” or greater (Fleckenstein, Allen, and Schultz, 2002). Tack coat can also be used on the exposed face of the wedge if needed.

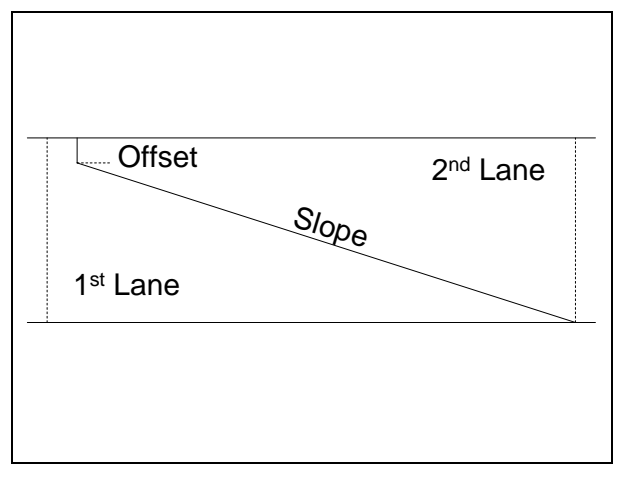

Figure 2.7: Basic Wedge Configuration with an Offset

\subsubsection{New Jersey Wedge (3:1)}

This technique calls for a wedge that has a 3:1 slope as shown in Figure 2.7., but without an offset. The desired shape is achieved by using a sloping steel plate attached to 
the inside corner of the paver screed, or the screed extension if used. The roller stays approximately 3 to 5” away from the top edge of the wedge joint slope. Asphalt is luted 3 to 4 ” on the hot side of the joint. An infrared heater is recommended to reheat the cold lane.

\subsubsection{Tapered 3:1 with 1" Offset}

Developed in Colorado, this method uses a vertical step for the top inch of a pavement layer. A 3:1 taper is used for the joint beneath the top 1” layer. The vertical edge does not get a tack coat, but a tack coat is used on the taper before the hot lane is placed. The taper is produced by dragging a steel sheet behind the paver screed.

\subsubsection{Edge Restraining Device}

An edge compaction device provides restraint when placing a lane. A hydraulically powered wheel, usually tapered as shown in Figure 2.8, is used to provide lateral resistance. The adjacent lane is then butted against the compacted edge.

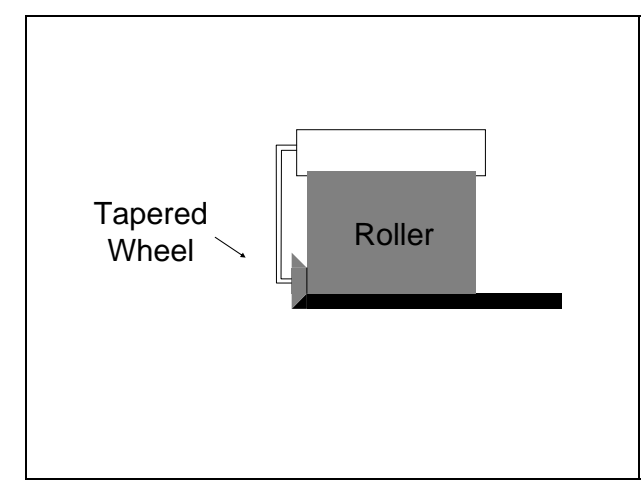

Figure 2.8: Edge Restraining Device

\subsubsection{Cutting Wheel (or Joint Trimming)}

This device removes 2" (50mm) of pavement along the unconfined edge after compaction while the mix is still soft. A 10 inch diameter cutting wheel mounted on an intermediate roller is generally used. Alternatively, the cutting wheel can also be mounted to a grader. A concrete saw can be used, but is slow and inefficient. 


\subsubsection{Cutting Wheel with Tack Coat}

This is done the same way as the cutting wheel. A tack coat is placed on the vertical face before the placement of the hot lane.

\subsubsection{Rubberized Asphalt Tack Coat}

The unconfined edge is not tapered. A rubberized asphalt tack coat (i.e. Crafco pavement joint adhesive) is placed on the unconfined edge before placing the adjacent lane. This coat should be about $1 / 8$ ” thick.

\subsubsection{Joint Maker}

A device is used to force additional material to the joint. This is done by forcing extra material through the paver the screed. A schematic of this device is shown in Figure 2.9. The device is shown in Figure 2.10. This device is attached to the front corner of the screed. A kicker plate can also be used to lute back the overlapped asphalt, which eliminates the need for a lute man.

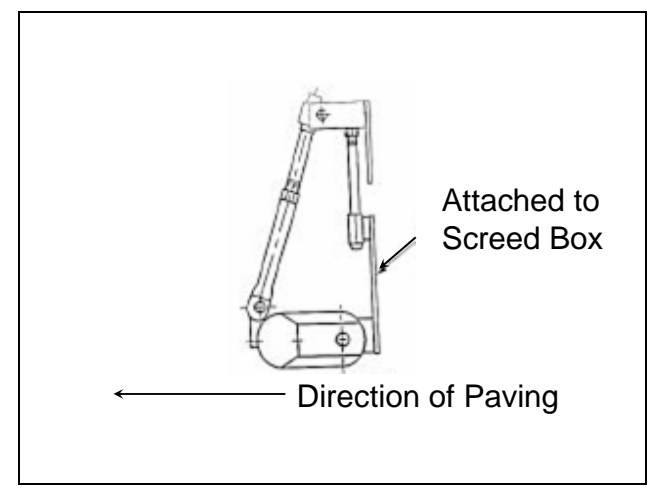

Figure 2.9: Schematic of a Joint Maker

\subsubsection{Joint Heating}

Figure 2.11a shows an infrared joint heater warming the joint. This device is typically mounted on the side of the paver screed as shown in Figure 2.11b. Preheaters can also be operated in front of the screed if necessary as seen in Figure 2.11c. Joint heaters are designed to heat the asphalt up to decrease viscosity prior to the placing of the hot lane. The decrease in viscosity makes the mix easier to compact. This should result in better joint consolidation which makes the joint denser and less permeable. 


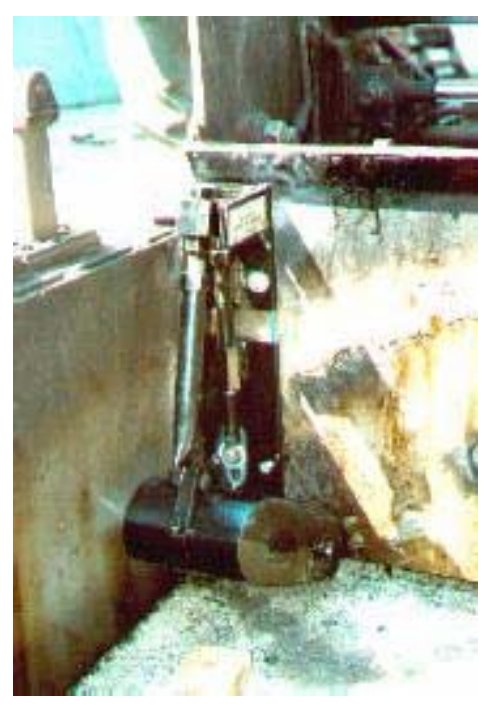

Figure 2.10: Joint Maker Attached to the End Gate of a Paver

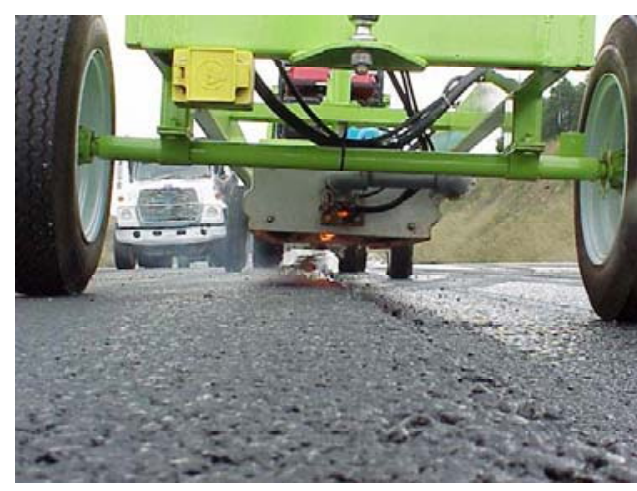

(a)

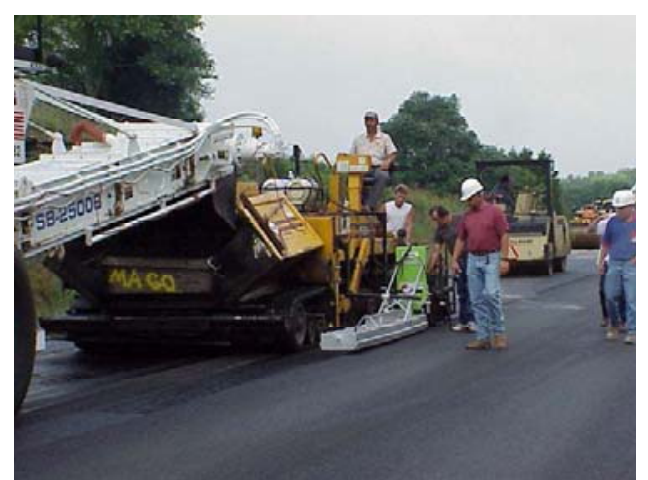

(b)

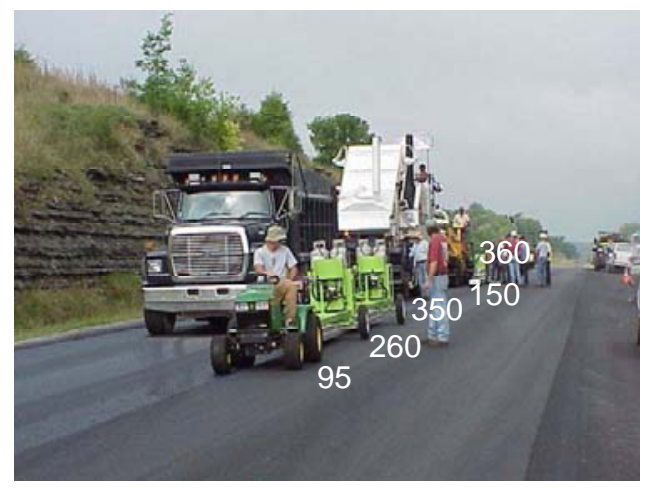

(c)

Figure 2.11: (a) Infrared Heater; (b) Infrared Heater Attached to the Side of the Paver Screed; (c) Effect that the Infrared Heater has on Pavement Temperature 


\subsubsection{Summary of Joint Placement Techniques}

Table 2.1 is a summary of the joint placement techniques introduced in this section along with a brief description of each technique.

Table 2.1: Summary of Joint Placement Techniques

\begin{tabular}{|l|l|}
\hline \multicolumn{1}{|c|}{ Method } & \multicolumn{1}{c|}{ Description } \\
\hline Michigan Wedge $^{\mathrm{a}}$ & 12:1 slope. 1/2" offset can be used. \\
\hline New Jersey Wedge & 3:1 slope. 2" offset can be used. \\
\hline Edge Restraining Device $^{\mathrm{a}}$ & A metal wheel attached to the roller provides lateral resistance. \\
\hline Cutting Wheel $^{\mathrm{a}}$ & 2" of the unconfined edge of the cold lane is removed. \\
\hline Rubberized Asphalt tack coat & An 1/8" thick layer is applied to the joint. \\
\hline Joint Maker & Extra material is forced through the paver screed at the joint. \\
\hline Joint Heater & An Infrared heater is used to warm the cold lane at the joint. \\
\hline${ }_{\text {tack coat can be used }}$
\end{tabular}

\subsection{JOINT DENSITY MEASUREMENT}

In order to properly assess the density of the mat and the joint, a way of measuring the density is needed. It is also important to have a system for checking the density throughout the project.

\subsubsection{Quality Control}

The ability to accurately and precisely measure the density of a pavement is crucial. Water infiltrates through the low-density area with high air voids and results in premature failures (Akpinar and Hossain, 2004). The two methods of quality control for density in West Virginia are lot sampling and roller pass.

According the 2003 revised edition of the West Virginia Division of Highways Standard Specifications for Roadways and Bridges, a lot can be no longer than 1000 feet in length. The density is specified to be between $92 \%$ and $96 \%$. If the first trial is outside the range, then the contractor must sample at five other randomly selected locations. The average density of these samples must be between $92 \%$ and $96 \%$. 
The West Virginia specifications also govern the use of roller pass. A test section is randomly selected for roller pass quality control. The pavement is compacted so that it is within the required density range. The number of passes needed to obtain the required density is recorded. This number of roller passes for the test section is then the number of roller passes to be used throughout the project.

\subsubsection{Density Tests}

The density of the material in the pavement is generally measured using laboratory techniques or with a nuclear density gauge. More recently, equipment has been developed that measures the dielectric properties of the material to estimate density.

\subsubsection{Laboratory Methods}

Testing asphalt cores in the laboratory is considered the most accurate technique (Romero, 2001). However, coring is not very feasible for quality control. This method is destructive and tends to be expensive. The cores have to be taken to a laboratory to be tested, which takes time. There are two AASHTO test methods for measuring the density of asphalt concrete, T 166 Standard Method of Test for Bulk Specific Gravity of Compacted Asphalt Mixtures Using Saturated Surface-Dry (SSD) Specimens, and Standard Method of Test for Bulk Specific Gravity of Compacted Bituminous Mixtures Using Paraffin-Coated Specimens designated as test number T 275.

\subsubsection{Nuclear Density Gauges}

One common method often used to measure pavement density for quality control is the nuclear density gauge. The nuclear density gauge is operated in backscatter mode for asphalt as shown in Figure 2.12. In this mode, the retractable rod is lowered so that the bottom tip of the rod is level with the detector. The retractable rod emits gamma rays from the bottom tip, which interacts with the material under the gauge. The detector then measures the energy loss of the rays that deflect from the material to the detector.

According to Troxler Electronic Laboratories, the reading from this machine is not affected by the pavement depth as long as the depth is greater than four inches. Many overlays are thinner than this depth. The material underlying these materials can have dramatic results on the gauge reading. If the underlying material is stiff, the gauge will 
display a higher density for the overlay. Inversely, a soft material will display a density that is lower than the actual density of the asphalt.

The standard nuclear density gauges made by Troxler use a correction equation to compensate for thin lifts. This equation requires the operator to know the density of the underlying material.

$D_{T}=\frac{W D-\left[D_{B} \cdot K(x)\right]}{1-K(x)}$

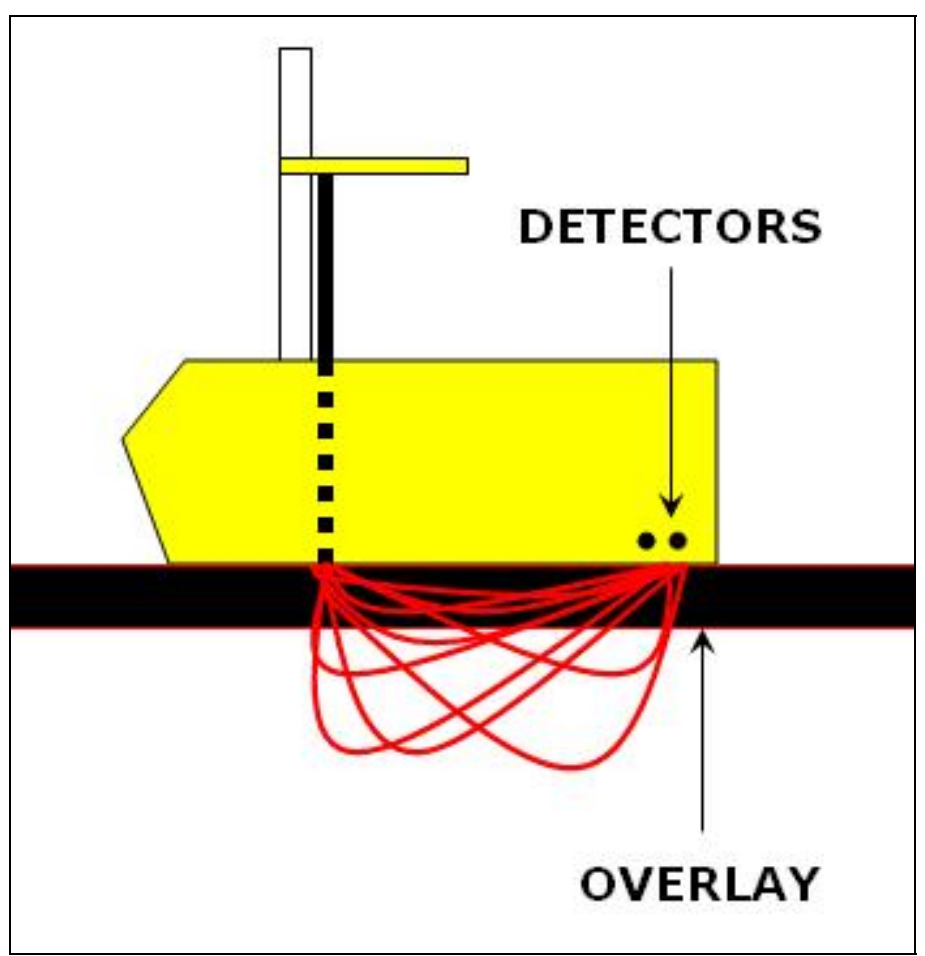

Figure 2.12: Nuclear Density Gauge

where:

$\mathrm{WD}=$ density, gauge measurement

$\mathrm{D}_{\mathrm{B}}=$ bottom layer density

$\mathrm{K}(\mathrm{x})$ = value that quantifies the influence of the density of the overlay and of the bottom layer on the resulting density (determined by factory calibration) 
Another solution is to use a thin lift nuclear gauge which was also developed by Troxler Electronic Laboratories. This gauge works by using a second detector that is positioned between the retractable rod and the first detector as shown in Figure 2.13. The difference in the depth of material measured by each system, factory calibration, and mathematical models allows the thin layer gauge to determine the density of the top layer of asphalt (Troxler Labs, 2004).

The following equation is used by the thin-lift gauge to determine the pavement density:

$$
D_{T}=\frac{K_{2}(x) \cdot D G 1-K_{1}(x) \cdot D G 2}{K_{2}(x)-K_{1}(x)}
$$

where:

$\mathrm{D}_{\mathrm{T}}=$ overlay density

$\mathrm{x}=$ overlay thickness

DG1 = bulk density, gauge measurement determined by sensor one

DG2 = bulk density, gauge measurement determined by sensor two

$\mathrm{K}_{1}(\mathrm{x}) \& \mathrm{~K}_{2}(\mathrm{x})$ = values that quantify the influences of the overlay material and of the underlying material on the bulk density measured by the gauge

Figure 2.13: Thin-lift Nuclear Gauge

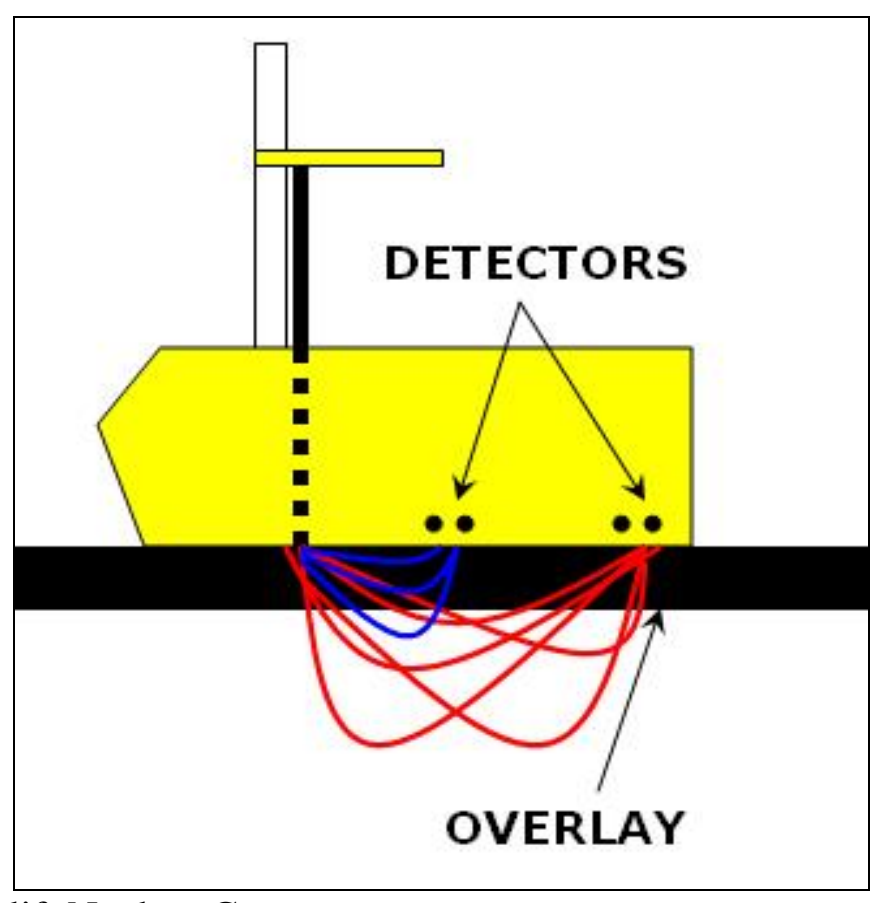




\subsubsection{Dielectric Devices for Measuring Density}

Recent research has developed non-nuclear methods for evaluating the density of asphalt pavements. Troxler markets the PaveTracker device and TransTech markets the Pavement Quality Indicator (PQI). Both of these devices resemble the nuclear density gauge but use electronic measurements of the dielectric constants to the asphalt concrete to determine density. As shown on Figure 2.14, based on the operations manual for the TransTech PQI device, sensing fields generated by the device penetrate into the material and variations in the sensing fields are evaluated to determine the density of the material. Sargand, et al. (2005) compared both the PaveTracker and PQI in a research project for the Ohio Department of Transportation. The PQI, when properly calibrated, compared favorably to results from nuclear density gauges while the PaveTracker results were statistically different from both nuclear gauge and laboratory results. The PQI results showed better correlation with laboratory results than the nuclear gauge did.

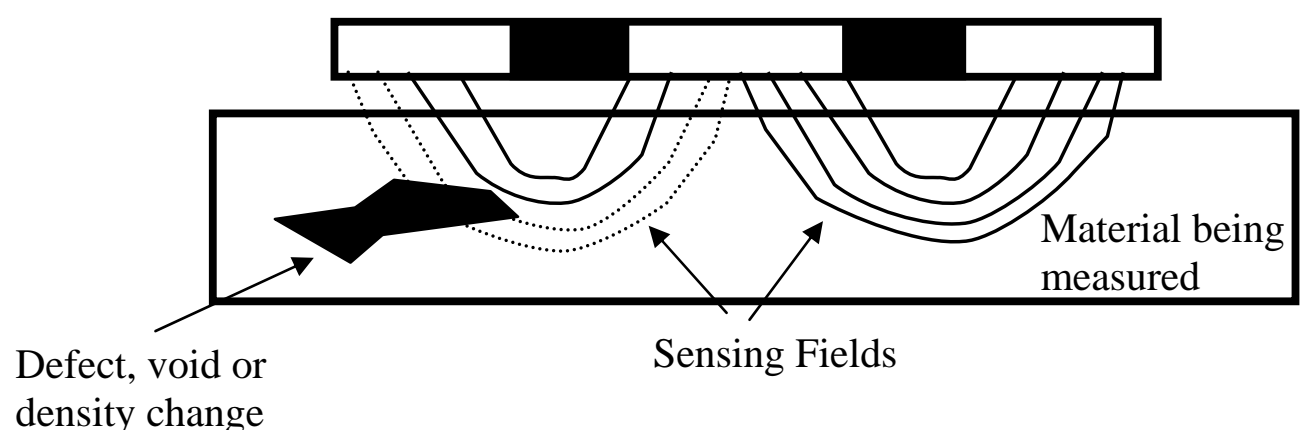

Figure 2.14: Operating Principle of Pavement Quality Indicator

\subsection{CASE STUDIES}

\subsubsection{Wisconsin Department of Transportation}

Wisconsin was concerned with longitudinal joint cracking and raveling that occurred at the centerline of their pavements (Toepel, 2003). In 1992, Wisconsin with the help of the National Center for Asphalt Technology (NCAT) began a study on the methods of paving and compacting longitudinal joints. 
The test section was United States Highway 61 located in Crawford County, Wisconsin. A 16-mile section of highway was divided into eight different sections. Different methods of joint compaction were randomly assigned to the sections. Figure 2.15 shows the various sections with their relative size. Table 2.2 shows the starting and ending stations along with the section length.

Table 2.2: Section Stations and Lengths

\begin{tabular}{|c|r|r|r|}
\hline Section & $\begin{array}{c}\text { Starting } \\
\text { Station }\end{array}$ & $\begin{array}{r}\text { Ending } \\
\text { Station }\end{array}$ & $\begin{array}{c}\text { Section } \\
\text { Length }\end{array}$ \\
\hline \hline 1 & $510+50$ & $615+60$ & 10510 \\
\hline 2 & $724+00$ & $838+00$ & 11400 \\
\hline 3 & $621+89$ & $723+20$ & 10131 \\
\hline 4 & $319+00$ & $386+00$ & 6700 \\
\hline 5 & $218+00$ & $319+00$ & 10100 \\
\hline 6 & $386+00$ & $510+50$ & 12450 \\
\hline 7 & $12+00$ & $61+00$ & 4900 \\
\hline 8 & $89+09$ & $212+00$ & 12291 \\
\hline
\end{tabular}

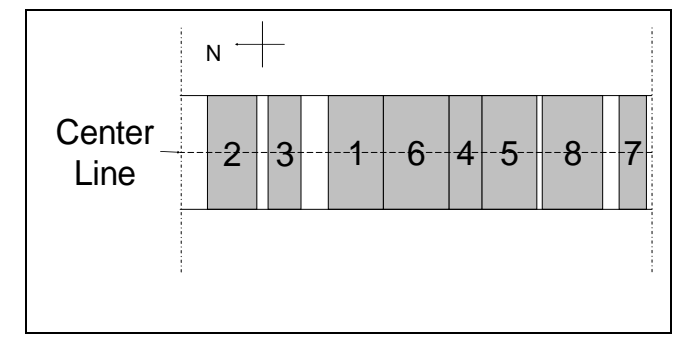

Figure 2.15: WSDOT Test Section Layout

Section one was rolled from the hot side 6" away from the joint. Sections two through six used the Michigan wedge technique with a $1 \frac{1}{2}$ ” offset. In section two, the wedge was compacted by the tires of the hauling trucks. The wedge was not compacted for section three. The wedge in section four was compacted by an edge restraining device as shown in Figure 2.8 installed on the roller. Section five was compacted by a rubber side roller wheel attached to a pneumatic roller. The wedge at joint six was compacted by an edge restraining device as shown in Figure 2.8 installed on the paver. 
The joint at section seven was trimmed with a cutting wheel. Section eight was compacted using an edge restraining device as shown in Figure 2.8 installed on the roller.

The initial results of the experiment indicated that the steel side roller method and the tag along roller method produced the most desirable densities, as shown in Table 2.3. These sections also had the least amount of longitudinal cracking after ten years of service, which is displayed in Table 2.4.

Table 2.5 and 2.6 shows the density for the saturated surface dry (SSD) test and nuclear density gauge, respectively. Due to the large amount of variation between these methods, another nuclear density gauge was used to check the data. All three testing trials produced different results (the SSD test was considered the most accurate).

It was concluded that the wedge joint (especially if the joint is compacted by the steel side roller or tag along-roller) is the best alternative. Unlike the cutting wheel, the wedge technique left very little debris. The wedge was also safer for traffic since there is little vertical step-off from the cold lane. The contractor preferred the steel side roller attached to the roller over the tag-along roller attached to the paver due to the paver operator's inability to see the tag-along roller. As a result of this study, Wisconsin created a special provision specification for wedge joints on asphalt pavements.

Table 2.3: Percent Maximum Density

\begin{tabular}{|c|r|r|r|}
\hline \multirow{2}{*}{} & \multicolumn{3}{|c|}{$\begin{array}{l}\text { Percent Maximum Density (\%) } \\
\text { (SSD Test Procedure) }\end{array}$} \\
\cline { 2 - 4 } Section & $\begin{array}{l}\text { Hot Lane } \\
\text { 1' off CL }\end{array}$ & $\begin{array}{l}\text { Centerline } \\
\text { Joint }\end{array}$ & $\begin{array}{l}\text { Cold Lane } \\
\text { 1' off CL }\end{array}$ \\
\hline \hline 1 & 94.37 & 90.68 & 93.71 \\
\hline 2 & 92.62 & 90.30 & 92.94 \\
\hline 3 & 92.45 & 90.57 & 92.49 \\
\hline 4 & 94.56 & 92.19 & 93.45 \\
\hline 5 & 92.90 & 89.12 & 91.88 \\
\hline 6 & 94.02 & 92.28 & 93.48 \\
\hline 7 & 95.23 & 91.38 & 92.01 \\
\hline 8 & 92.64 & 89.61 & 93.32 \\
\hline
\end{tabular}

Table 2.4: Percent of Longitudinal Cracking after Ten Years

\begin{tabular}{|c|l|r|}
\hline Section & Joint Treatment & \% Cracked \\
\hline \hline 1 & Rolled 6" from joint & 86 \\
\hline 2 & Michigan w/ offset & 62 \\
\hline 3 & Michigan w/ offset & 46 \\
\hline 4 & Michigan w/ offset & 33 \\
\hline 5 & Michigan w/ offset & 69 \\
\hline 6 & Michigan w/ offset & 21 \\
\hline 7 & Cut Joint & 100 \\
\hline 8 & Edge Constraint & 94 \\
\hline
\end{tabular}


Table 2.5: Density from SSD Test

\begin{tabular}{|c|r|r|r|}
\hline \multirow{2}{*}{ Section } & \multicolumn{3}{|c|}{$\begin{array}{c}\text { Lab Density Readings }\left(\mathrm{Ib} / \mathrm{ft}^{3} \text { ) }\right. \\
\text { (SSD Test Procedure) }\end{array}$} \\
\cline { 2 - 4 } & $\begin{array}{c}\text { Hot Lane } \\
\text { 1' off CL }\end{array}$ & $\begin{array}{c}\text { Centerline } \\
\text { Joint }\end{array}$ & $\begin{array}{c}\text { Cold Lane } \\
\text { 1' off CL }\end{array}$ \\
\hline \hline 1 & 144.54 & 138.89 & 143.53 \\
\hline 2 & 141.86 & 138.31 & 142.36 \\
\hline 3 & 141.60 & 138.73 & 141.67 \\
\hline 4 & 144.84 & 141.20 & 143.13 \\
\hline 5 & 142.30 & 136.51 & 140.74 \\
\hline 6 & 144.01 & 141.34 & 143.19 \\
\hline 7 & 145.87 & 139.96 & 140.93 \\
\hline 8 & 141.90 & 137.26 & 142.94 \\
\hline
\end{tabular}

Table 2.6: Density from Nuclear

Density Gauge

\begin{tabular}{|c|r|r|r|}
\hline \multirow{2}{*}{ Section } & \multicolumn{3}{|c|}{$\begin{array}{c}\text { Lab Density Readings }\left(\mathrm{Ib} / \mathrm{ft}^{\mathrm{S}} \text { ) }\right. \\
\text { (Nuclear Density Gauge) }\end{array}$} \\
\cline { 2 - 4 } & $\begin{array}{c}\text { Hot Lane } \\
\text { 1' off CL }\end{array}$ & $\begin{array}{c}\text { Centerline } \\
\text { Joint }\end{array}$ & $\begin{array}{c}\text { Cold Lane } \\
1^{\prime} \text { off } \mathrm{CL}\end{array}$ \\
\hline \hline 1 & 137.13 & 136.46 & 135.56 \\
\hline 2 & 138.74 & 138.34 & 137.93 \\
\hline 3 & 140.09 & 139.43 & 138.97 \\
\hline 4 & 140.69 & 138.47 & 139.26 \\
\hline 5 & 138.99 & 137.94 & 136.77 \\
\hline 6 & 139.40 & 138.30 & 139.61 \\
\hline 7 & 142.30 & 135.06 & 136.99 \\
\hline 8 & 137.91 & 139.10 & 139.24 \\
\hline
\end{tabular}

\subsubsection{National Center for Asphalt Technology}

In 1992, NCAT coordinated with the states of Colorado, Michigan, Pennsylvania, and Wisconsin in order to perform a study on longitudinal joint construction methods. Wisconsin's study was reviewed in section 2.5.1 (Kandhal and Mallick, 1997). The other three states did studies the same way with only a few noted exceptions. The following section briefly describes the research conducted by NCAT.

Wisconsin was the only state that had the paver screed run flush to the cold lane. The other states used a 1" to 1.5 ” (25 to $38 \mathrm{~mm}$ ) overlap over the cold lane. Michigan and Wisconsin used static rollers while Colorado and Pennsylvania used vibratory rollers. Colorado did not lute the overlapped material. Table 2.7 summarizes the rankings of the different longitudinal joint compaction methods evaluated by Kandhal and Mallick (1997); a 1 indicates the best performance.

NCAT made several conclusions by comparing the results from the different states. The Wisconsin joints had a much lower density than the other states. This was attributed to having the lanes butt together instead of having them overlap (Kandhal and Mallick, 1997). Placing the hot lane close enough to the cold lane without causing cracks (less than $1 / 8$ ”) requires a much more experienced operator than allowing the lanes to overlap. The performance of the Michigan wedge is enhanced considerably by the use of a $1 / 2$ " vertical offset. Performance appears to be influenced by density. 
Table 2.7: Joint Technique for each Project

\begin{tabular}{|c|c|c|c|c|}
\hline \multirow{2}{*}{ Construction/Rolling Technique } & \multicolumn{4}{|c|}{ Project } \\
\hline & MI & WI & $\mathrm{CO}$ & PA \\
\hline 1. Rolling from hot side & 5 & 6 & $6^{a}$ & 3 \\
\hline 2. $\quad$ Rolling from cold side & 7 & 8 & $7^{a}$ & 6 \\
\hline 3. Rolling from hot side 6" (152mm) away from joint & 6 & 7 & $5^{a}$ & 5 \\
\hline 4. Michigan wedge & 1 & $5^{b}$ & & \\
\hline 5. Michigan wedge with tack & 2 & $3^{b}$ & & \\
\hline 6. $\quad$ Edge restraining device & & 1 & & 7 \\
\hline 7. Cutting wheel with tack & 3 & 2 & $2^{a}$ & 1 \\
\hline 8. Cutting wheel without tack & & & $4^{a}$ & \\
\hline 9. Joint maker & 4 & 4 & & 4 \\
\hline 10. Tapered (3:1) joint with vertical 1" $(25 \mathrm{~mm})$ offset & & & $1^{a}$ & \\
\hline 11. Rubberized asphalt tack coat & & & $3^{a}$ & 2 \\
\hline 12. NJ wedge (3:1) with infrared heating & & & & 8 \\
\hline
\end{tabular}

a Joint has a 3:1 taper

b Joint did not have 0.5 " $(12.5 \mathrm{~mm})$ vertical offset

NCAT also gave the following recommendations as a result of this study:

- Of all the techniques tested, the Michigan wedge has the most potential of giving satisfactory results. The $1 / 2$ ” offset is vital.

- The cutting wheel and the edge restraining device both have good potential, but are highly dependent of the skill of the operator.

- Of the three rolling techniques, rolling from the hot side is the most desirable.

- When making pavers, manufacturers should mount a steel plate on the screed that will form a taper (preferably a 12:1 like the Michigan wedge). The paver should also be equipped with a vibratory or tamping mechanism to compact the unconfined edge.

- Highway agencies should develop specifications for minimum compaction levels at the longitudinal joint. Specifying a joint density of no more than two percent lower than the lane density is recommended. 


\subsubsection{Kentucky Transportation Center}

Many of the pavements in the Kentucky were prematurely failing due to poor permeability of the pavement. Water was entering the pavement structure where it often led to: debonding of the surface layer, stripping, hardening, and freeze/thaw damage. As a result, the Kentucky Transportation Center at the University of Kentucky began a study on longitudinal joint compaction.

Twelve construction projects were selected for this study (Fleckenstein et al, 2002). Each method described above in sections 2.3 and 2.4 were tested and evaluated. Construction problems were observed and noted along with performance of each joint compared to the control sections. Recommendations were also made for each method.

The sections that used notched wedges (or wedges with a vertical offset) had higher densities and lower permeability than the control section. There was some difficulty in these sections with maintaining the upper vertical notch during compaction. Raveling also occurred on the lower portion of the wedge before the overlay was placed due to the lower notch being cut too small. It was recommended that this technique should only be used on pavement sections thicker than 1.5” (38mm). A strike-off plate should be installed on the wedge compaction wheel. By keeping the paving train moving, segregation and raveling may be prevented.

Density was significantly higher with the restrained edge method than for the control section. However, permeability was only slightly decreased. The restraining wheel caused the mat to push up between the drum and the restraining wheel. It was recommended that the restraining wheel and the main drum be placed side by side.

The joint maker showed slight increase in the density, but there was no significant decrease in the permeability. The contractor was unclear on how to correctly set up and properly position the joint maker. Dragging of the mix was also noted, but this was corrected by preheating the joint maker.

The infrared joint heater yielded positive results. The density was increased and the permeability was decreased. However, this method is unattractive to the contractor. Due to the position of the heater, the contractor was unable to use "ski poles" which 
slowed down the paving train. The heater should be mounted at a different place so the paving train speed is not affected and the use of "ski poles" is possible.

Although tack coats at the joint do not improve the density, they do significantly decrease permeability. The method with the highest density was the restrained edge method followed by the notched wedges. However, the notched wedges and the joint heater had the lowest average permeability. The joint maker decreased the permeability by very little if any. This study showed that the contractor was able to consistently obtain a joint density within 3\% of the mat density using methods commonly used by contractors (Fleckenstein, Allen, and Schultz, 2002).

As a result of this study, the following conclusions were observed:

- The density of the hot lane after compaction is usually greater than the density of the cold lane after compaction.

- Although the infrared heater showed some promise, the effects of reheating the asphalt should be studied before this technique is widely used.

- The use of the joint maker is not recommended since the joint maker shows almost no improvement over conventional methods.

- The restrained edge (and the notched wedge to a lesser degree) improved density not only at the joint, but across the entire mat.

- The following recommendations were made as a result of this study:

- A specification should be made that requires the joint density to be within $3 \%$ of the mat density.

- The restrained edge method should be tested further using the recommended modified wheel.

- The use of joint adhesives is encouraged.

\subsection{REVIEW OF CURRENT SPECIFICATIONS FOR DENSITY}

A study of the specifications regarding density is reviewed in this section for the following states:

- West Virginia (WVDOH, 2003) 
- Pennsylvania (PennDOT 2003)

- Ohio (ODOT 2005)

- Kentucky (KDOT 2004)

- Virginia (VDOT, 2002)

- Maryland (MDSHA, 2002)

The following topics are reviewed for each state:

- Compaction procedure

- Mat density requirements

- Joint density requirements

- Specified maximum number of passes

- Provisions for site condition changes when using the rollerpass method

- Provisions for lot sampling

- Procedure for using the nuclear density gauge

- Adjustments for the nuclear density gauge when measuring thin-lifts

\subsubsection{West Virginia}

The specifications call for the mat density to be between 92 and 96\%. The rolling procedure specified by West Virginia is as follows (WVDOH, 2003):

During rolling, roller wheels shall be kept moist with only enough water to avoid picking up material. Fuel oil on roller wheels or pneumatic tires is not allowed. Rollers shall move at a slow but uniform speed with the drive roll or wheels nearest the paver. If rolling causes material displacement, the affected area shall be loosened at once with lutes or rakes and restored to its original grade with loose material before being re-rolled. Heavy equipment, including rollers, should not be permitted to stand on the finished surface before it has thoroughly cooled or set.

Mat temperature shall be measured using a non-contact infrared thermometer. The required density shall be obtained prior to the mat temperature reaching $175^{\circ} \mathrm{F}$ $\left(80^{\circ} \mathrm{C}\right)$. The Contractor shall be allowed to lower this temperature to $165^{\circ} \mathrm{F}\left(74^{\circ}\right.$ C) if they can demonstrate during the first day of placement of each lift on each project that additional densification can be achieved without causing any pavement distress.

The rollerpass method is commonly used for quality control on low volume roads in West Virginia. A test section with a length of $100 \mathrm{ft}$ is constructed early in the project. 
The number of passes required by the roller to achieve the target density is recorded. Rolling cannot be done once the mat temperature reaches $175^{\circ} \mathrm{F}$, unless the contractor can demonstrate that there is no pavement distress. If the contractor can demonstrate this, rolling may resume until the mat reaches $165^{\circ} \mathrm{F}$. The project engineer may establish a new test section if the contractor fails to achieve the target density. If the contractor fails to reach the target density again, the project engineer may establish another test section. The project engineer may also adjust the mix design. The Division may request a new test section if the job site conditions, such as weather, change in such a way that the amount of energy required for compaction changes.

Another method of quality control used by West Virginia is the lot method. The project is broken up into $1000 \mathrm{ft}$ sections. A reading is taken using the nuclear density gauge from a random location in the lot. If the reading is not between 92 and $96 \%$, then five more readings shall be taken. The average of these five readings must be between 92 and $96 \%$.

No provisions for the thin-lift nuclear gauge have been established. If a standard nuclear density gauge is used to check the density, the gauge must be standardized first. The gauge must be within $2 \%$ of the manufacturer's standard when taking a density reading of a standard block provided with the gauge using a four minute count. If the gauge fails to be within $2 \%$ of the standard block, three more attempts may be made. If these attempts fail, the gauge must be recalibrated or another gauge must be used. The gauge must be operated using the manufacturer’s specified procedures.

The contractor's nuclear gauge must then be compared to the nuclear gauge used by the Division of Highways. Five readings are made with each gauge on a standard aluminum block with a known density of $110 \mathrm{lb} / \mathrm{ft}^{3}$. The range for both data sets shall not exceed $1.5 \mathrm{lb} / \mathrm{ft}^{3}$. If the readings are within this range, then they are averaged together and the two nuclear gauges are compared. The average for both nuclear gauges should be within $3 \mathrm{lb} / \mathrm{ft}^{3}$. 


\subsubsection{Pennsylvania}

No step-by-step rolling procedure is specified by Pennsylvania Department of Transportation (PennDOT), but there are specifications that govern some steps of the compaction process:

- The roller speed, amplitude, frequency, and size shall be adjusted to eliminate cracking, shoving, and aggregate breakage.

- Operate rollers slowly enough to avoid displacement of pavement surface and satisfactorily correct displacement from reversing roller directions or from other causes.

- Use pneumatic tire rollers for any scratch or leveling course.

- Keep wheels of steel-wheel rollers moist and clean to prevent adhesion of fresh material, but do not use excess water.

- Fix irregularities in the base course before placing the wearing course.

- If possible, do not permit traffic on the base course to prevent contamination. Clean the base course if foreign material comes in contact with the surface of the course. Remove and replace the base course if foreign material cannot be cleaned and removed.

- The mat density must be between 92 and $97 \%$ of the maximum theoretical specific gravity.

- The joint density must be at least $90 \%$ of the maximum theoretical specific gravity.

Pennsylvania defines a lot as "the daily placement of each material course.” Each lot is divided into three equal sub-lots. Sample locations for each material course will be selected independently. Density is measured by testing cores.

With projects that places small quantities of asphalt (less than 50 tons a day or 230 tons for the total project), rollerpass can be used with a nuclear density gauge in place of coring the samples by lots. The nuclear gauge must be calibrated and operated by a licensed operator. A control strip is tested to determine the optimum rolling pattern. 


\subsubsection{Ohio}

The Ohio Department of Transportation (ODOT) Construction and Materials

Specifications give the following procedure regarding a rolling method:

Unless otherwise directed, begin rolling at the sides and proceed longitudinally parallel to the centerline at a slow, uniform speed. After each coverage or complete round trip, move the roller towards the crown of the road to begin its next pass, overlapping the previous pass by at least one-half the width of the previous pass. On superelevated curves, begin rolling at the low side and progress toward the high side. Where a longitudinal joint is being made, roll the joint then follow the applicable rolling procedure.

Various characteristics regarding the roller are also specified. The roller weight and dimensions are specified (see section 401.13 of the ODOT Construction and Materials Specifications for specific details). The surface of the roller (or wheel) is to be kept moist with water or an approved mixture to prevent adhesion.

The spreading rate shall not exceed the total specified capacities of the rollers in use. Base mixtures and courses with variable depths shall be compacted using a combination of steel and pneumatic rollers. Surface mixtures shall be compacted using a static steel wheel roller. Pneumatic rollers should not be used for polymer asphalt concrete due to excessive pick up. Vibratory rollers shall not be used on courses with a thickness under $1 \frac{1}{2}$ ”. If a wedge joint is used, the wedge is to have a 3:1 slope.

The ODOT specifications provide a detailed definition of a lot:

A Lot consists of an area of pavement placed during a production day, including the shoulders. If less than 400 tons (400 metric tons) is produced in a production day, then that production day is combined with the next production day into a single Lot. If greater than 250 tons (250 metric tons) and less than 400 tons (400 metric tons) is produced on the last day of production for the project, then the day's production is a separate Lot. If less than 250 tons (250 metric tons) is produced on the last production day for the project, it is part of the previous Lot for acceptance, provided the previous Lot was placed within 3 days; otherwise, it is a separate Lot.

Each lot is divided into five equal sub-lots. Two cores are to be taken from the mat of each sub-lot. An additional core (referred to as a sister core) shall be taken longitudinally from and within 4 inches of the random core. 


\subsubsection{Kentucky}

The wheels shall be kept moist to prevent adhesion, but excess water is not to be used. A small quantity of detergent may be used, but kerosene, oil, and other harmful liquids may not be used. The roller drive wheels shall be nearest the paver. A layer of tack coat is required for longitudinal and transverse joints.

Kentucky specifications define a lot as 4000 tons of asphalt concrete. There are four sub-lots in each lot. For the rollerpass method, the number of passes shall be determined for the project within the first four hours of project production or by the end of the first sub-lot. After the project is finished, the contractor will take four cores from the mat and two cores from the longitudinal joint in each sub-lot (except for the first sublot). These cores are tested to ensure that the number of passes used was adequate throughout the project. The target percent air voids for the mat is from $4 \%$ to $8 \%$. If the percent air for all four cores taken from the mat of a sub-lot is less than $1.5 \%$ or greater than $11 \%$, the sub-lot is to be removed and replaced.

For the lot method, the breakdown rolling shall be done with a steel-wheel roller. The intermediate rolling shall be done with a tandem (or double drum) steel-wheel roller. If the nominal aggregate size is $1 \frac{1 / 2}{2}$ " or 1 ”, a pneumatic roller shall be used for the intermediate rolling. A pneumatic roller shall be used for the final rolling of the base courses. A tandem steel wheel roller shall be used for the final rolling of the surface course. Operate the roller parallel to the centerline at all times. Begin rolling at the sides and progress towards the crown of the road. On superelevated sections, begin rolling on the low side and progress to the high side. See section 403.03.10 section B for the size, weight, and other roller characteristics specified by the Kentucky Department of Transportation. Table 2.8 shows the density required by the Kentucky Department of Transportation. 
Table 2.8: Density Requirements Specified by KDOT

\begin{tabular}{|l|l|l|l|}
\hline \multirow{2}{*}{} & \multicolumn{3}{|c|}{ Percent Volume of the Total Mix (\%) } \\
\cline { 2 - 4 } & \multicolumn{1}{|c|}{ Full Pay } & Reduced Pay & $\begin{array}{c}\text { Remove and } \\
\text { Replace }\end{array}$ \\
\hline \hline Mat & $92-96$ & $89-92$ or 96-98.5 & $\begin{array}{l}\text { Less than 89 } \\
\text { Greater than 98.5 }\end{array}$ \\
\hline Joint & $89-96$ & $87-89$ or 96-97 & $\begin{array}{l}\text { Less than 87 } \\
\text { Greater than 97 }\end{array}$ \\
\hline
\end{tabular}

\subsubsection{Virginia}

Virginia Department of Transportation (VDOT) specifications have many provisions regarding the rolling procedure. Rolling of the mat shall begin at the sides and proceed longitudinally to the center of the pavement. On superelevated curves, rolling shall start at the low side and finish at the high side. The roller must overlap 50\% of the previous pass. Longitudinal joints shall be rolled before the mat is rolled. To prevent adhesion, the roller wheels shall be kept moist with water. Excess water is not permitted. The water may be mixed with a small amount of detergent or other approved material.

VDOT has specifications that require a thin-lift density gauge to be used. Density for overlays shall be determined using a thin-lift nuclear gauge, which shall be furnished and operated by the contractor. The gauge must have been calibrated within the previous 12 months. The required density shall not be less than $98 \%$ and no more than $102 \%$ of the control strip density.

Rollerpass shall be used on asphalt overlays placed directly on surface treatment roadways and on overlays with a thickness less than 1". A nuclear density gauge can be used to determine the number of passes. The control strip density is defined as the average of ten nuclear determinations selected at stratified random locations on the control strip (VDOT, 2002). A control strip shall be constructed for each roadway and shoulder course on all of the lifts. Additional control strips shall be constructed when a change is made in the type, composition, or source of materials. Control strips shall also be constructed whenever there is a significant change in the underlying material. The length of the control strip shall be approximately 300'. The control strip shall be started between 500 ' and 1000' from the beginning of the paving operation. The thickness of the 
control strip is to be the same as the thickness of the course that is being placed. A new control strip is required whenever the lift thickness changes. If it is determined that the required density cannot be obtained because of the condition of the existing pavement structure, the target nuclear control density will be determine from the roller pattern that achieves the optimum density and will be used on the remainder of roadway that exhibits similar pavement conditions (VDOT, 2002).

A lot shall consist of 5000 linear feet of any pass made by the paver regardless of the width of the pass or the thickness of the course. Pavers in echelon will be considered as separate lots. Each lot consists of five sub-lots of equal length. Two nuclear density readings taken at random locations on the mat are required for each sub-lot. The average density of the sub-lots will be used as the density of the lot. If two consecutive sub-lots have a density less than $98 \%$ or greater than $102 \%$ of the target density, the contractor shall take corrective action immediately. The density for base courses shall be at least $91.5 \%$ of the maximum theoretical specific gravity. Surface courses shall have a density of at least $92 \%$ of the maximum theoretical specific gravity. No more than one sample in every five shall be less than specified and such sample cannot be more than $2 \%$ below the minimum.

Any section that has a depth less than 1" and does not have sufficient quantity to establish a control strip shall be compacted with a minimum of three passes with a minimum eight-ton roller. No density testing will be required.

\subsubsection{Maryland}

Maryland State Highway Administration specifications list the compaction process to be used. Longitudinal joints and the pavement edge shall be rolled before the mat is rolled. Rolling of the mat should begin longitudinally at the sides and proceed towards the center of the pavement. On superelevated curves, rolling should begin at the low side and end at the high side. Half of the roller should overlap with the previous pass. Breakdown rolling should be done with a steel-wheel roller. The drive wheel shall be forward in the direction of paving. Intermediate rolling should follow breakdown rolling as closely as possible. A steel-wheel roller shall be used for finish rolling. Rolling must be completed before the pavement cools to $185^{\circ} \mathrm{F}$, except for gap graded 
mix which requires the pavement to be above $230^{\circ} \mathrm{F}$. Traffic must not be allowed on the pavement until it has cooled to $140^{\circ} \mathrm{F}$.

The roller wheels shall be kept slightly moist to avoid adhesion. An excessive amount of water is not permitted. Rollers shall be operated at a uniform speed not exceeding three miles per hour. If the abutting lane is not placed the same day or the longitudinal joint is distorted, the edge of the lane shall be carefully trimmed and a thin tack coat should be used on the joint. To determine density for quality control, the contractor shall use cores. If the depth is less than 3/4”, the density will be tested using a thin-lift nuclear density gauge.

\subsection{SUMMARY OF LITERATURE}

The issue of asphalt concrete density, particularly at longitudinal joints, has received considerable attention in the literature. Several agencies have studied innovative methods for improving the density of longitudinal joints. Unfortunately, the research has not identified a methodology which consistently produces satisfactory joints.

The specifications used by West Virginia and the surrounding states were reviewed and compared. Table 2.9 shows which density practices that these states govern with their specifications.

All of the states examined use specifications regarding the method and procedure for compaction. All of the states also have specifications governing the allowable mat density. West Virginia, Kentucky and Virginia are the only states that specify a procedure for the rollerpass method. Pennsylvania allows the rollerpass method, but the procedure is not described in their specification. The rollerpass specifications allow for reestablishing the required rollerpasses due to changing site conditions, but the specifications are vague with respect to the conditions that should trigger a change in the compaction process. All states specify that rolling is to be stopped if the roller starts to crush the aggregate in the mix. 
Table 2.9: Compaction Procedures Governed by State Specifications

\begin{tabular}{|c|c|c|c|c|c|c|c|c|}
\hline & \multicolumn{3}{|c|}{ Compaction } & \multicolumn{2}{|c|}{$\begin{array}{c}\text { Provisions for } \\
\text { Rollerpass }\end{array}$} & \multirow{2}{*}{$\begin{array}{l}\text { Provisions } \\
\text { for Lot } \\
\text { Sampling }\end{array}$} & \multicolumn{2}{|c|}{$\begin{array}{l}\text { Provisions for } \\
\text { Nuclear Density }\end{array}$} \\
\hline & Method & $\begin{array}{c}\text { Mat } \\
\text { Density }\end{array}$ & $\begin{array}{c}\text { Joint } \\
\text { Density }\end{array}$ & $\begin{array}{l}\text { Maximum } \\
\text { Number } \\
\text { of Passes }\end{array}$ & $\begin{array}{l}\text { Changing } \\
\text { Site } \\
\text { Conditions }\end{array}$ & & Method & $\begin{array}{l}\text { Changes } \\
\text { for Thin- } \\
\text { lifts }\end{array}$ \\
\hline West Virginia & $\bar{X}$ & $\bar{X}$ & & $\mathbf{X}$ & $\mathbf{X}$ & $\mathbf{X}$ & $\bar{X}$ & \\
\hline Pennsylvania & $x$ & $x$ & $\mathrm{X}$ & $x^{a}$ & $x^{a}$ & $x$ & $x$ & \\
\hline Ohio & $\mathrm{X}$ & $X$ & $\mathrm{X}$ & & & $\mathrm{X}$ & & \\
\hline Kentucky & $\mathrm{X}$ & $\mathbf{X}$ & $\mathrm{X}$ & $\mathbf{X}$ & $\mathbf{X}$ & $\mathbf{X}$ & & \\
\hline Virginia & $\mathbf{X}$ & $\mathbf{X}$ & $\mathrm{X}$ & $\mathbf{X}$ & $\mathbf{X}$ & $\mathbf{X}$ & $\mathbf{X}$ & $\mathbf{X}$ \\
\hline Maryland & $\mathrm{X}$ & $\mathrm{X}$ & $\mathbf{X}$ & & & & & $\mathrm{X}$ \\
\hline
\end{tabular}

a Rollerpass method is allowed, but the method is not specified.

All of the states bordering West Virginia have specifications governing the density of longitudinal joints. Some specify a minimum percent of the maximum theoretical specific gravity while others restrict the maximum variance from the mat density. Pennsylvania is the only state to have a specification that recommends a procedure for constructing the joint. Ohio requires a 3:1 sloped wedge joint, but no procedure for constructing the wedge is described.

Virginia and Maryland are the only states that require the thin-lift nuclear gauge for thin overlays. Virginia also clearly lays out a procedure on testing with the thin-lift nuclear gauge. None of the other states clearly give any procedure to compensate for the underlying material when placing a thin overlay. Ohio recently reported favorable results for using the Pavement Quality Indicator as a replacement for the nuclear density gauge. 


\section{CHAPTER 3: RESEARCH METHODOLOGY}

\subsection{INTRODUCTION}

The emphasis of this research project was to compare various rolling and joint placement techniques in order to compact the asphalt to the target density (WVDOH specifies 4-8\% air voids). Various quality control methods for measuring density were also compared in order to determine the most accurate and precise method. Samples were taken from the following job sites:

- I-77 Kenna to Fairplain (MP 127-129)

- I-79 Elkview to Clendenin (MP 14-16)

- I-79 Big Otter to Servia Rd (MP 40-46)

- I-64 Crooked Cr. to St. Albans (MP 41-44)

- US 60 Hurricane to St. Albans (Putnam)

- WV 622 Goff Mountain Rd (Kanawha)

- US 250 Monterey to Bartow (Pocahontas)

- WV 34 Confidence to Paradise (Putnam)

- CR 39 Glenwood Road (Mason)

- CR 41 Ashton-Upland Rd (Mason)

- WV 34 Teays Valley to Winfield (Putnam)

- WV 16 Hartland to Clay Junction (Clay)

- WV 114 Airport Rd (Kanawha)

\subsection{FIELD DENSITY MEASUREMENT}

Three different methods were used to obtain the density for quality control during construction:

Nuclear density gauge

Nuclear density gauge with equation to compensate for thin lifts 
Thin lift nuclear gauge

Four measurements with the nuclear gauge were taken at each test location. The second reading is made by rotating the nuclear density gauge $90^{\circ}$. The third reading is made by rotating the gauge $180^{\circ}$ with respect to the original position, and the fourth reading is made by rotating the gauge $270^{\circ}$ with respect to the original position. The density measurements obtained were recorded and the location of each reading was noted. After construction, samples were cored from the same location. Figures 3.1 and 3.2 show how the nuclear density gauge was positioned with respect to the location of the core.

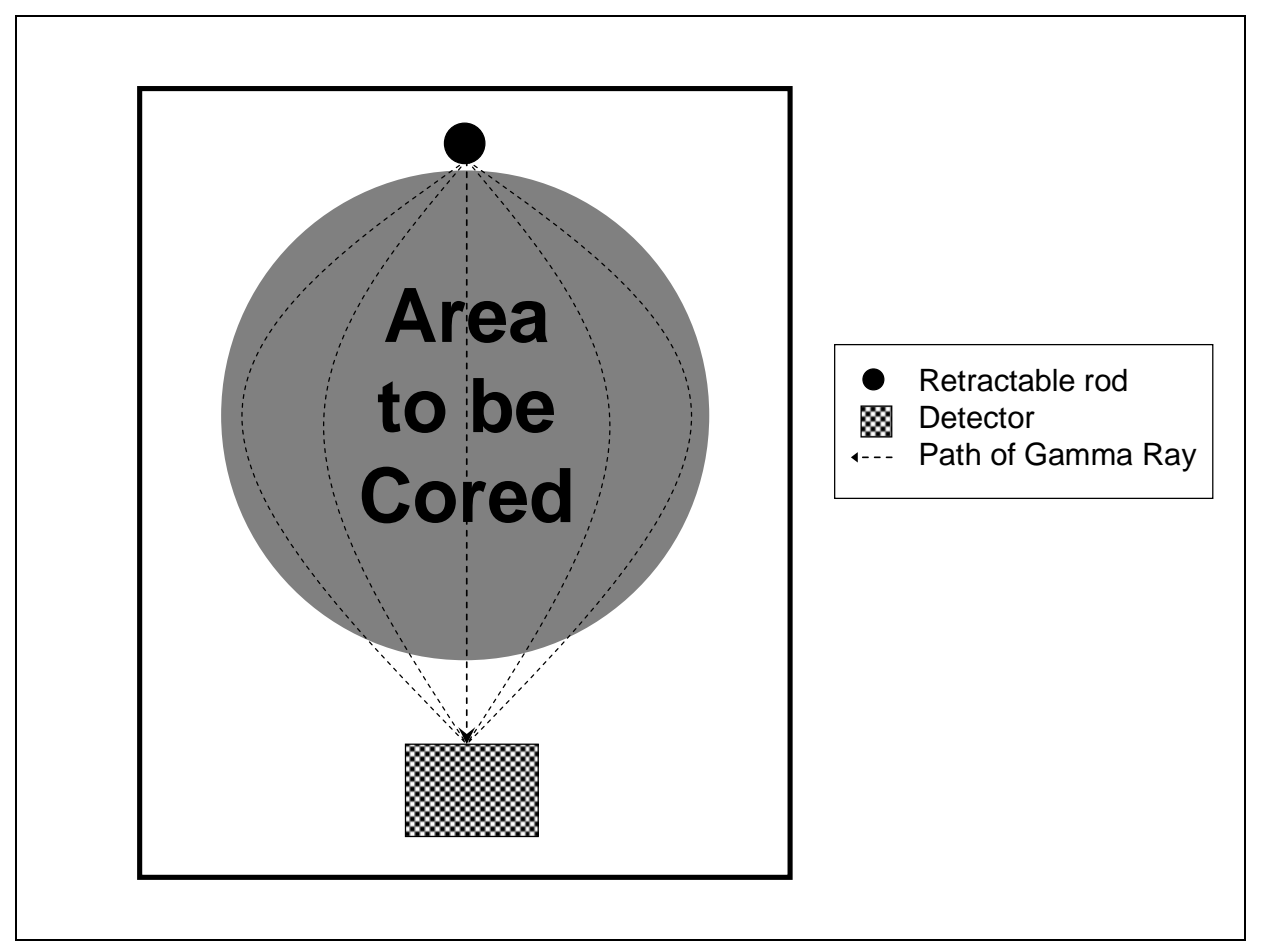

Figure 3.1: Placement of Nuclear Density Gauge with Respect to the Core Sample 


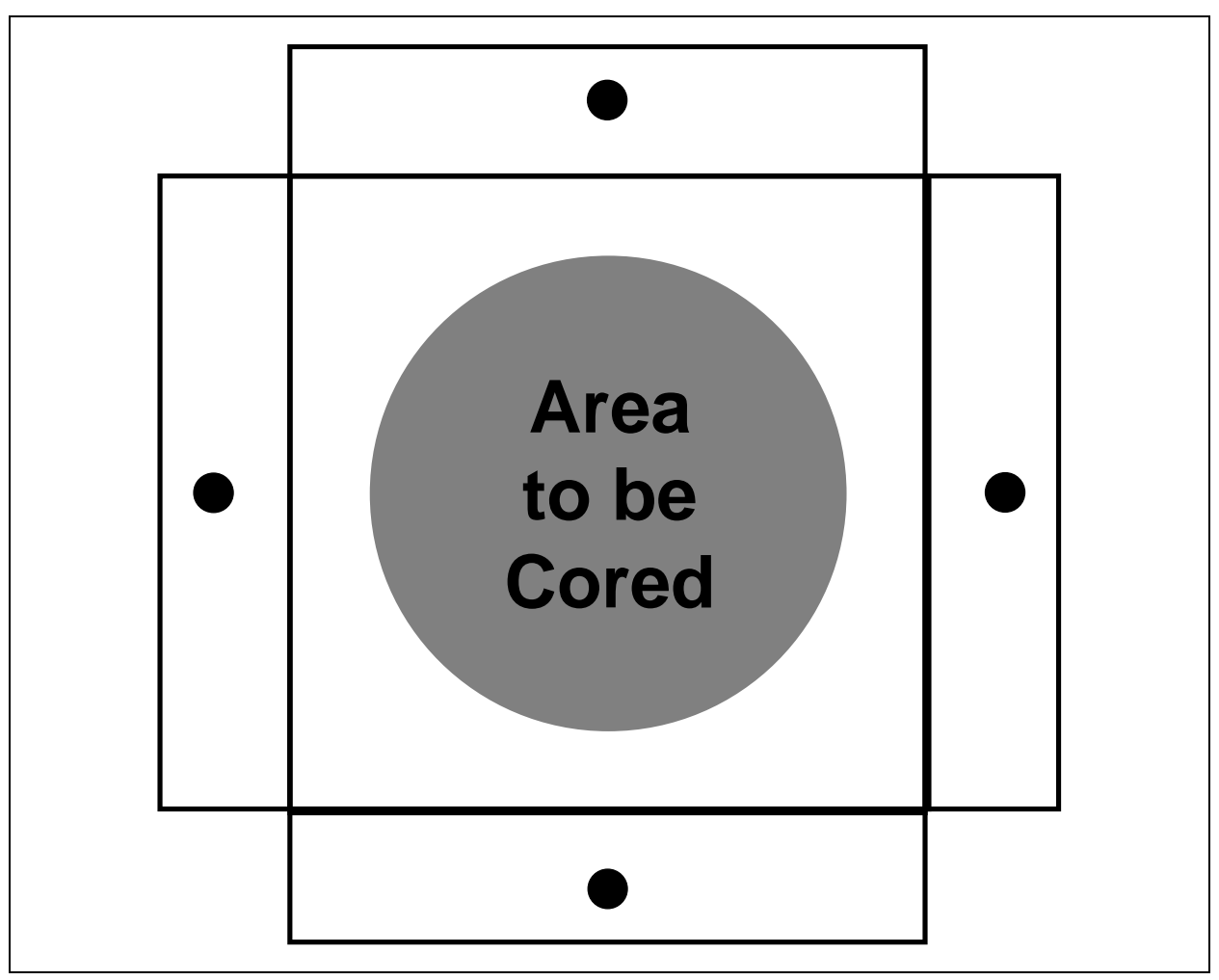

Figure 3.2: Orientation of the Nuclear Density Gauge for each Reading with Respect to the Core Sample

\subsection{LAB DENSITY PROCEDURE}

Once the cores were taken to the lab, they were placed in an oven and heated at $52 \pm 3^{\circ} \mathrm{C}$ until no change in mass was noticed when measuring the mass of the specimen at two hour intervals. Once a constant mass was reached, the original pavement was separated from the overlay while the sample was still hot.

After the cores returned to room temperature, they were tested in accordance with the AASHTO Standard Method of Test for Bulk Specific Gravity of Compacted Asphalt Mixtures Using Saturated Surface-Dry (SSD) Specimens, T 166. Method A was used to determine which mass measurements to record. With these mass measurements, the bulk specific gravity can be calculated with the following equation:

$G_{m b}=\frac{A}{B-C}$

where: 
$\mathrm{G}_{\mathrm{mb}}=$ bulk specific gravity

$A=$ mass of the dry specimen in air

$\mathrm{B}=$ mass of the specimen at SSD in air

$\mathrm{C}=$ mass of the specimen in water

The mass values used in this equation must all have the same units.

If the absorption of the cores is more than $2 \%$, the paraffin method should be used. The cores were again placed in an oven and heated at $52 \pm 3^{\circ} \mathrm{C}$ until a constant mass was obtained. Once the cores cooled to room temperature, the specimens were then tested in accordance with the AASHTO Standard Method of Test for Bulk Specific Gravity of Compacted Bituminous Mixtures Using Paraffin-Coated Specimens designated as test number T 275. Method A was used to determine which mass measurements to record. With these mass measurements, the bulk specific gravity can be determined:

$$
G_{m b}=\frac{A}{D-E-\left(\frac{D-A}{F}\right)}
$$

where:

$\mathrm{G}_{\mathrm{mb}}=$ bulk specific gravity

$\mathrm{A}=$ mass of the dry specimen in air

$\mathrm{D}=$ mass of the dry specimen with paraffin coating in air

$\mathrm{E}=$ mass of the dry specimen with paraffin coating in water

$\mathrm{F}=$ specific gravity of the paraffin

The mass values used in this equation must also have consistent units. 
The specific gravity of the paraffin was tested using the AASHTO Standard Method of Test for Specific Gravity of Semi-Solid Bituminous Materials designated as T 228 (ASTM D70-97). This value was compared to the value obtained in the literature.

The paraffin was removed from the samples and excess powdered talc was removed with a brush. The specimens were then tested in accordance with the AASHTO Standard Method of Test for Theoretical Maximum Specific Gravity and Density of Bituminous Paving Mixtures designated as test number T 209. This method was done by weighing the container and contents in water, not in air. The theoretical maximum specific gravity can be calculated from the following equation:

$G_{m m}=\frac{A}{A-C}$

where:

$\mathrm{G}_{\mathrm{mm}}=$ theoretical maximum specific gravity

$A=$ mass of oven-dry sample in air

$\mathrm{C}=$ mass of water displaced by sample at $25^{\circ} \mathrm{C}$

All mass measurements must have consistent units.

\subsection{METHOD OF ANALYSIS}

The data gathered in this experiment were analyzed with a spreadsheet program. A two sample t-test assuming equal variances was used to make comparisons between different treatments that were conducted on different samples. A paired two sample t-test for means was used to compare the different test methods that used different treatments on the same samples. If the sample size was greater than 30 for both sets that were being compared, a z-test was used in place of the t-test. The specific gravity values were then organized into a chart for visual comparison.

After construction of both I-77 projects and the first I-79 project (Elkview to Clendenin), the West Virginia Division of Highways (WVDOH) questioned the quality of joints that were being constructed on the roads. As a result, cores were extracted from 
these projects and sent to the Asphalt Technology Laboratory at West Virginia University so that comparisons between density and the appearance of the joint could be made.

Concern about the density of the mat was raised along with the joint density concerns. As a result, cores were taken from the CR 41, WV 16, WV 114, and the WV 34 (Teays Valley to Winfield) projects. These data were then used to study the rollerpass method of quality control.

The next quality control concern regarded the accuracy of the nuclear density gauge. The I-64, CR 39, and the second I-79 (Big Otter to Servia Rd) projects were selected so that the accuracy of the nuclear density gauge could be compared with the results from the laboratory tests.

The correction equation developed by Troxler requires the measuring the density of the existing mat prior to placing the overlay. Ideally the density measured prior to and after the overlay should be measured at the same location. This is somewhat inconvient. An alternative to the correction equation is the use of a thin lift nuclear gauge, which was also developed by Troxler Electronic Laboratories. Projects at US 60 and WV 622 were selected to compare the thin lift nuclear gauge with other methods for the testing of density.

The cores that were sent to the Asphalt Technology Laboratory for specific gravity testing were extracted from the following locations:

- I-77 Kenna to Fairplain (MP 127-129)

- I-79 Elkview to Clendenin (MP 14-16)

- US 60 Hurricane to St. Albans (Putnam)

- WV 622 Goff Mountain Rd (Kanawha)

- WV 34 Confidence to Paradise (Putnam)

- CR 39 Glenwood Road (Mason)

These samples were tested according to the testing procedures stated in section 3.3. 
Table 3.1 shows a summary of the accumulated data recorded for each project.

Table 3.1: Summary of the Density Measurements Recorded

\begin{tabular}{|c|c|c|c|c|c|c|}
\hline & \multicolumn{2}{|c|}{$\mathrm{Gmb}$} & \multirow{2}{*}{$\begin{array}{c}\mathrm{Gmm} \\
\text { Maximum }\end{array}$} & \multicolumn{2}{|c|}{ Nuclear Density Gauge $^{a}$} & \multirow{2}{*}{$\begin{array}{c}\text { Thin Lift }^{\mathrm{a}} \\
\text { Nuclear } \\
\text { Gauge } \\
\end{array}$} \\
\hline & SSD & Paraffin & & Uncorrected & Corrected & \\
\hline | 64 & $x^{a}$ & & & $\mathrm{X}$ & & \\
\hline 177 & $\mathbf{X}$ & $\mathrm{X}$ & $\mathrm{X}$ & & & \\
\hline | $79(1)$ & $\mathbf{X}$ & $\mathbf{x}$ & $\mathbf{X}$ & & & \\
\hline $79(2)$ & $x^{a}$ & & & $x$ & & \\
\hline US 60 & $\mathbf{X}$ & $X$ & $x$ & $\mathbf{X}$ & & $X$ \\
\hline WV 622 & $\mathbf{X}$ & $\mathbf{X}$ & $\mathbf{X}$ & $\mathbf{X}$ & & $\mathbf{X}$ \\
\hline US 250 & & & & $\mathbf{X}$ & $X$ & \\
\hline WV 34 (1) & $\mathbf{x}$ & $x$ & $x$ & $\mathbf{X}$ & $\mathbf{X}$ & \\
\hline CR 39 & $\mathbf{X}$ & $\mathbf{X}$ & $\mathbf{X}$ & $\mathbf{X}$ & & \\
\hline CR 41 & & & & $X$ & $\mathrm{X}$ & \\
\hline WV 34 (2) & & & & $\mathbf{X}$ & $\mathbf{X}$ & \\
\hline WV 16 & $x^{a}$ & & & $x$ & $x$ & \\
\hline WV 114 & & & & $\mathbf{X}$ & $\mathbf{X}$ & \\
\hline
\end{tabular}

With these data, various techniques can be studied. Table 3.2 shows the different data sets that can be used to make certain comparisons.

Table 3.2: Projects Used in Various Comparisons

\begin{tabular}{|l|c|c|c|c|}
\hline & $\begin{array}{c}\text { Visual } \\
\text { Inspection }\end{array}$ & $\begin{array}{c}\text { Mat density } \\
\text { vs. Joint } \\
\text { density }\end{array}$ & $\begin{array}{c}\text { Rollerpass } \\
\text { vs. Lot }\end{array}$ & $\begin{array}{c}\text { Density } \\
\text { Measurement } \\
\text { Comparison }\end{array}$ \\
\hline \hline 164 & & $\mathbf{X}$ & $\mathbf{X}$ & $\mathbf{X}$ \\
\hline 177 & $\mathbf{X}$ & $\mathbf{X}$ & $\mathbf{X}$ & $\mathbf{X}$ \\
\hline 179 & & $\mathbf{X}$ & $\mathbf{X}$ & $\mathbf{X}$ \\
\hline I79 & & $\mathbf{X}$ & $\mathbf{X}$ & $\mathbf{X}$ \\
\hline US 60 & & & $\mathbf{X}$ & $\mathbf{X}$ \\
\hline WV 622 & & & $\mathbf{X}$ & $\mathbf{X}$ \\
\hline US 250 & & $\mathbf{X}$ & $\mathbf{X}$ & $\mathbf{X}$ \\
\hline WV 34 & & & $\mathbf{X}$ & $\mathbf{X}$ \\
\hline CR 39 & & & $\mathbf{X}$ & \\
\hline CR 41 & & & $\mathbf{X}$ & $\mathbf{X}$ \\
\hline WV 34 (2) & & & $\mathbf{X}$ & $\mathbf{X}$ \\
\hline WV 16 & & & & \\
\hline WV 114 & & & & \\
\hline
\end{tabular}




\section{CHAPTER 4: RESULTS AND ANALYSIS}

\subsection{INTRODUCTION}

The data assembled during this project allows four catagories of comparisons to be made:

- Density of longitudinal joints with visual evidence of good and poor performance.

- Mat versus joint density.

- Average density of projects constructed under the rollerpass and lot quality control methods.

- Methods for measuring density

After all the samples were tested as described in Chapter 3, the results were analyzed. For this project, Microsoft Excel was used for data analysis. The comparisons of the various testing methods were analyzed using the two sample paired t-test for sample means. The other comparisons made were tested using the t-test assuming equal variances. Data for the base and wearing courses were used when comparing the methods for measuring density. Data for the wearing course was used when making other comparisons. If there were more than 30 samples for each set that was being compared, the z-test was used in place of the t-test.

\subsection{VISUAL INSPECTION OF LONGITUDINAL JOINTS}

After construction of the I-77 and I-79 (Elkview to Clendenin) projects, some joints appear to be uniform with the mat while others are made quite obvious by the longitudinal crack that emerges. Joints where cracking and raveling emerges are labeled as visually "bad", and joints that appear to be uniform with the mat are labeled as visually “good". Figure 4.1 shows some good joints that were tested and Figure 4.2 shows some bad joints. The photos from the I-77 project were taken 1 to 2 years after construction and the photos of the I-79 project were taken less than a year after construction.

Photographs of the samples prior to coring are shown in Figures 4.1 and 4.2. The visual comparisons were made with the naked eye. A two-tail t-test assuming equal 
variances was used to compare the densities of the good and bad joints. Figure 4.3 shows the bulk specific gravity data obtained by the SSD method. Figure 4.4 shows the bulk specific gravity data obtained by the paraffin method. Table 4.1 shows the t-test used to compare good and bad joints for both the SSD data set and the paraffin data set.

The null hypothesis of this t-test was that good and bad joints will have the same specific gravity. The results of this t-test using the SSD and paraffin data showed there is insufficient data to reject the null hypothesis at the 95 percent confidence level.

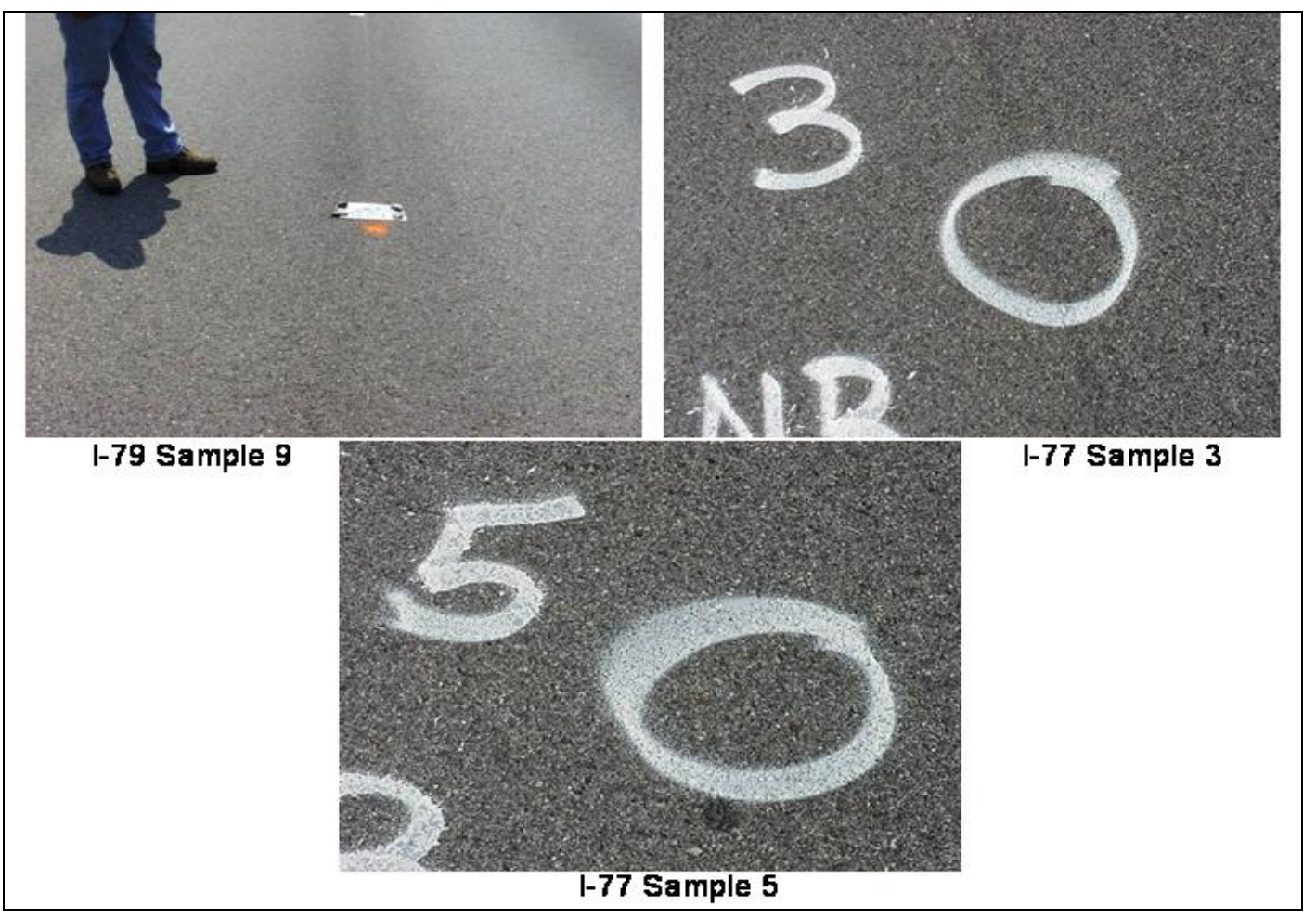

Figure 4.1: Visually Good Joints 


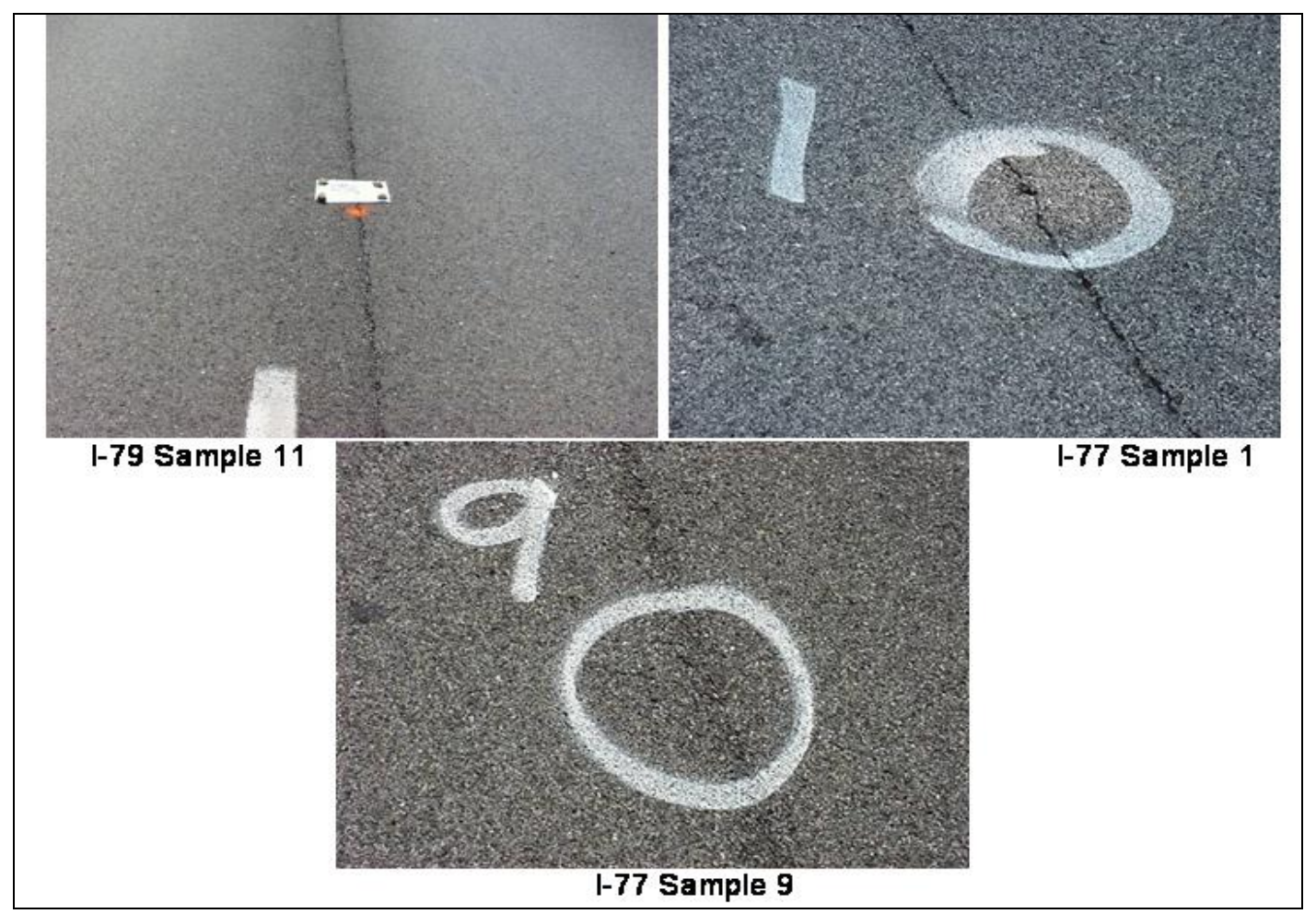

Figure 4.2: Visually Bad Joints

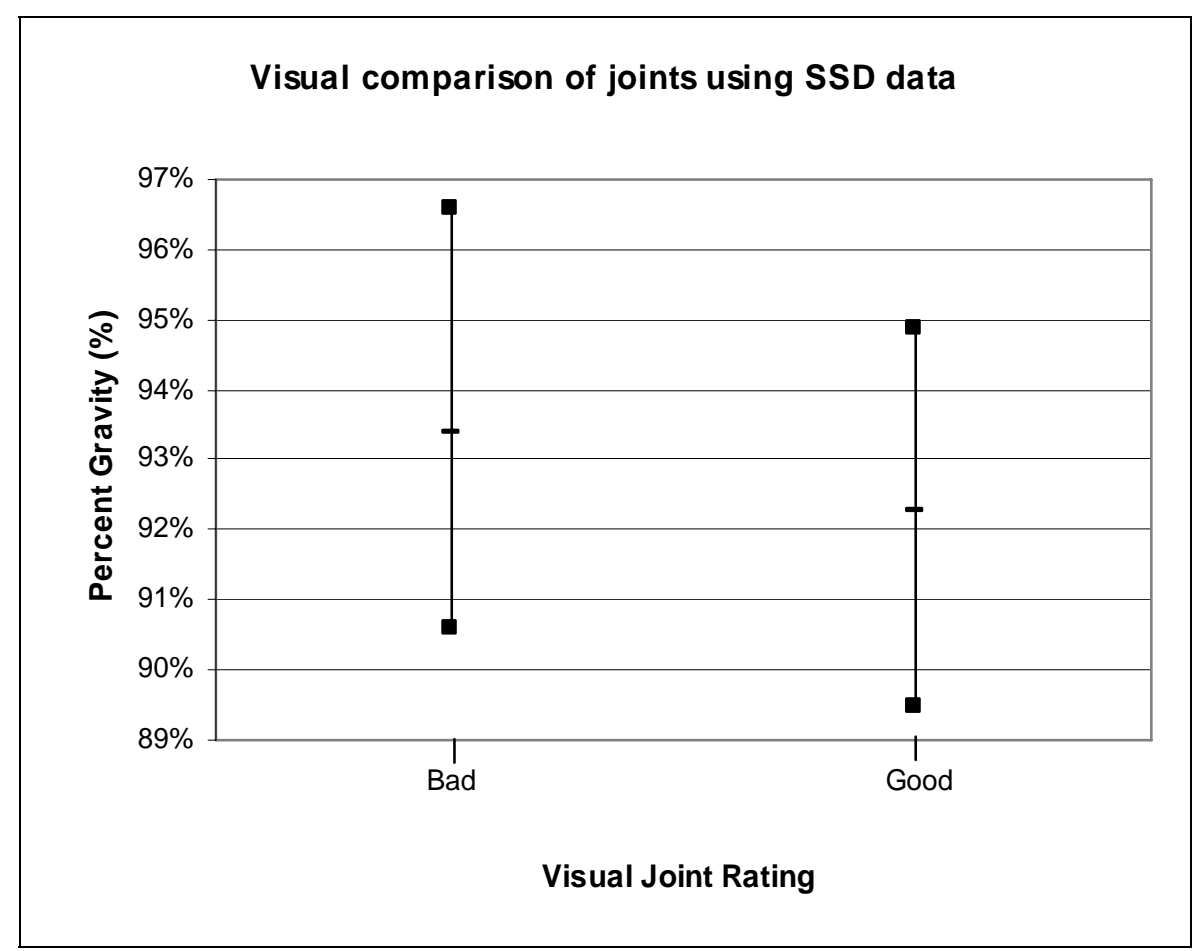

Figure 4.3: Comparison Between Visually Good and Bad Joints using SSD Data 


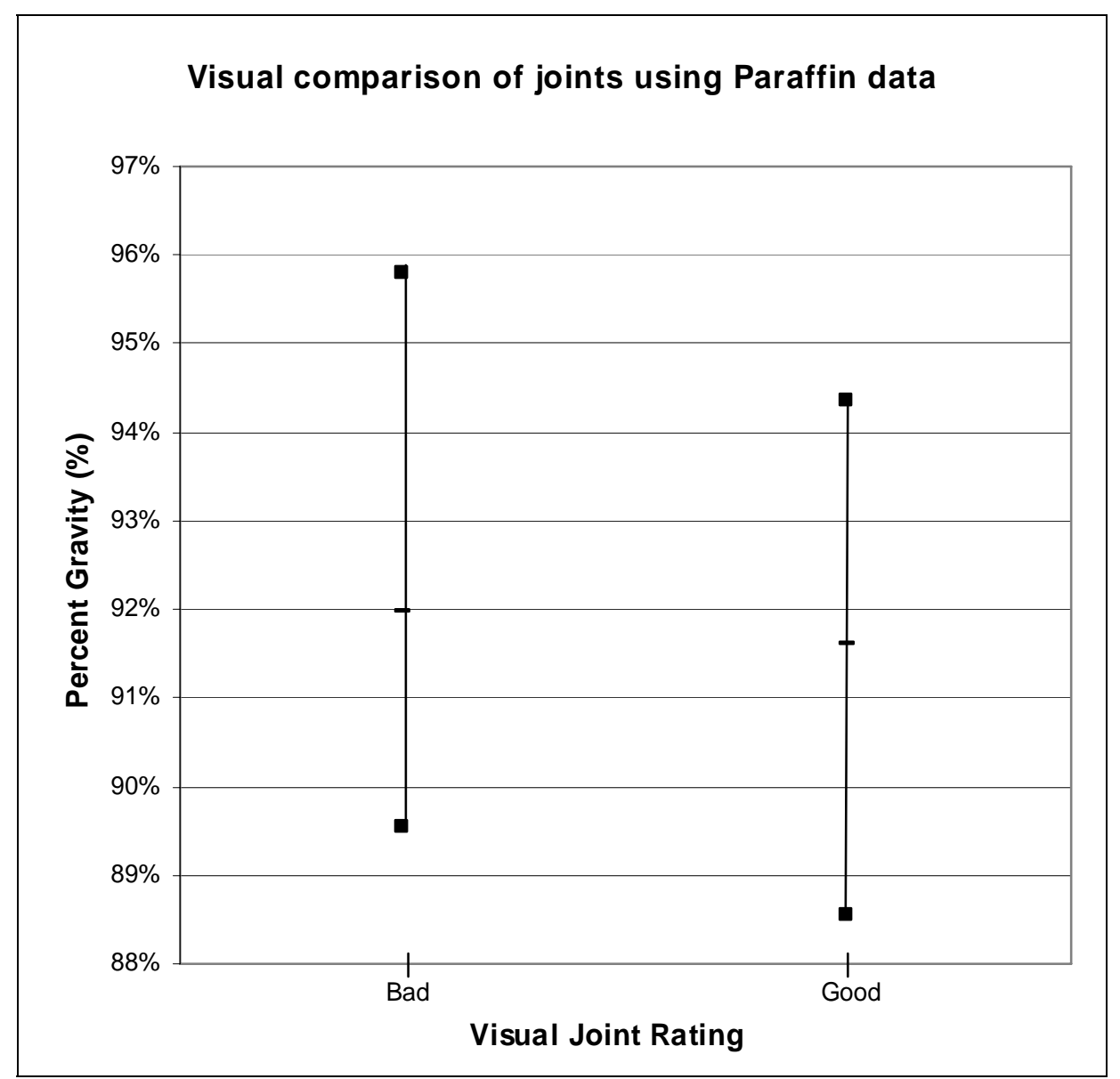

Figure 4.4: Comparison Between Visually Good and Bad Joints using Paraffin Data

Table 4.1: t-Test Comparing Good and Bad Joint Density

\begin{tabular}{|l|r|r|r|r|}
\hline \multirow{2}{*}{} & \multicolumn{2}{|c|}{ SSD } & \multicolumn{2}{c|}{ Paraffin } \\
\cline { 2 - 5 } & \multicolumn{1}{|c|}{ Bad } & Good & Bad & Good \\
\hline \hline Mean & 2.230 & 2.203 & 2.196 & 2.187 \\
\hline Variance & 0.00356 & 0.00334 & 0.00417 & 0.00335 \\
\hline Observations & 4 & 4 & 4 & 4 \\
\hline Pooled Variance & 0.00345 & & 0.00376 & \\
\hline Hypothesized Mean Difference & 0 & & 0 & \\
\hline df & 6 & & 6 & \\
\hline $\mathrm{t}$ Stat & 0.632 & & 0.202 & \\
\hline $\mathrm{P}(\mathrm{T}<=\mathrm{t})$ two-tail & 0.551 & & 0.847 & \\
\hline $\mathrm{t}$ Critical two-tail & 2.447 & & 2.447 & \\
\hline
\end{tabular}




\subsection{COMPARISON OF MAT AND JOINT DENSITIES}

Figures 4.5 to 4.8 show the mat and joint densities using the data from the paraffin method. The stations for the US-60 and WV-34 (Confidence to Paradise) projects were not recorded, so sample numbers were used for Figures 4.7 and 4.8. Table 4.2 shows results from the t-tests used to compare the mat and joint using the paraffin and SSD data for projects where measurements were taken at both the mat and the joint. The statistical analysis indicated there is not sufficient data to reject the hypothesis that the specific gravity of the joints and mats were equal for I-77, US 60 and WV 34 projects. The hypothesis was rejected for the I-79 (Elkview) project.

Figure 4.9 shows the data collected on the I-79 (Big Otter) project. The stations were not recorded for this data set. The t-test in Table 4.3 shows the hypothesis of equal means is rejected at the 95 percent confidence level; the mat density is higher than the joint density.

\subsection{ROLLERPASS AND LOT METHODS FOR QUALITY CONTROL}

With the rollerpass method, the number of passes is determined when the paving operation begins. As the job site conditions change, especially temperature, no changes are made to the number of passes to accommodate for these changes. With the lot method, the density of the mat is monitored and compaction continues until the required density is achieved. The data set included projects constructed under both quality control methods. The data were analyzed as a percent of the maximum theoretical specific gravity to correspond with the target specification requirements of 92 to 96 percent. The results are shown in Figure 4.10 using SSD data and Figure 4.11 for the nuclear density data. The average density under both specifications is similar; however, there is a large range of results. The t-test, Table 4.4, shows there is insufficient data to reject the null hypothesis that the average percent maximum theoretical specific gravity under the two quality control methods is equal at the 95 percent confidence level. This indicates that there is no apparent advantage of using either quality control method. It was observed that the average percent of maximum theoretical specific gravity for both methods was less than the minimum target value of 92 percent. 


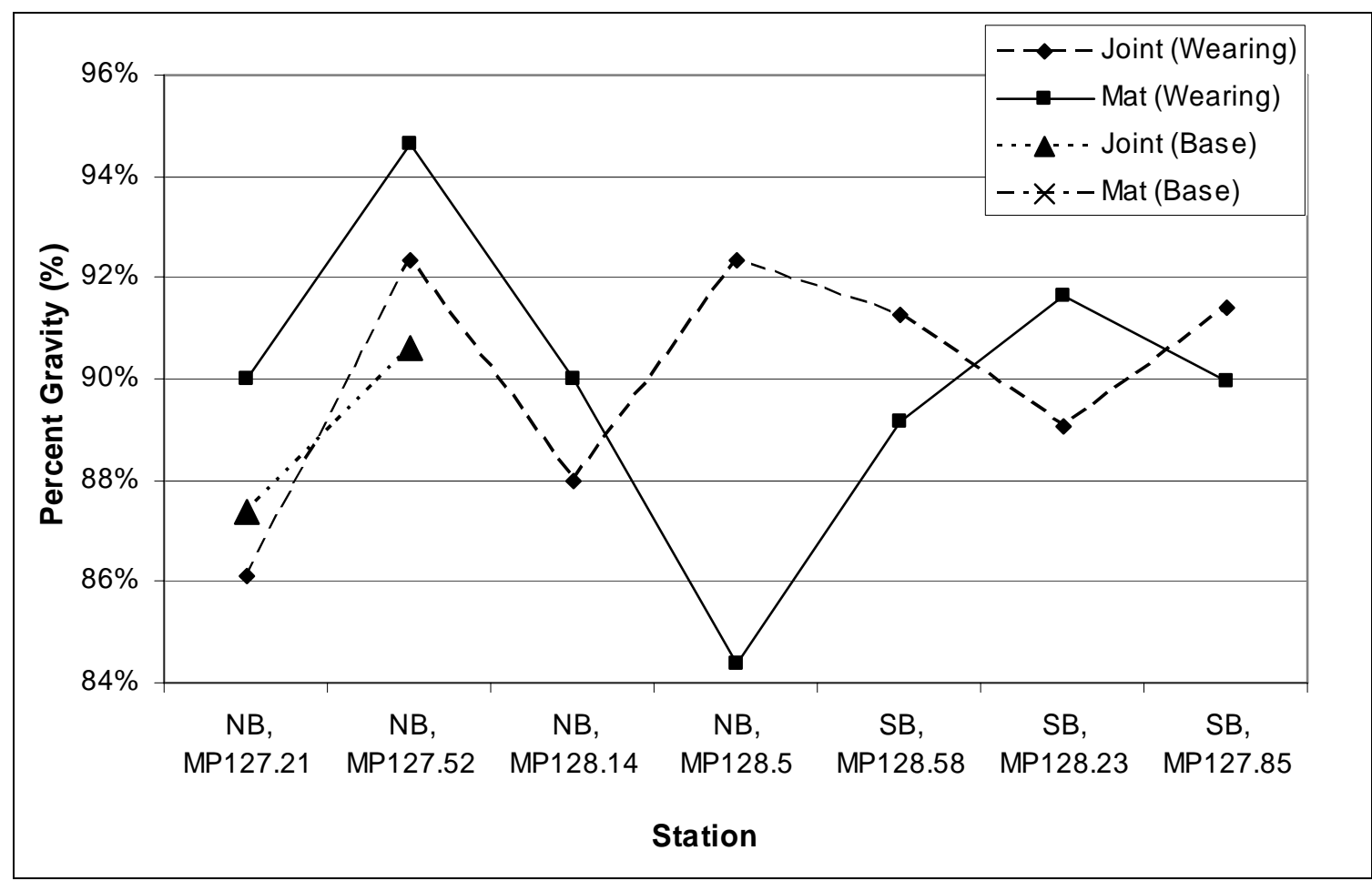

Figure 4.5: Comparison of Mat and Joint Densities using the Paraffin Data for I-77

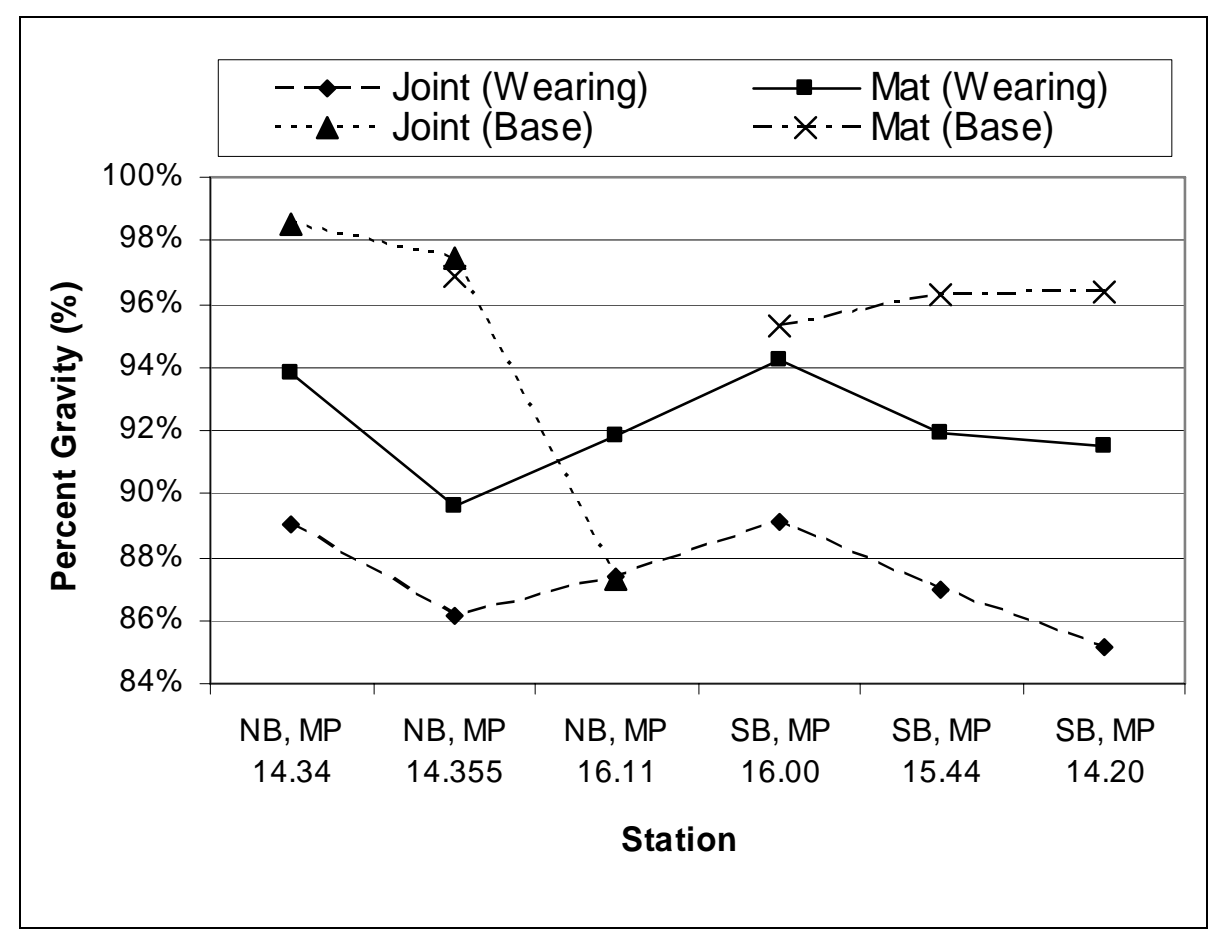

Figure 4.6: Comparison of Mat and Joint Densities using the Paraffin Data for I-79 (Elkview) 


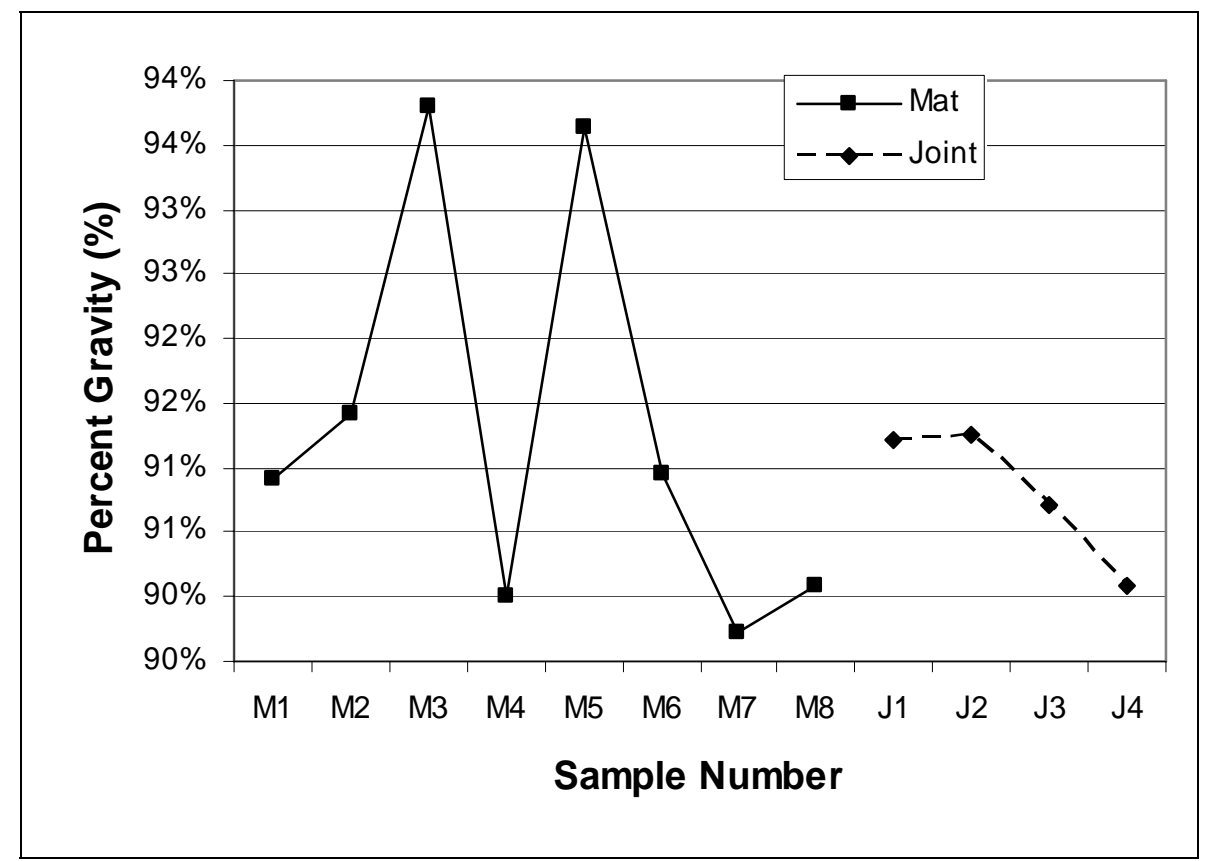

Figure 4.7: Comparison of Mat and Joint Densities using the Paraffin Data for US-60

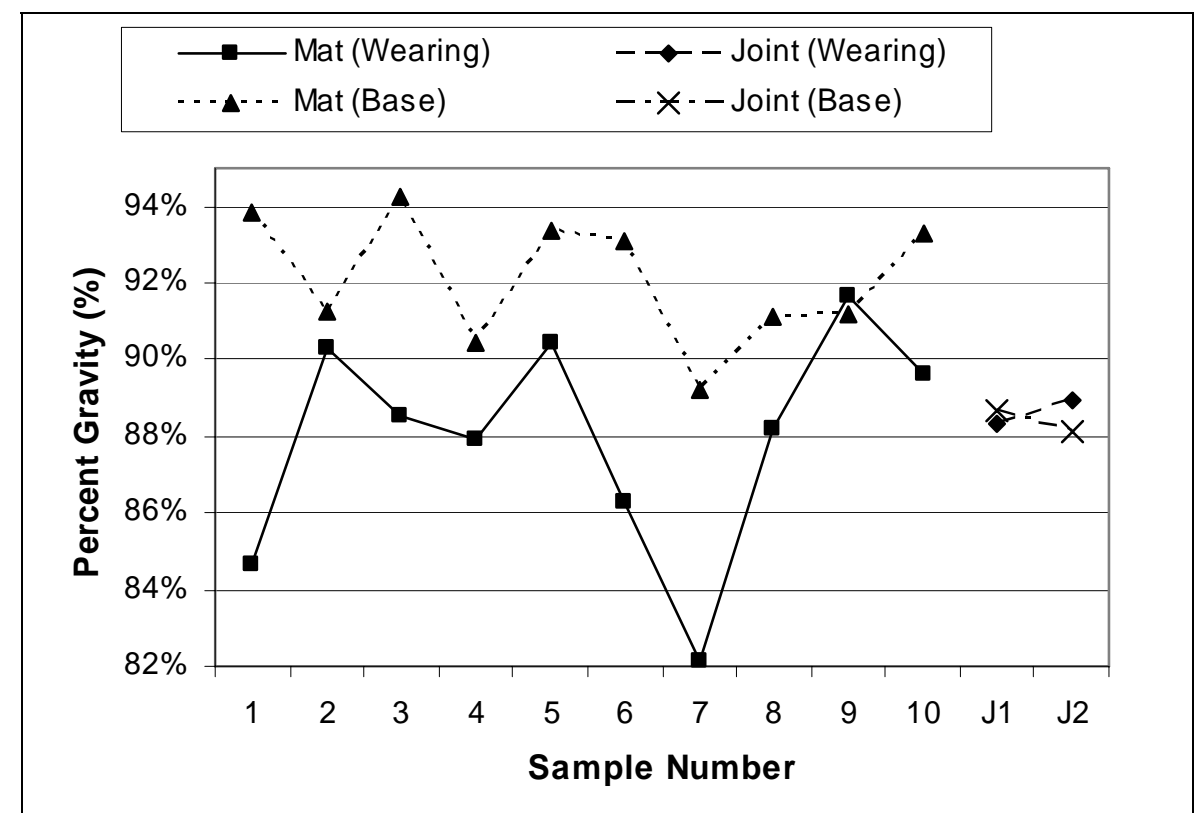

Figure 4.8: Comparison of Mat and Joint Specific Gravities using Paraffin Data for WV-34 
Table 4.2: t-Test Comparing Mat and Joint Specific Gravities using Paraffin and SSD Data

\begin{tabular}{|c|c|c|c|c|c|c|c|c|}
\hline & \multicolumn{4}{|c|}{ I-77 } & \multicolumn{4}{|c|}{ I-79 (Elkview) } \\
\hline & \multicolumn{2}{|c|}{ Paraffin } & \multicolumn{2}{|c|}{ SSD } & \multicolumn{2}{|c|}{ Paraffin } & \multicolumn{2}{|c|}{ SSD } \\
\hline & Joint & Mat & Joint & Mat & Joint & Mat & Joint & Mat \\
\hline Mean & 2.138 & 2.136 & 2.168 & 2.16857 & 2.096 & 2.212 & 2.1335 & 2.22683 \\
\hline Variance & 0.00325 & 0.00532 & 0.00264 & 0.00407 & 0.00143 & 0.00164 & 0.00124 & 0.00179 \\
\hline Observations & 7 & 7 & 7 & 7 & 6 & 6 & 6 & 6 \\
\hline Pooled Variance & 0.00428 & & 0.00336 & & 0.00154 & & 0.00151 & \\
\hline Hypothesized Mean Difference & 0 & & 0 & & 0 & & 0 & \\
\hline df & 12 & & 12 & & 10 & & 10 & \\
\hline t Stat & 0.069 & & -0.0184 & & -5.13702 & & -4.1546 & \\
\hline$P(T<=t)$ two-tail & 0.946 & & 0.98558 & & 0.00044 & & 0.00197 & \\
\hline \multirow[t]{4}{*}{ t Critical two-tail } & 2.179 & & 2.17881 & & 2.228 & & 2.22814 & \\
\hline & \multicolumn{4}{|c|}{ US-60 } & \multicolumn{4}{|c|}{ WV-34 } \\
\hline & \multicolumn{2}{|c|}{ Paraffin } & \multicolumn{2}{|c|}{ SSD } & \multicolumn{2}{|c|}{ Paraffin } & \multicolumn{2}{|c|}{ SSD } \\
\hline & Joint & Mat & Joint & Mat & Joint & Mat & Joint & Mat \\
\hline Mean & 2.181 & 2.193 & 2.18175 & 2.202 & 2.122 & 2.106 & 2.119 & 2.1248 \\
\hline Variance & 0.00017 & 0.00145 & 1.7E-05 & 0.0013 & 0.00011 & 0.00485 & 0.00097 & 0.00259 \\
\hline Observations & 4 & 8 & 4 & 8 & 2 & 10 & 2 & 10 \\
\hline Pooled Variance & 0.00106 & & 0.00092 & & 0.00438 & & 0.00242 & \\
\hline Hypothesized Mean Difference & 0 & & 0 & & 0 & & 0 & \\
\hline df & 10 & & 10 & & 10 & & 10 & \\
\hline t Stat & 0.601 & & 1.09172 & & -0.300 & & 0.15208 & \\
\hline$P(T<=t)$ two-tail & 0.562 & & 0.30056 & & 0.770008 & & 0.88215 & \\
\hline t Critical two-tail & 2.228 & & 2.22814 & & 2.228139 & & 2.22814 & \\
\hline
\end{tabular}




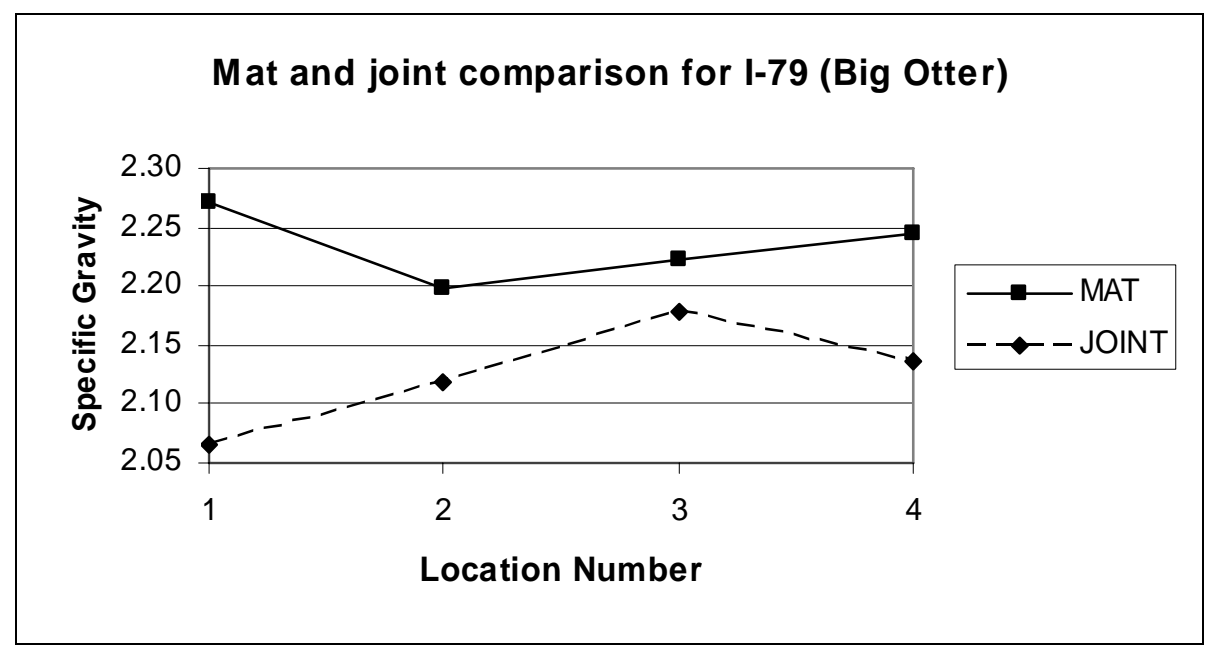

Figure 4.9: Comparison of Mat and Joint Specific Gravities using the SSD Data

Table 4.3: t-Test Comparing Mat and Joint Specific Gravities using SSD Data

\begin{tabular}{|l|r|r|}
\hline & \multicolumn{2}{|c|}{ I-79 (Big Otter) } \\
\hline & \multicolumn{1}{|c|}{ Mat } & Joint \\
\hline \hline Mean & 2.235 & 2.125 \\
\hline Variance & 0.00098 & 0.00216 \\
\hline Observations & 4 & 4 \\
\hline Pooled Variance & 0.00157 & \\
\hline Hypothesized Mean Difference & 0 & \\
\hline df & 6 & \\
\hline $\mathrm{t}$ Stat & 3.918 & \\
\hline $\mathrm{P}(\mathrm{T}<=\mathrm{t})$ two-tail & 0.008 & \\
\hline $\mathrm{t}$ Critical two-tail & 2.447 & \\
\hline
\end{tabular}

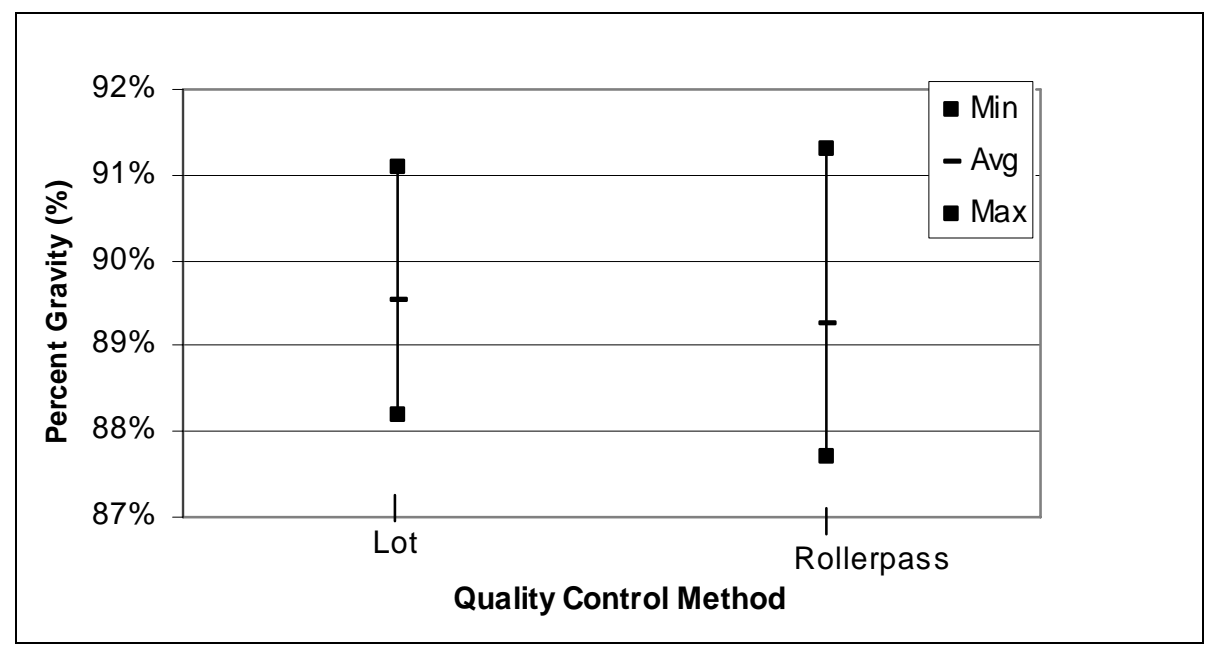

Figure 4.10: Comparison of Rollerpass and Lot Methods using SSD Data 


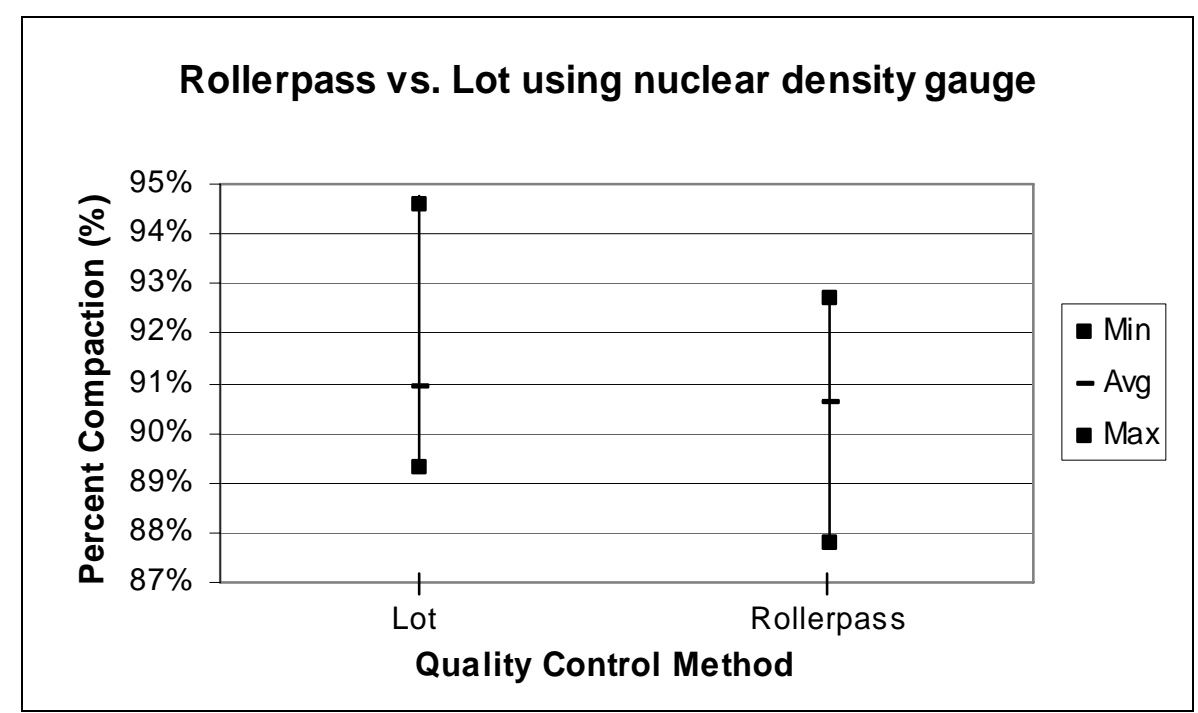

Figure 4.11: Comparison of Rollerpass and Lot Methods using Nuclear Gauge Data

Table 4.4: t-Test Comparing Rollerpass to Lot Method

\begin{tabular}{|l|r|r|r|r|}
\hline & \multicolumn{2}{|c|}{ Nuclear Gauge } & \multicolumn{2}{c|}{ SSD } \\
\cline { 2 - 5 } & \multicolumn{1}{|c|}{ Lot } & Rollerpass & \multicolumn{1}{c|}{ Lot } & Rollerpass \\
\hline \hline Mean & 0.909 & 0.906 & 0.895 & 0.893 \\
\hline Variance & $6.14 \mathrm{E}-04$ & $3.37 \mathrm{E}-04$ & $7.73 \mathrm{E}-05$ & $2.24 \mathrm{E}-04$ \\
\hline Observations & 4 & 7 & 7 & 4 \\
\hline Pooled Variance & $4.30 \mathrm{E}-04$ & & $1.26 \mathrm{E}-04$ & \\
\hline Hypothesized Mean Difference & 0 & & 0 & \\
\hline df & 9 & & 9 & \\
\hline t Stat & 0.228 & & 0.416 & \\
\hline$P(T<=t)$ two-tail & 0.825 & & 0.687 & \\
\hline t Critical two-tail & 2.262 & & 2.262 & \\
\hline
\end{tabular}

\subsection{CORRECTIONS TO NUCLEAR DENSITY GAUGE READINGS}

Four projects were used to examine how the correction to the nuclear gauge based on the density of the existing surface affects the results. Figure 4.12 shows the results for these four projects. As expected from the equation, if the underlying surface has a lower density than the value measured for the overlay, then the correction results in an increase in the final density.

\subsection{METHODS FOR MEASURING SPECIFIC GRAVITY}

Five methods of determining density were used during this research:

- SSD, AASHTO T166 
- Paraffin, AASHTO T275

- Standard nuclear density, uncorrected

- Standard nuclear density, corrected for the density of the underlying layer

- Thin lift nuclear density gauge.

The testing program evolved during the project so only limited comparisons could be made, as shown in Table 4.5

Table 4.5: Project Data Available for each Comparison

\begin{tabular}{|c|c|c|c|c|c|c|}
\hline & $\begin{array}{c}\text { SSD } \\
\text { to } \\
\text { Paraffin }\end{array}$ & $\begin{array}{c}4640-B \\
\text { to } \\
3430 \\
\end{array}$ & $\begin{array}{c}\text { Paraffin } \\
\text { to } \\
3430 \\
\end{array}$ & $\begin{array}{c}\text { SSD } \\
\text { to } \\
4640-B \\
\end{array}$ & $\begin{array}{c}\text { SSD } \\
\text { to } \\
3430 \\
\end{array}$ & $\begin{array}{l}\text { Paraffin } \\
\text { to } \\
4640-B\end{array}$ \\
\hline 164 & & & & & $\bar{x}$ & \\
\hline | 77 & $x$ & & & & & \\
\hline | 79 (1) & $x$ & & & & & \\
\hline $179(2)$ & & & & & $x$ & \\
\hline US 60 & $\mathrm{x}$ & $\mathrm{X}$ & $\mathrm{X}$ & $\mathrm{X}$ & $\mathrm{X}$ & $x$ \\
\hline WV 622 & $x$ & $x$ & $x$ & $x$ & $x$ & $x$ \\
\hline WV $34(1)^{a}$ & $x$ & & $x$ & & $x$ & \\
\hline CR 39 & $x$ & & $\mathrm{X}$ & & $x$ & \\
\hline$W \vee 16^{a}$ & & & & & $x$ & \\
\hline WV $114^{a}$ & $x$ & & $\mathrm{x}$ & & $\bar{x}$ & \\
\hline
\end{tabular}



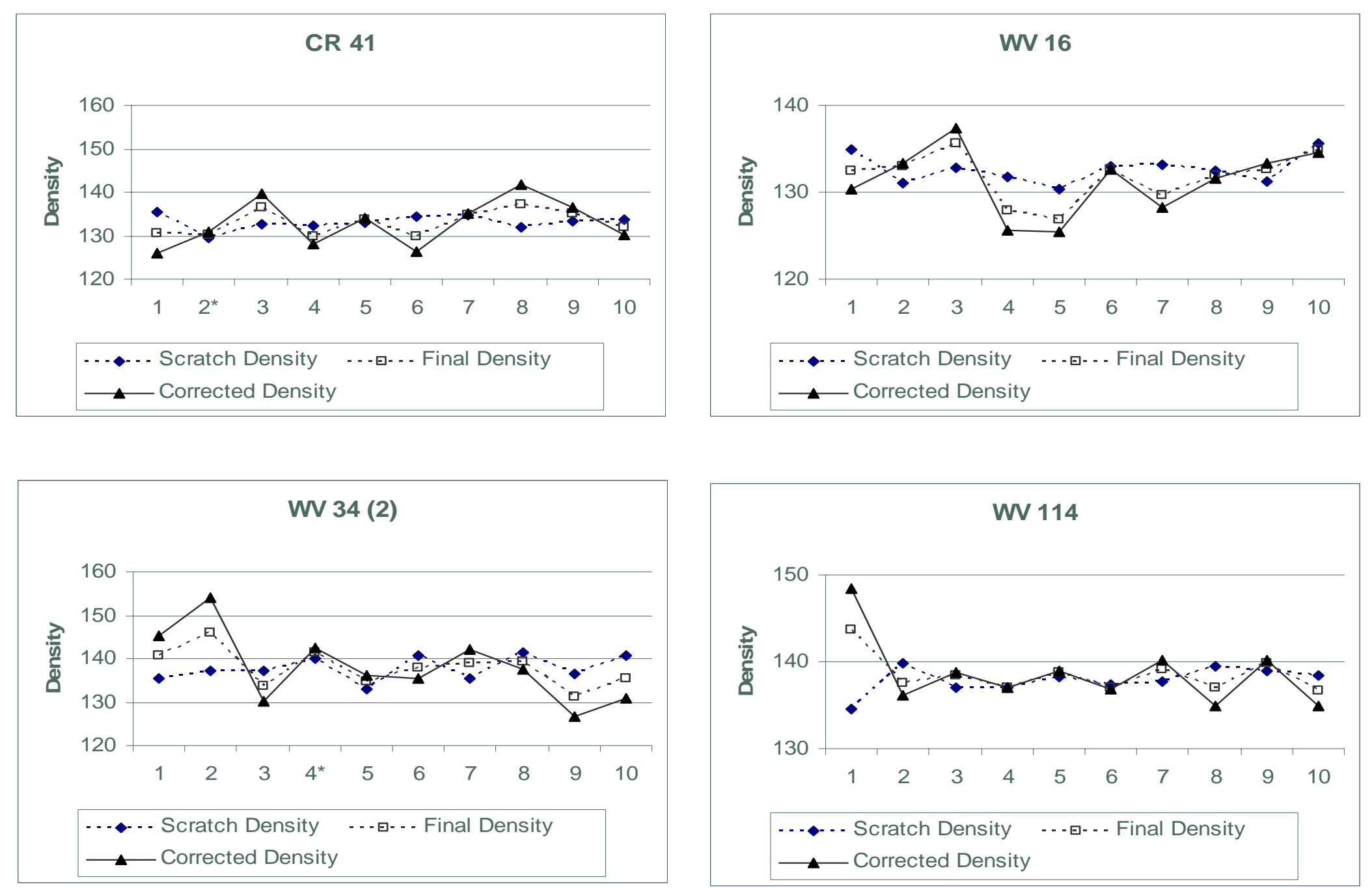

Figure 4.12: Nuclear Density Gauge Measurements Corrected for Base Density 


\subsubsection{Comparing the SSD and Paraffin Methods}

To compare the SSD and paraffin methods, a paired t-test for two sample means was conducted on several projects where both methods were used to test the density. Data for both original and overlay courses were used for the t-tests in this section. Figures 4.13 to 4.18 show the data for each project. Table 4.6 shows the result of the ttests performed for each project.

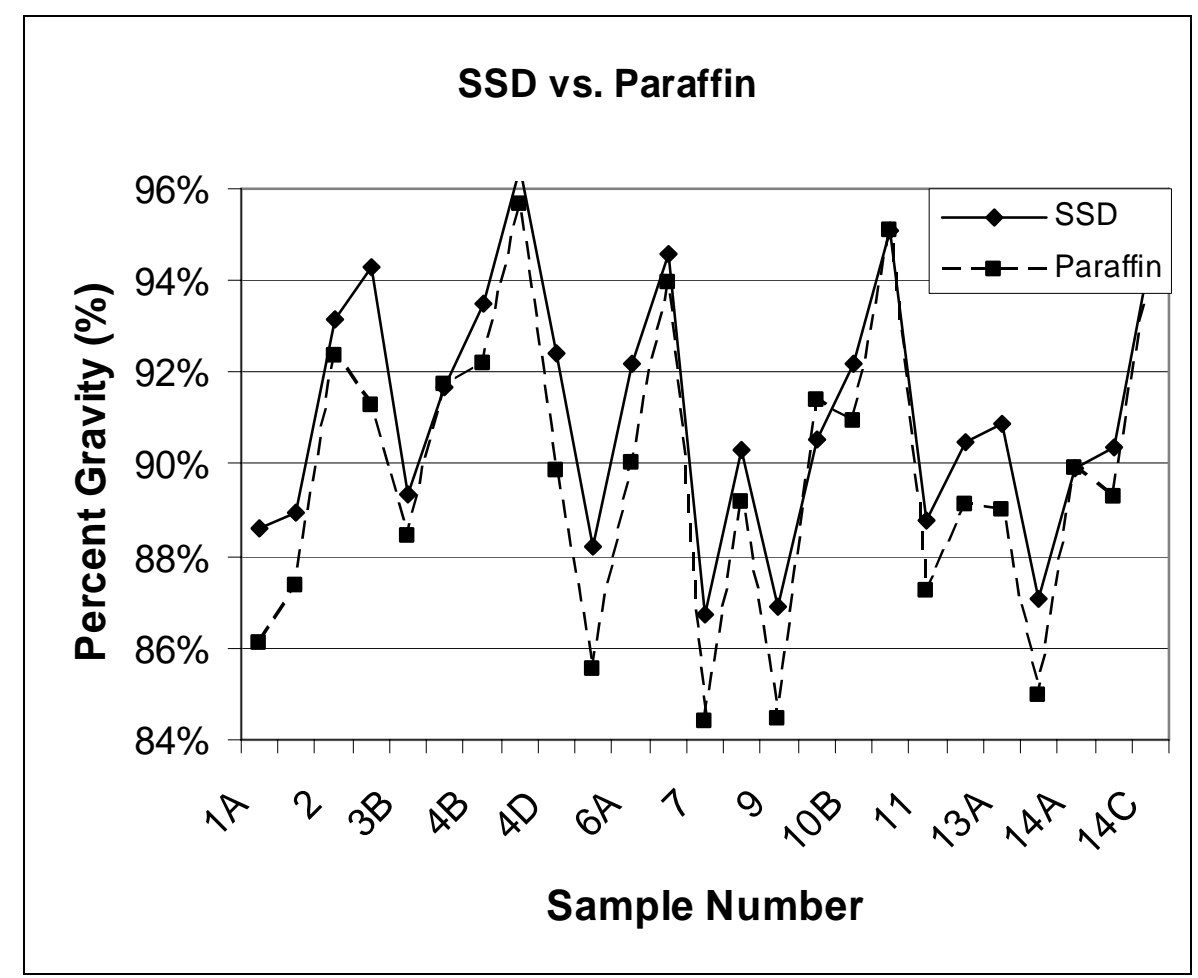

Figure 4.13: SSD and Paraffin Data for I-77 Project

Since there were more than 30 samples from the WV-34 data set, the z-test was used in place of the t-test. The data for this project is shown in Figure 4.19 and the statistical analysis results of this test are shown in Table 4.7.

The t-tests, Table 4.6, indicates the hypothesis that the two test methods will yield the same results was rejected for the I-77, I-79, and CR-39 projects. Figures 4.13, 4.14, and 4.18 show the paraffin method consistently produced lower results than the SSD 
method. However, the hypothesis for the US-60, WV-622, and WV-114 projects was not rejected. The hypothesis for the WV-34 data was not rejected using the z-test.

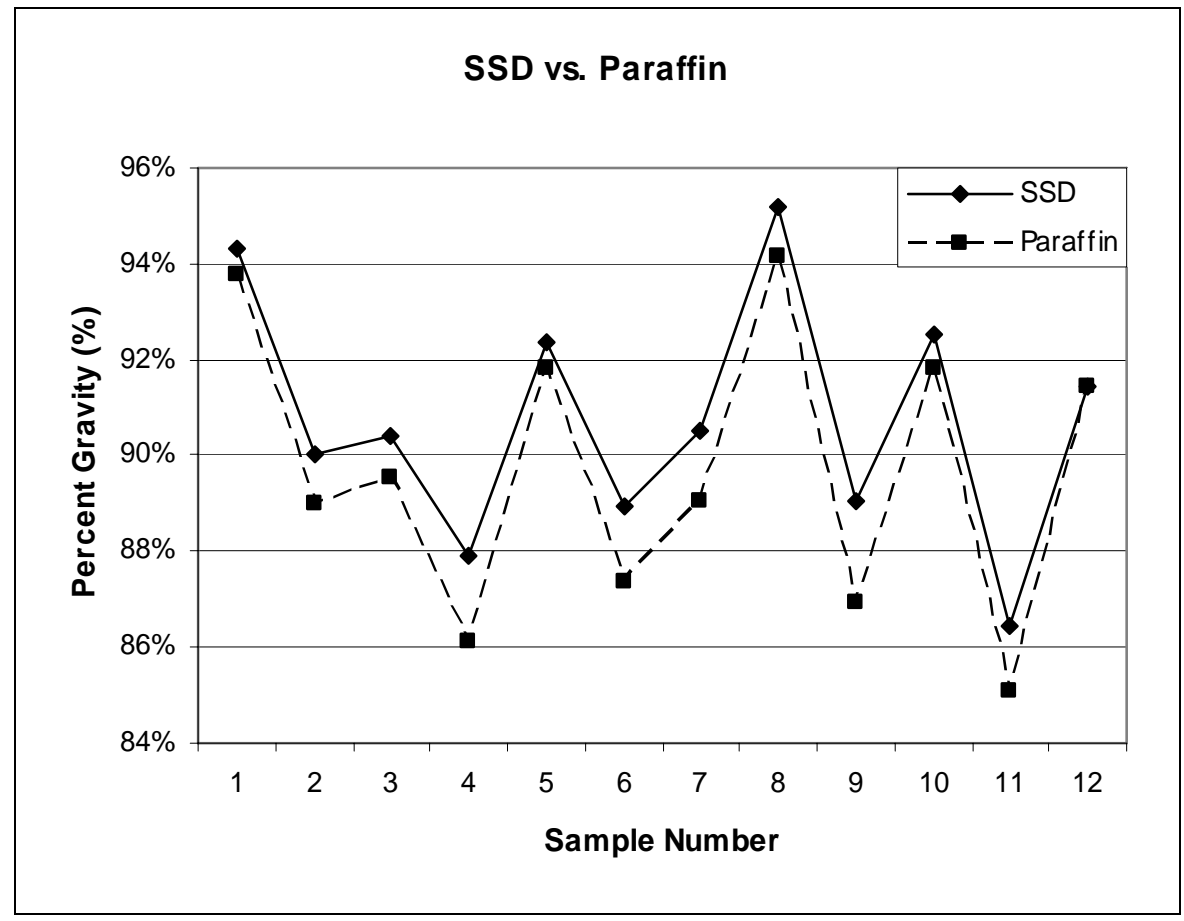

Figure 4.14: SSD and Paraffin Data for I-79 (Elkview) Project

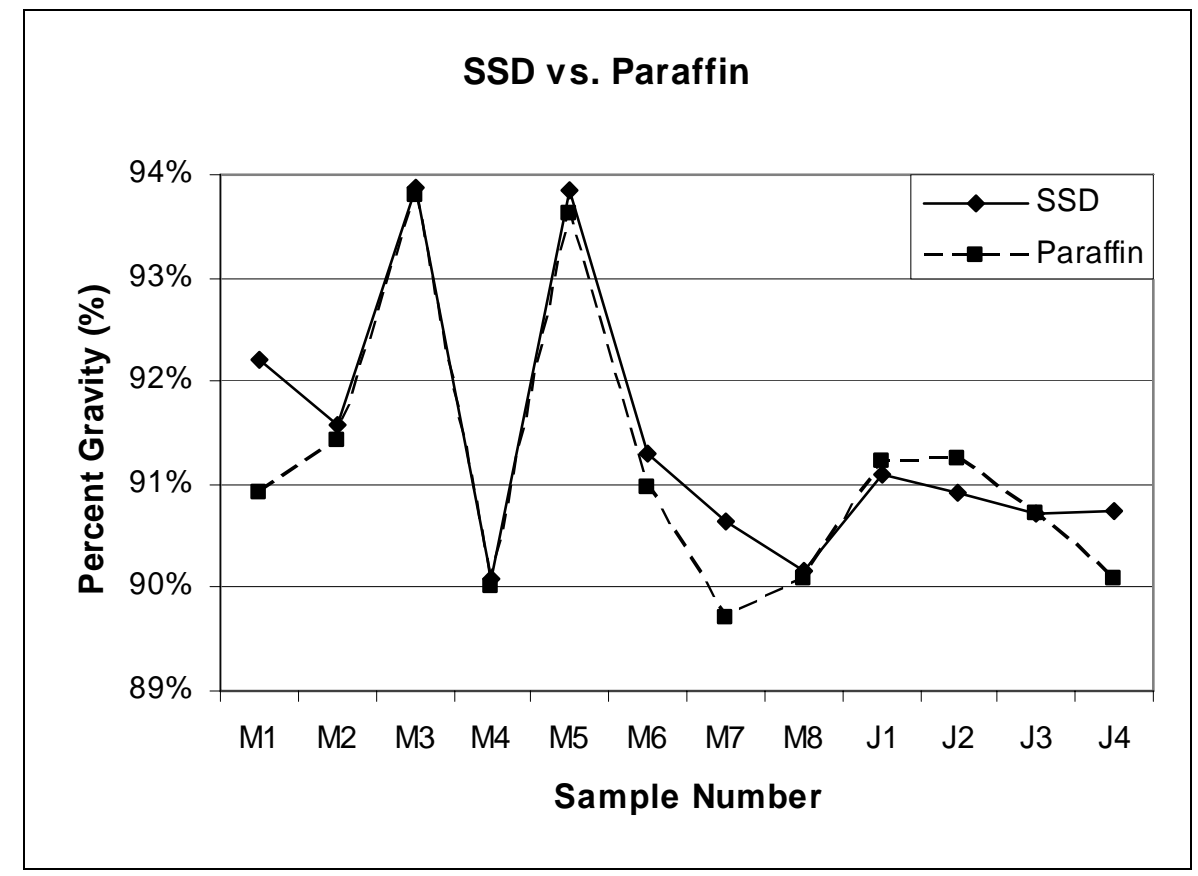

Figure 4.15: SSD and Paraffin Data for US-60 Project 


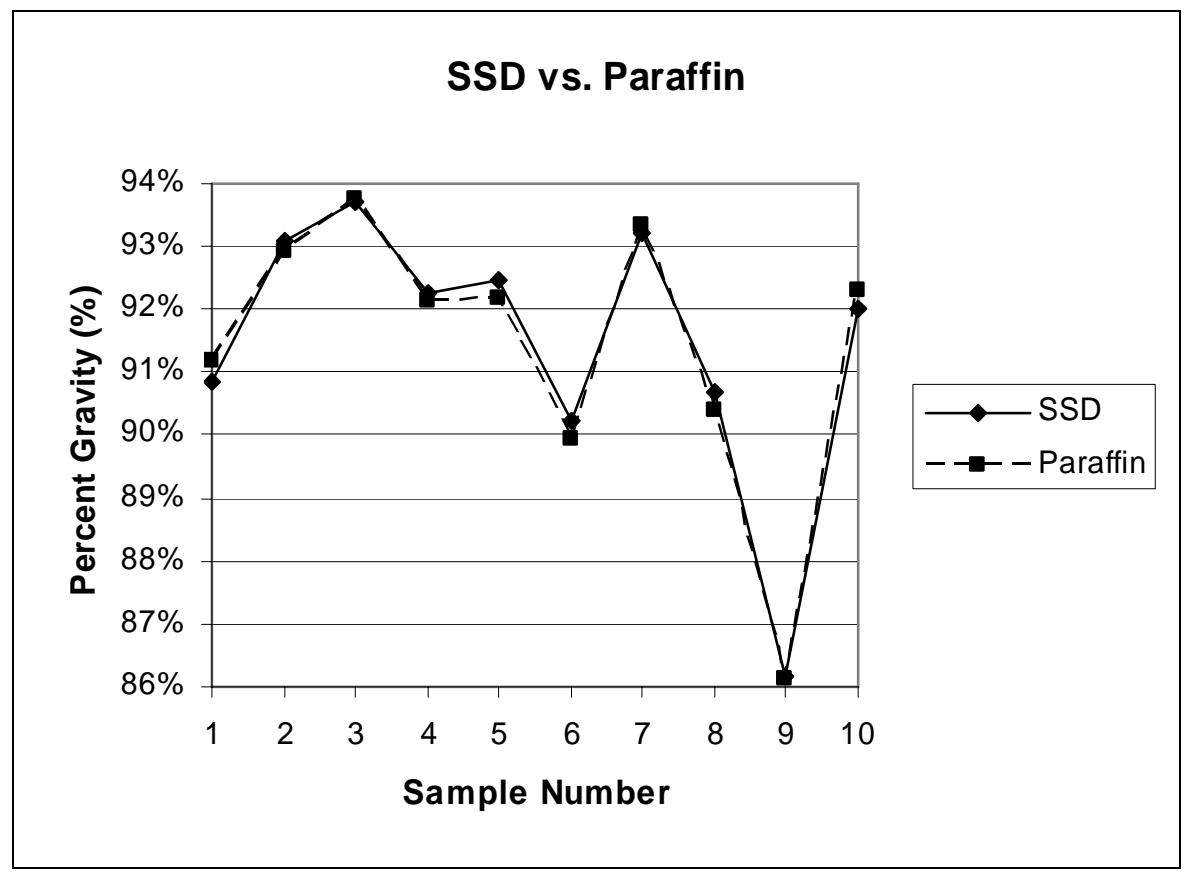

Figure 4.16: SSD and Paraffin Data for WV-622 Project

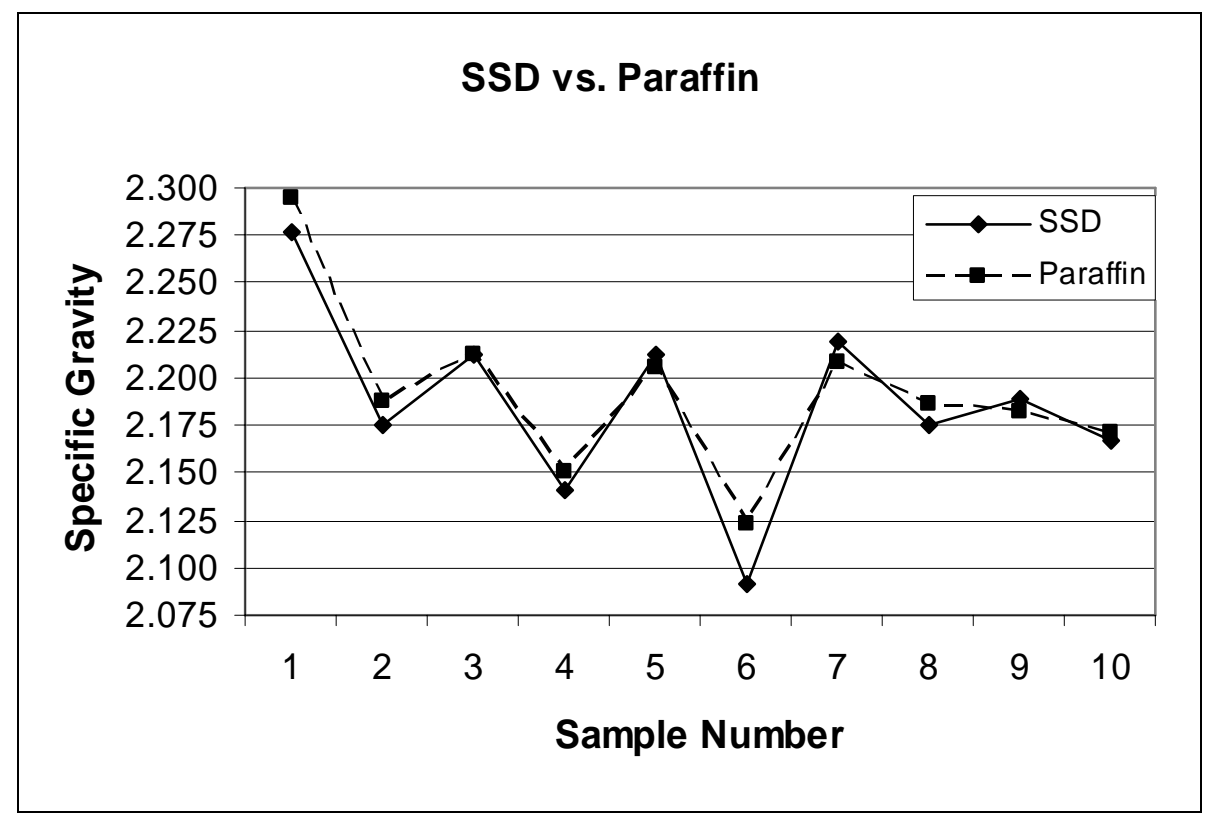

Figure 4.17: SSD and Paraffin Data for WV-114 Project 


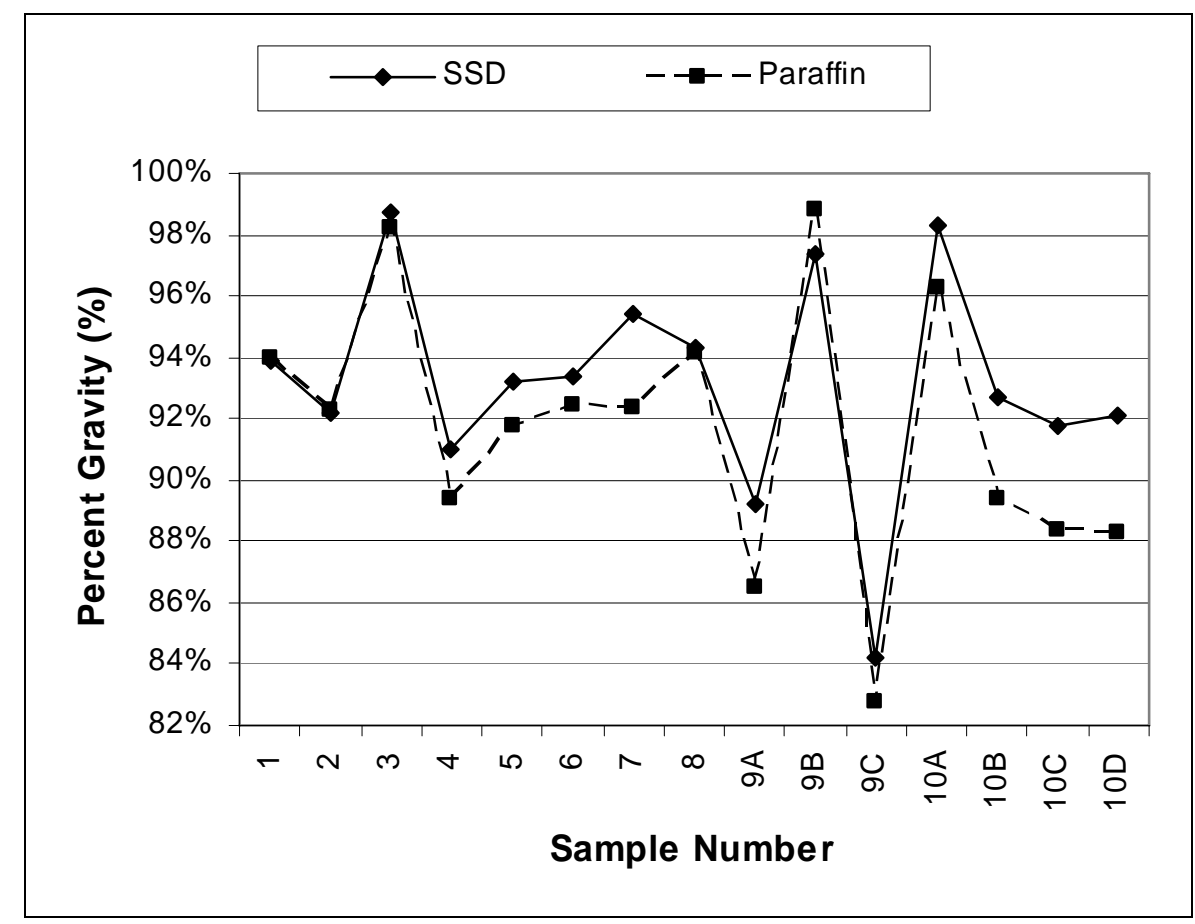

Figure 4.18: SSD and Paraffin Data for CR-39 Project

Table 4.6: Comparison of SSD and Paraffin Methods using the t-Test

\begin{tabular}{|c|c|c|c|c|c|c|}
\hline & \multicolumn{2}{|c|}{$1-77$} & \multicolumn{2}{|c|}{$1-79$} & \multicolumn{2}{|c|}{ US-60 } \\
\hline & $S S D$ & Paraffin & $S S D$ & Paraffin & SSD & Paraffin \\
\hline Mean & 2.169 & 2.138 & 2.234 & 2.209 & 2.195 & 2.189 \\
\hline Variance & 0.00463 & 0.00649 & 0.00963 & 0.01134 & 0.00093 & 0.00100 \\
\hline Observations & 25 & 25 & 19 & 19 & 12 & 12 \\
\hline Pearson Correlation & 0.96113 & & 0.99183 & & 0.93749 & \\
\hline Hypothesized Mean Difference & 0 & & 0 & & 0 & \\
\hline df & 24 & & 18 & & 11 & \\
\hline t Stat & 6.560 & & 6.845 & & 2.115 & \\
\hline $\mathrm{P}(\mathrm{T}<=\mathrm{t})$ two-tail & 0.000 & & 0.000 & & 0.058 & \\
\hline \multirow[t]{3}{*}{ t Critical two-tail } & 2.064 & & 2.101 & & 2.201 & \\
\hline & \multicolumn{2}{|c|}{ WV-622 } & \multicolumn{2}{|c|}{ WV-114 } & \multicolumn{2}{|c|}{ CR-39 } \\
\hline & SSD & Paraffin & SSD & Paraffin & $S S D$ & Paraffin \\
\hline Mean & 2.196 & 2.195 & 2.186 & 2.192 & 2.190 & 2.154 \\
\hline Variance & 0.00277 & 0.00285 & 0.00249 & 0.00204 & 0.00738 & 0.01053 \\
\hline Observations & 10 & \begin{tabular}{|r|}
10 \\
\end{tabular} & 10 & 10 & 15 & 15 \\
\hline Pearson Correlation & 0.99446 & & 0.96684 & & 0.94167 & \\
\hline Hypothesized Mean Difference & 0 & & 0 & & 0 & \\
\hline df & 9 & & 9 & & 14 & \\
\hline t Stat & 0.561 & & -1.549 & & 3.848 & \\
\hline$P(T<=t)$ two-tail & 0.589 & & 0.156 & & 0.002 & \\
\hline t Critical two-tail & 2.262 & & 2.262 & & 2.145 & \\
\hline
\end{tabular}




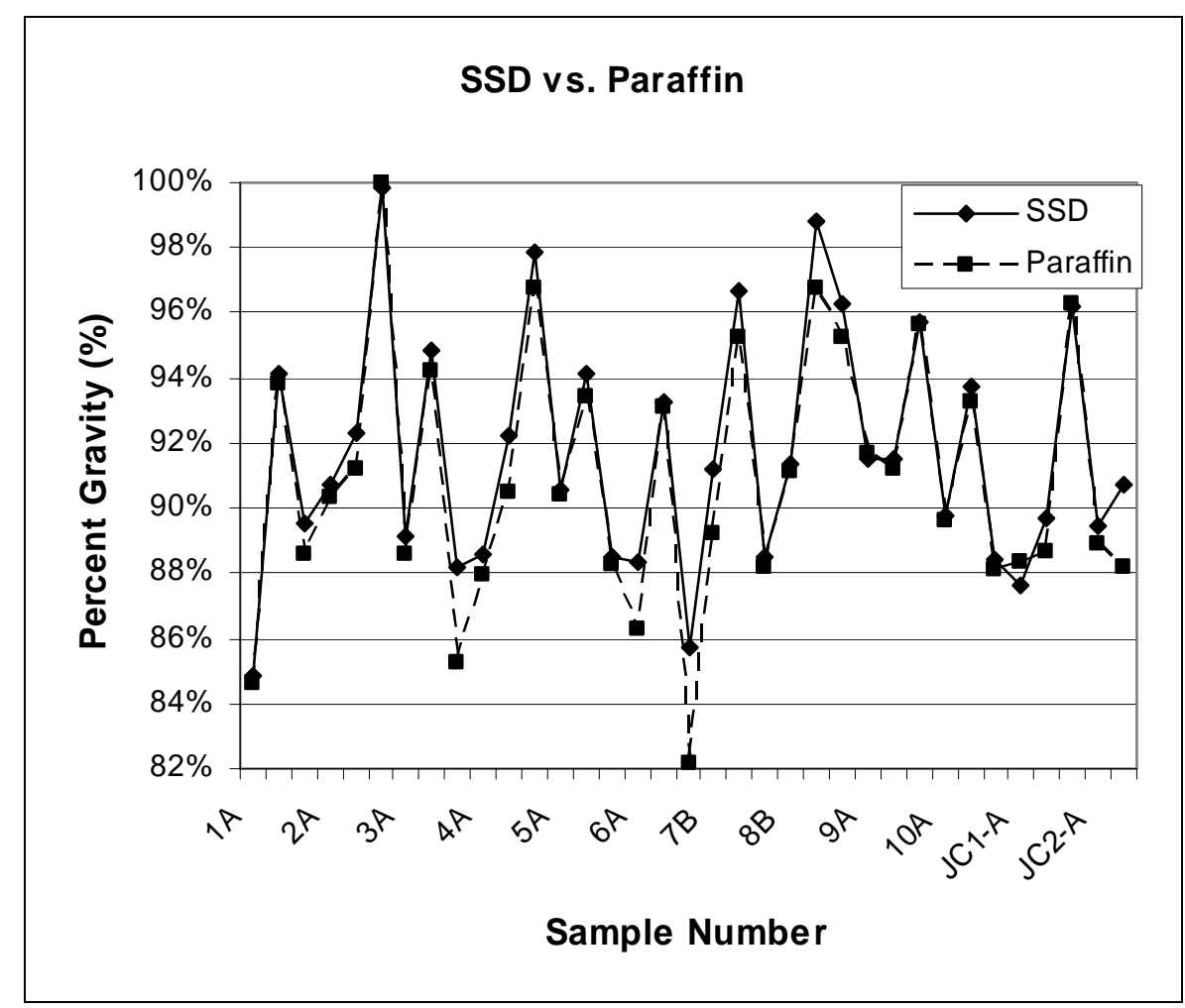

Figure 4.19: SSD and Paraffin Data for WV-34 Project

Table 4.7: Comparison of SSD and Paraffin Tests using the z-Test

\begin{tabular}{|l|r|r|}
\hline & \multicolumn{2}{|c|}{ WV-34 } \\
\hline & $S S D$ & Paraffin \\
\hline \hline Mean & 2.182 & 2.162 \\
\hline Known Variance & 0.00670 & 0.00780 \\
\hline Observations & 35 & 35 \\
\hline Hypothesized Mean Difference & 0 & \\
\hline$Z$ & 0.952 & \\
\hline P(Z<=z) two-tail & 0.341 & \\
\hline Z Critical two-tail & 1.960 & \\
\hline
\end{tabular}

\subsubsection{Comparing the Nuclear Density Gauge to the Thin-lift Gauge}

The data obtained for the projects with the nuclear density gauge and the thin lift nuclear gauge can be seen on Figure 4.20 and Figure 4.21, respectively. Table 4.8 shows the results of the t-test comparing the uncorrected data from the Troxler 3430 nuclear density gauge to the data from the Troxler 4640-B thin-lift nuclear gauge. The hypothesis 
of equal means was rejected for both projects. This is due to the large difference between the means of both projects.

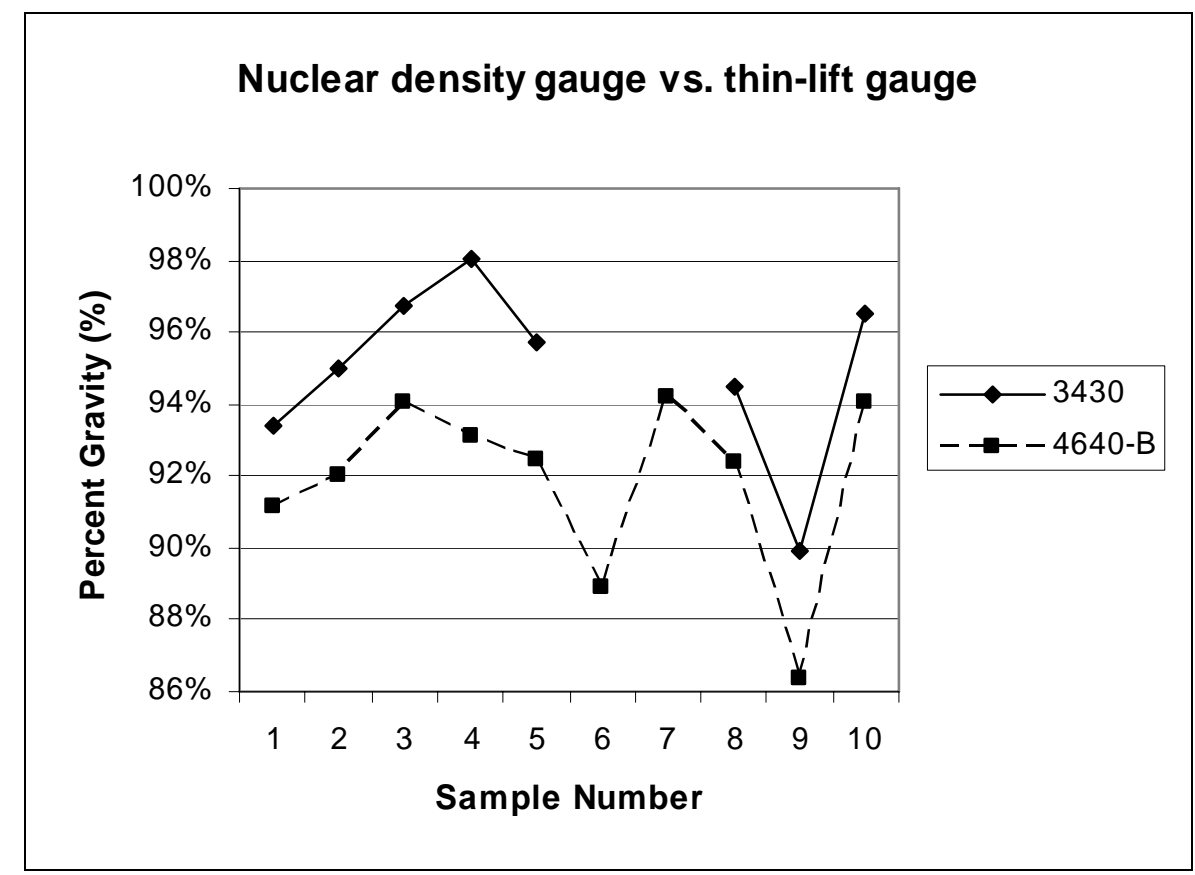

Figure 4.20: Nuclear Gauge and Thin-lift Gauge Data for WV-622 Project

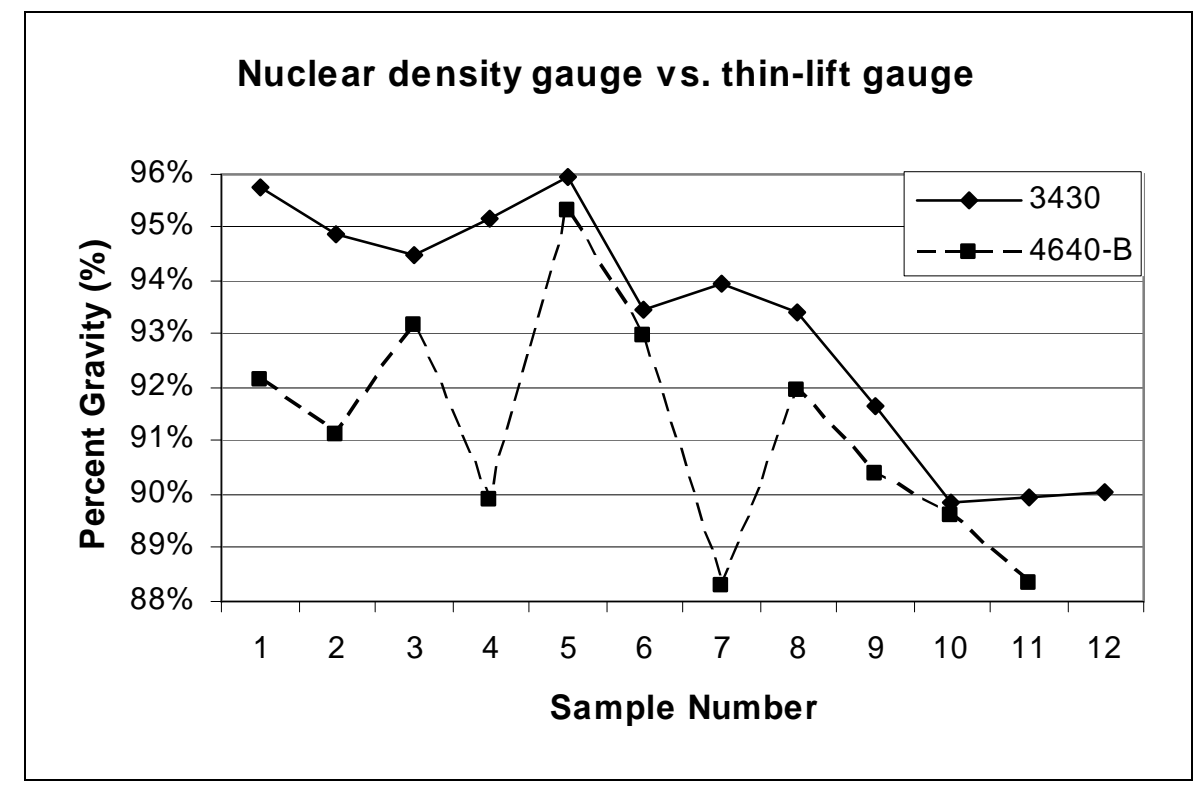

Figure 4.21: Nuclear Gauge and Thin-lift Gauge Data for US-60 project 
Table 4.8: t-Test Comparing Thin-lift Gauge to Nuclear Gauge

\begin{tabular}{|l|r|r|r|r|}
\hline & \multicolumn{2}{|c|}{ WV-622 } & \multicolumn{2}{c|}{ US-60 } \\
\hline & 3430 & $4640-B$ & 3430 & $4640-B$ \\
\hline \hline Mean & 2.280 & 2.208 & 2.245 & 2.190 \\
\hline Variance & 0.00359 & 0.00355 & 0.00267 & 0.00270 \\
\hline Observations & 8 & 8 & 11 & 11 \\
\hline Pearson Correlation & 0.93171 & & 0.60279 & \\
\hline Hypothesized Mean Difference & 0 & & 0 & \\
\hline df & 7 & & 10 & \\
\hline $\mathrm{t} \mathrm{Stat}$ & 9.270 & & 3.977 & \\
\hline $\mathrm{P}(\mathrm{T}<=\mathrm{t})$ two-tail & 0.000 & & 0.003 & \\
\hline $\mathrm{t}$ Critical two-tail & 2.365 & & 2.228 & \\
\hline
\end{tabular}

\subsubsection{Comparing Paraffin Method to the Nuclear Density Gauge}

The t-test was used to compare the data from the paraffin method to the data measured by the Troxler 3430 nuclear density gauge. The data for the US-60, WV-622, and CR-39 projects can be seen on Figure 4.22, Figure 4.23, and Figure 4.24, respectively. The data from the nuclear gauge was not corrected with the formula as recommended by Troxler Electronic Laboratories. The t-test results, Table 4.9, show the hypothesis of equal means is rejected for projects US 60 and WV 622 and was not rejected for project CR 39.

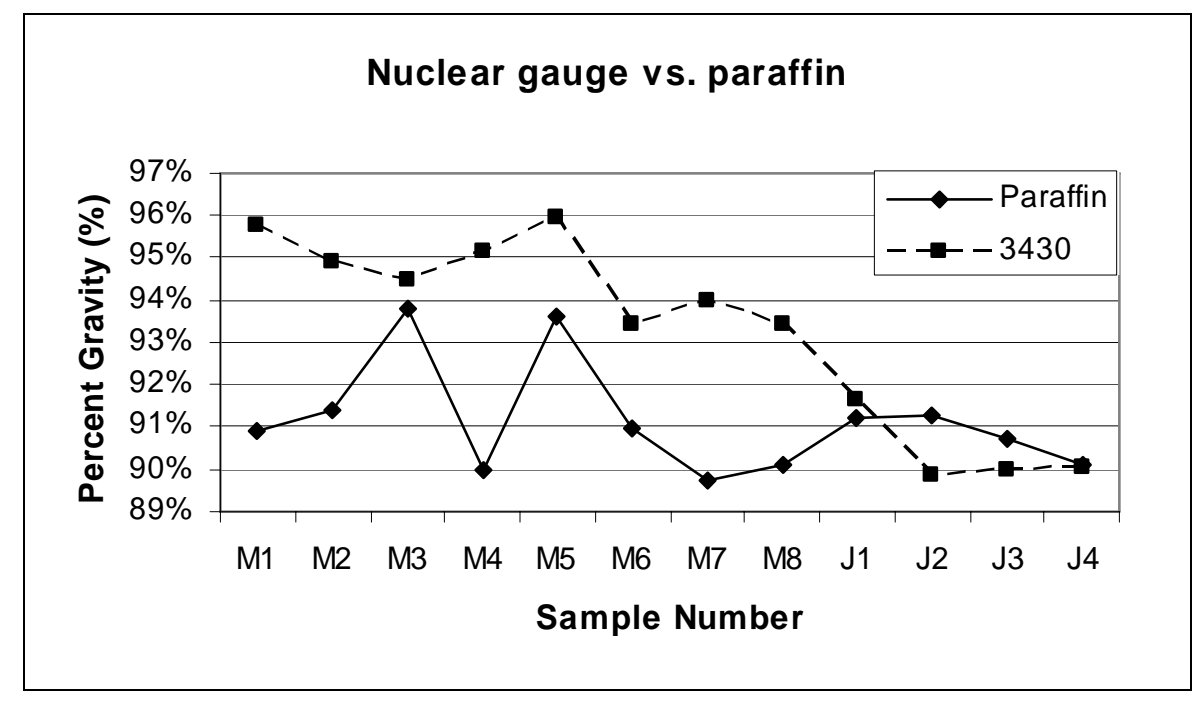

Figure 4.22: Nuclear Gauge and Paraffin Data for US-60 Project 


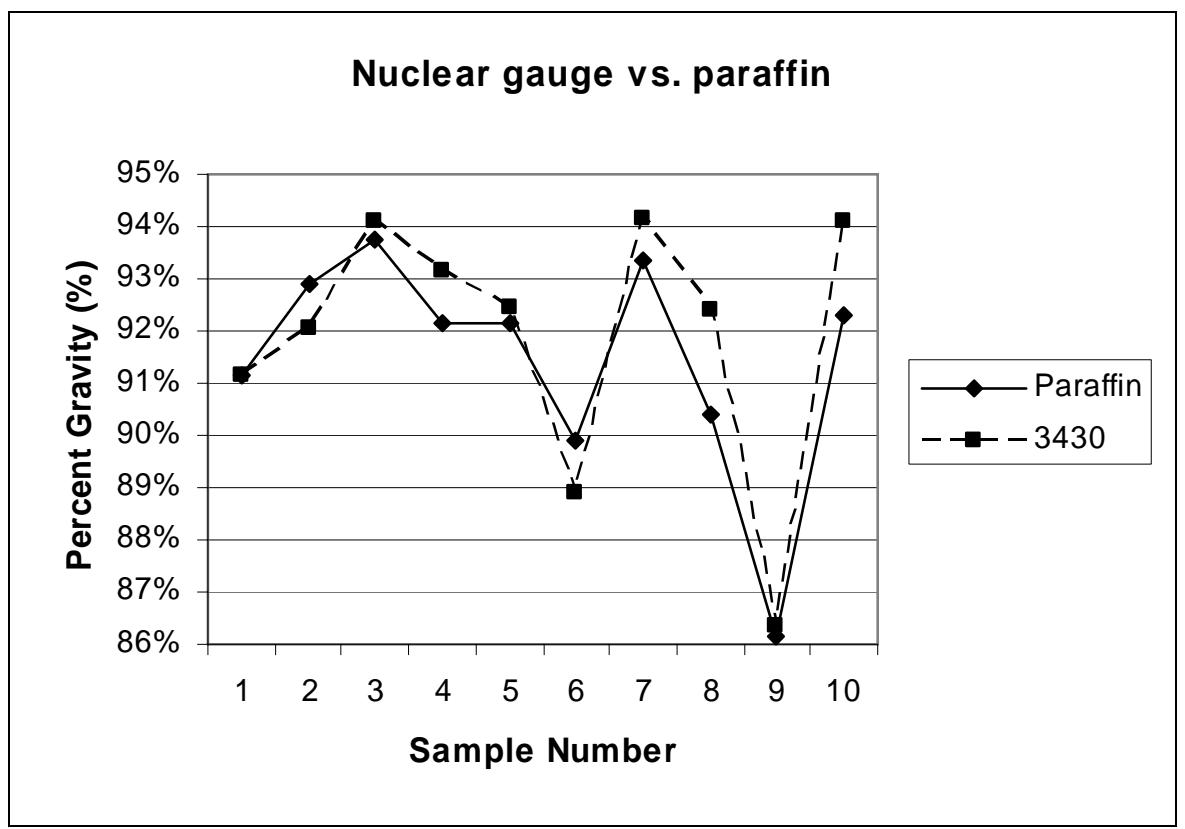

Figure 4.23: Nuclear Gauge and Paraffin Data for WV-622 Project

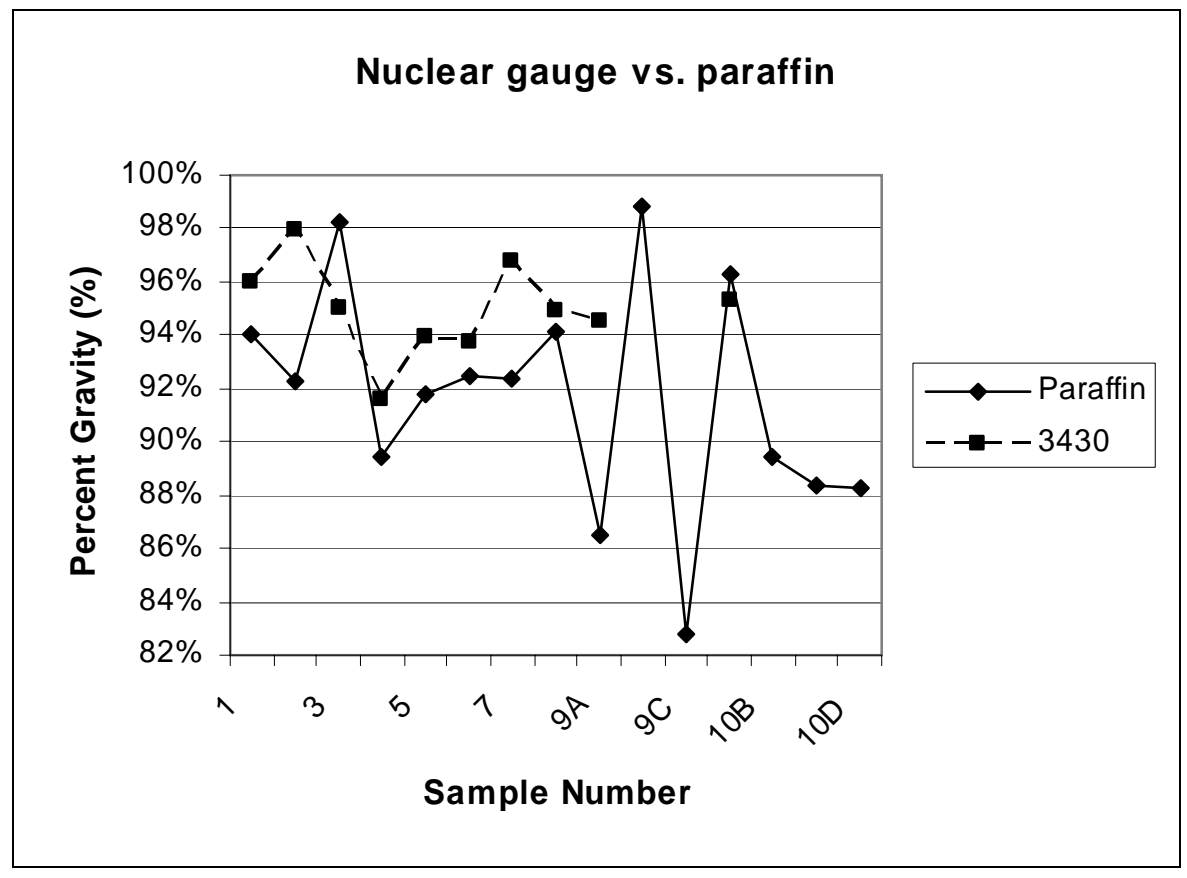

Figure 4.24: Nuclear Gauge and Paraffin Data for CR-39 Project 
Table 4.9: t-Test Comparing Paraffin Data to Unadjusted Nuclear Density Gauge Data

\begin{tabular}{|l|r|r|r|r|r|r|}
\hline & \multicolumn{2}{|c|}{ US-60 } & \multicolumn{2}{c|}{ WV-622 } & \multicolumn{2}{c|}{ CR-39 } \\
\hline & Paraffin & 3430 & Paraffin & 3430 & Paraffin & 3430 \\
\hline \hline Mean & 2.189 & 2.238 & 2.194 & 2.280 & 2.179 & 2.232 \\
\hline Variance & 0.00100 & 0.00300 & 0.00318 & 0.00359 & 0.00603 & 0.00168 \\
\hline Observations & 12 & 12 & 8 & 8 & 10 & 10 \\
\hline Pearson Correlation & 0.32752 & & 0.87189 & & 0.30988 & \\
\hline Hypothesized Mean Difference & 0 & & 0 & & 0 & \\
\hline df & 11 & & 7 & & 9 & \\
\hline t Stat & -3.213 & & -8.257 & & -2.201 & \\
\hline $\mathrm{P}(\mathrm{T}<=\mathrm{t})$ two-tail & 0.008 & & 0.000 & & 0.055 & \\
\hline $\mathrm{t}$ Critical two-tail & 2.201 & & 2.365 & & 2.262 & \\
\hline
\end{tabular}

For projects WV-34 and WV 114, the data from the nuclear density gauge were corrected using the equation recommended by Troxler Electronic Laboratories. The data from those sets are shown in Figures 4.25 to 4.26. The t-test, Table 4.10, indicates the hypothesis of equal means is rejected for both projects. In both cases, the means of the corrected nuclear density gauge results were greater than the paraffin results.

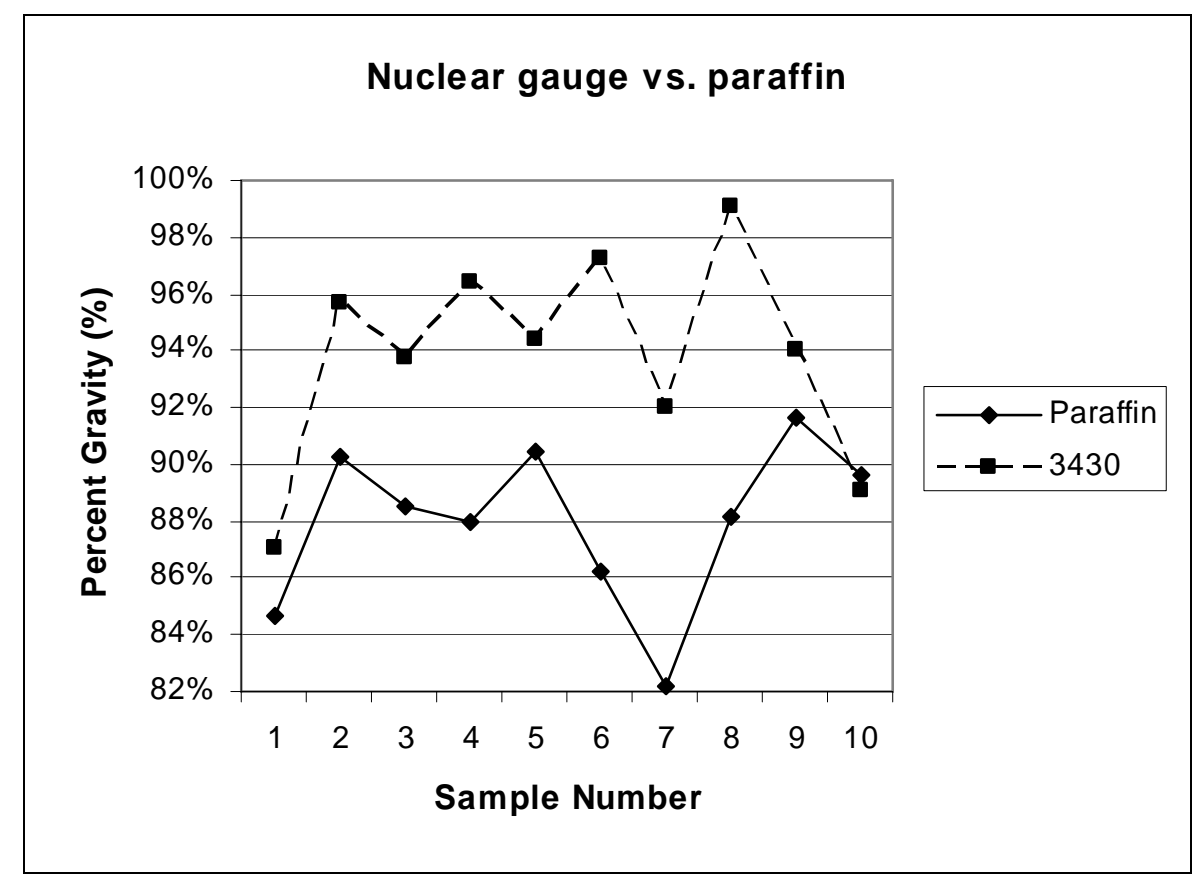

Figure 4.25: Nuclear Gauge and Paraffin Data for WV-34 Project 


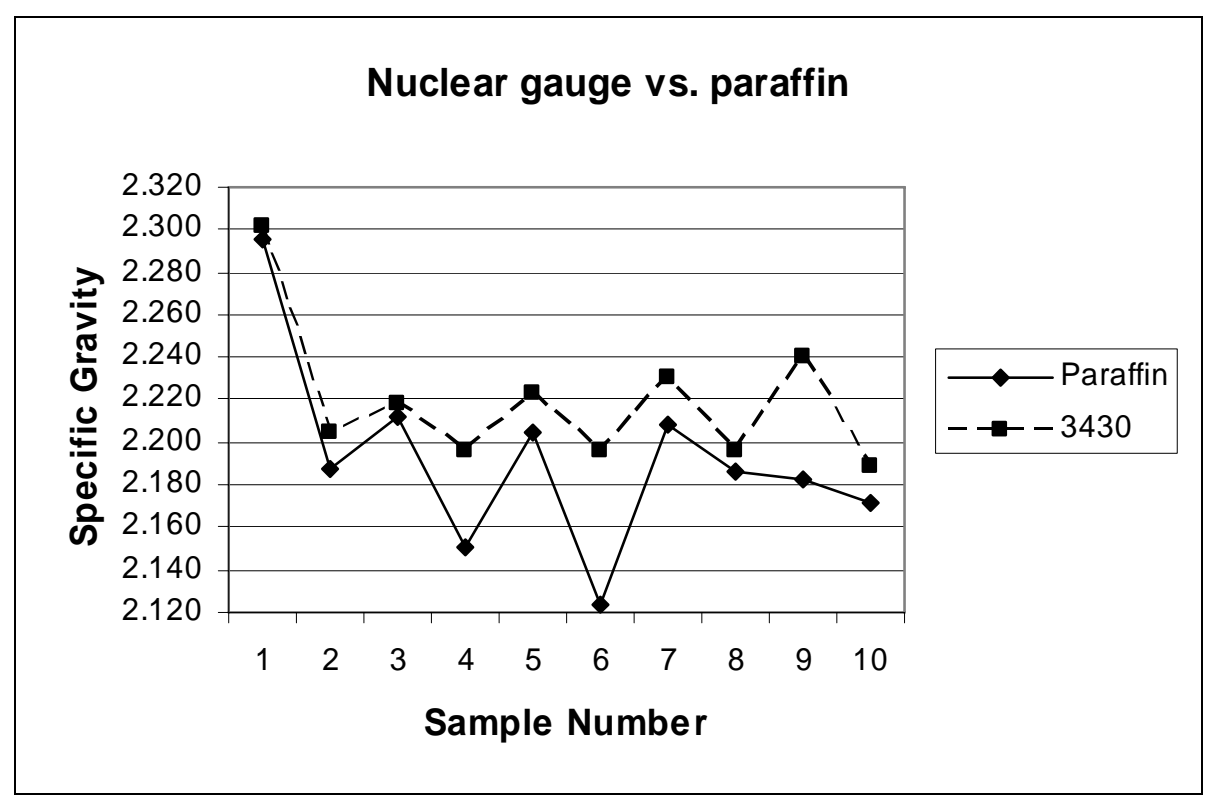

Figure 4.26: Nuclear Gauge and Paraffin Data for WV-114 Project

Table 4.10: t-Test Comparing Paraffin Data to Adjusted Nuclear Density Gauge Data

\begin{tabular}{|l|r|r|r|r|}
\hline \multirow{2}{*}{} & \multicolumn{2}{|c|}{ WV-34 } & \multicolumn{2}{c|}{ WV-114 } \\
\cline { 2 - 5 } & Paraffin & \multicolumn{1}{|c|}{3430} & Paraffin & \multicolumn{1}{c|}{3430} \\
\hline \hline Mean & 2.106 & 2.247 & 2.192 & 2.221 \\
\hline Variance & 0.00485 & 0.00779 & 0.00204 & 0.00399 \\
\hline Observations & 10 & 10 & 10 & 10 \\
\hline Pearson Correlation & 0.27926 & & 0.82555 & \\
\hline Hypothesized Mean Difference & 0 & & 0 & \\
\hline df & 9 & & 9 & \\
\hline $\mathrm{t}$ Stat & -4.652 & & -2.555 & \\
\hline P(T<=t) two-tail & 0.001 & & 0.031 & \\
\hline $\mathrm{t}$ Critical two-tail & 2.262 & & 2.262 & \\
\hline
\end{tabular}

\subsubsection{Comparing SSD Method to the Thin-lift Density Gauge}

The data from the WV-622 and US-60 projects are shown in Figures 4.27 and 4.28, respectively. The t-test, Table 4.11, indicates there is insufficient data to reject the hypothesis of equal means at the 95 percent confidence level for both projects. 


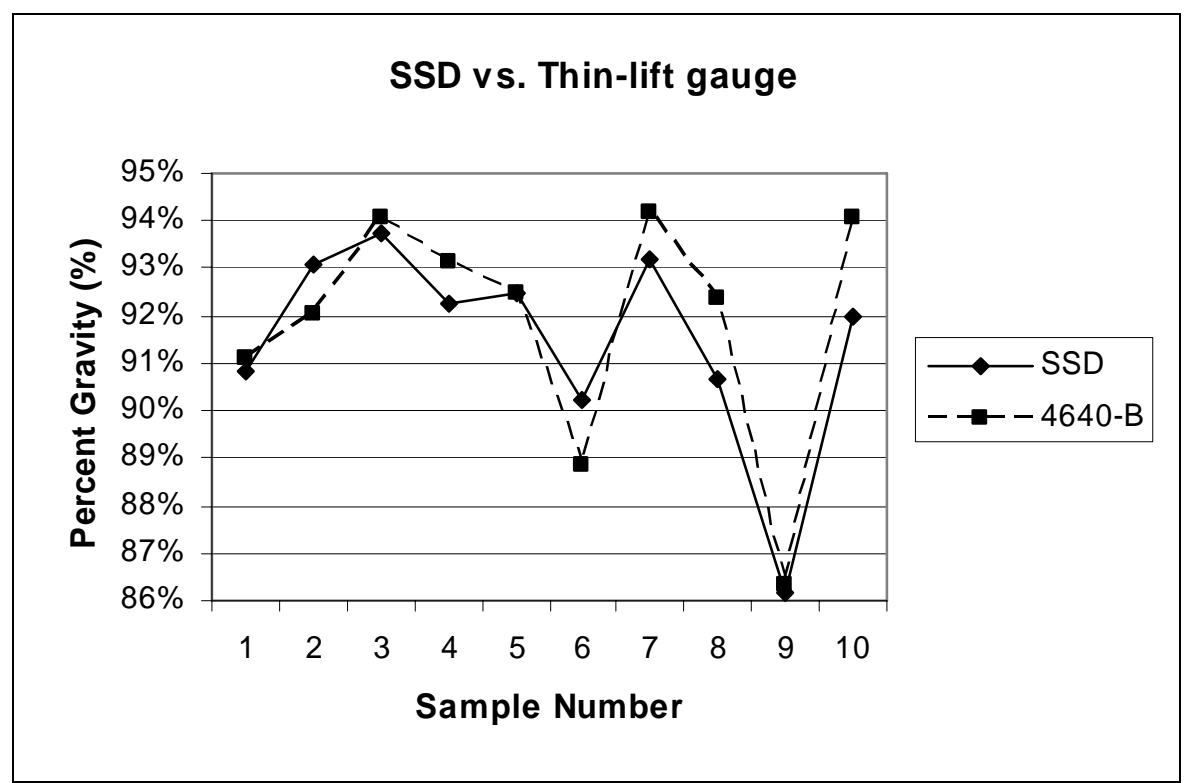

Figure 4.27: SSD and Thin-lift Gauge Data for WV-622 Project

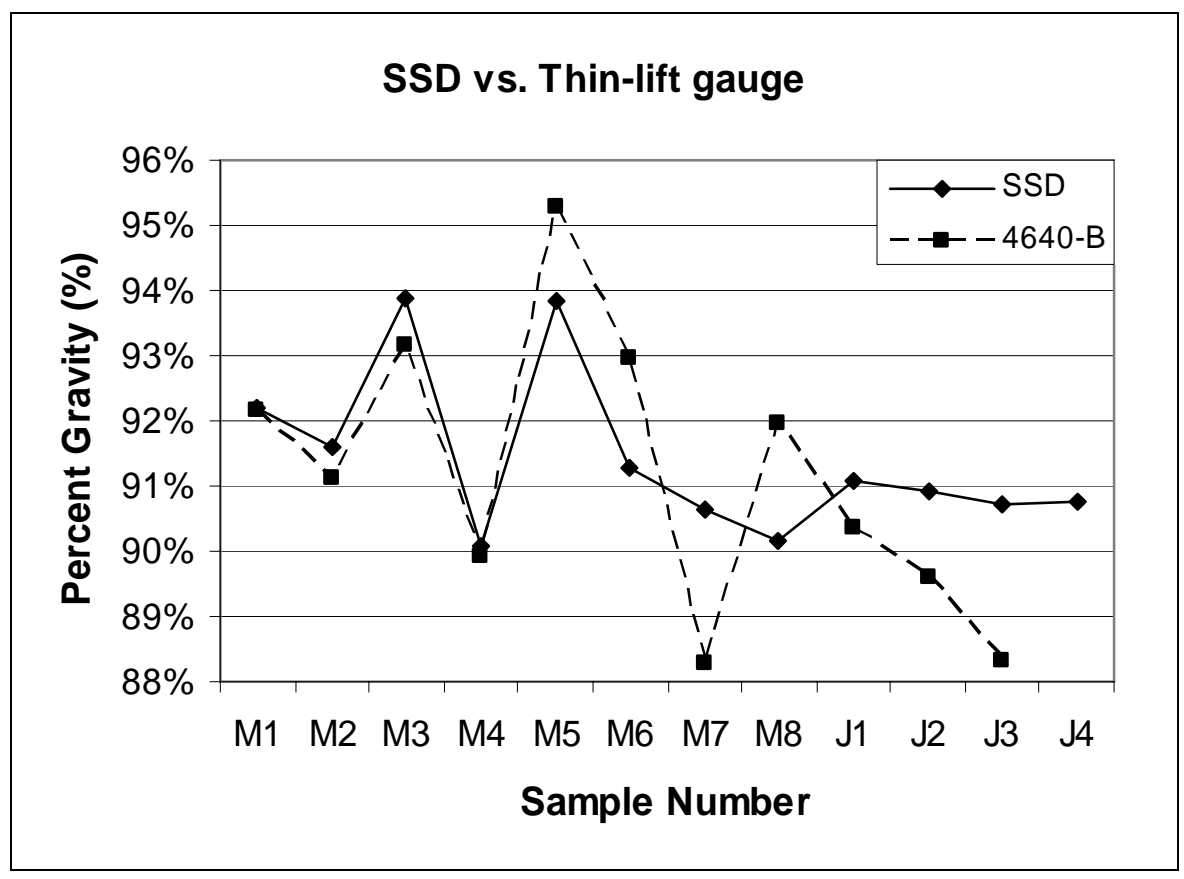

Figure 4.28: SSD and Thin-lift Gauge Data for US-60 Project 
Table 4.11: t-test Comparing SSD and Thin-lift Density Gauge Data

\begin{tabular}{|l|r|r|r|r|}
\hline & \multicolumn{2}{|c|}{ WV-622 } & \multicolumn{2}{c|}{ US-60 } \\
\hline & \multicolumn{1}{|c|}{$S S D$} & $4640-B$ & $S S D$ & $4640-B$ \\
\hline \hline Mean & 2.196 & 2.206 & 2.197 & 2.190 \\
\hline Variance & 0.00277 & 0.00368 & 0.00100 & 0.00270 \\
\hline Observations & 10 & 10 & 11 & 11 \\
\hline Pearson Correlation & 0.90587 & & 0.75256 & \\
\hline Hypothesized Mean Difference & 0 & & 0 & \\
\hline df & 9 & & 10 & \\
\hline $\mathrm{t} \mathrm{Stat}$ & -1.202 & & 0.663 & \\
\hline $\mathrm{P}(\mathrm{T}<=\mathrm{t})$ two-tail & 0.260 & & 0.522 & \\
\hline $\mathrm{t}$ Critical two-tail & 2.262 & & 2.228 & \\
\hline
\end{tabular}

\subsubsection{Comparing the SSD Method to the Nuclear Density Gauge}

Figures 4.29 to 4.33 show the data comparing the SSD method and the uncorrected nuclear density gauge. The t-test, Table 4.12, shows the hypothesis of equal means was rejected for I-64, US-60, and WV-622. In each case, the result with the nuclear density gauge was greater than the laboratory SSD results. There was insufficient data to reject the hypothesis for projects CR-39 and I-79 (Big Otter). Even though the difference in the means was not statistically significant, it was noted that in both cases the results from the nuclear density gauge were greater than the SSD results.

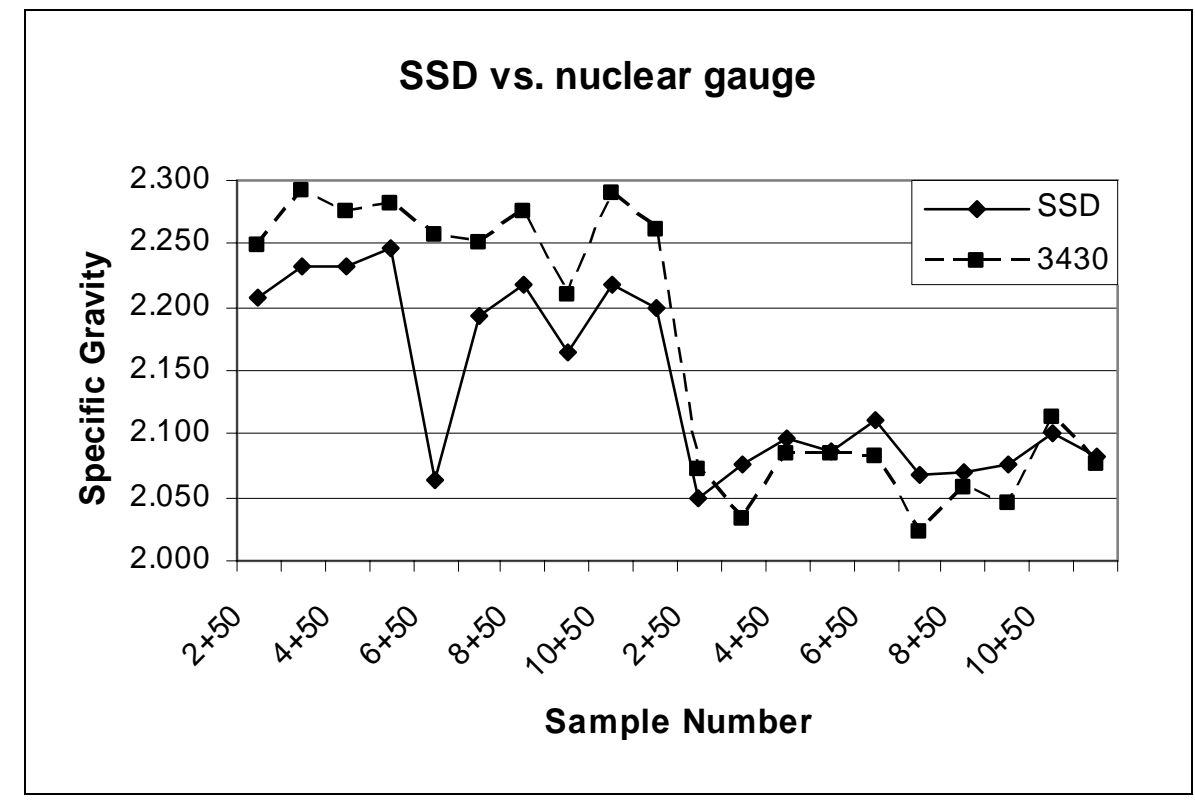

Figure 4.29: SSD and Nuclear Gauge Data for I-64 Project 


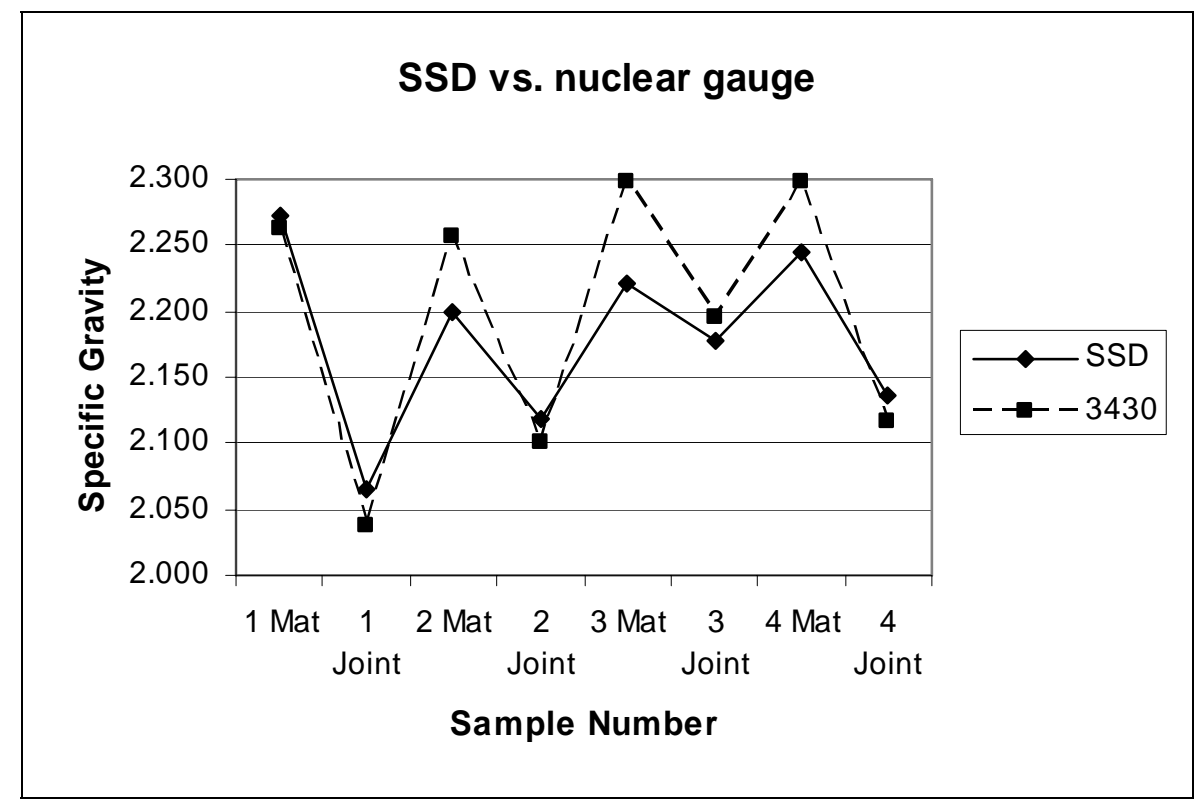

Figure 4.30: SSD and Nuclear Gauge Data for I-79 (Big Otter) Project

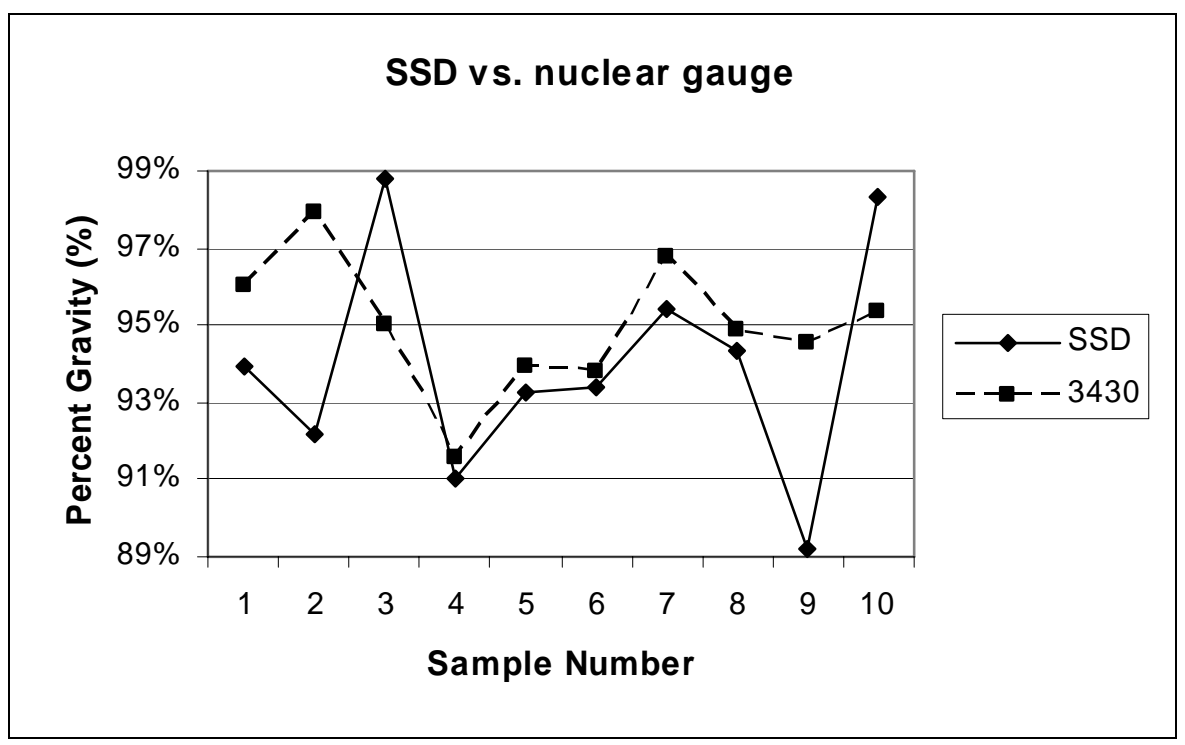

Figure 4.31: SSD and Nuclear Gauge Data for CR-39 Project 


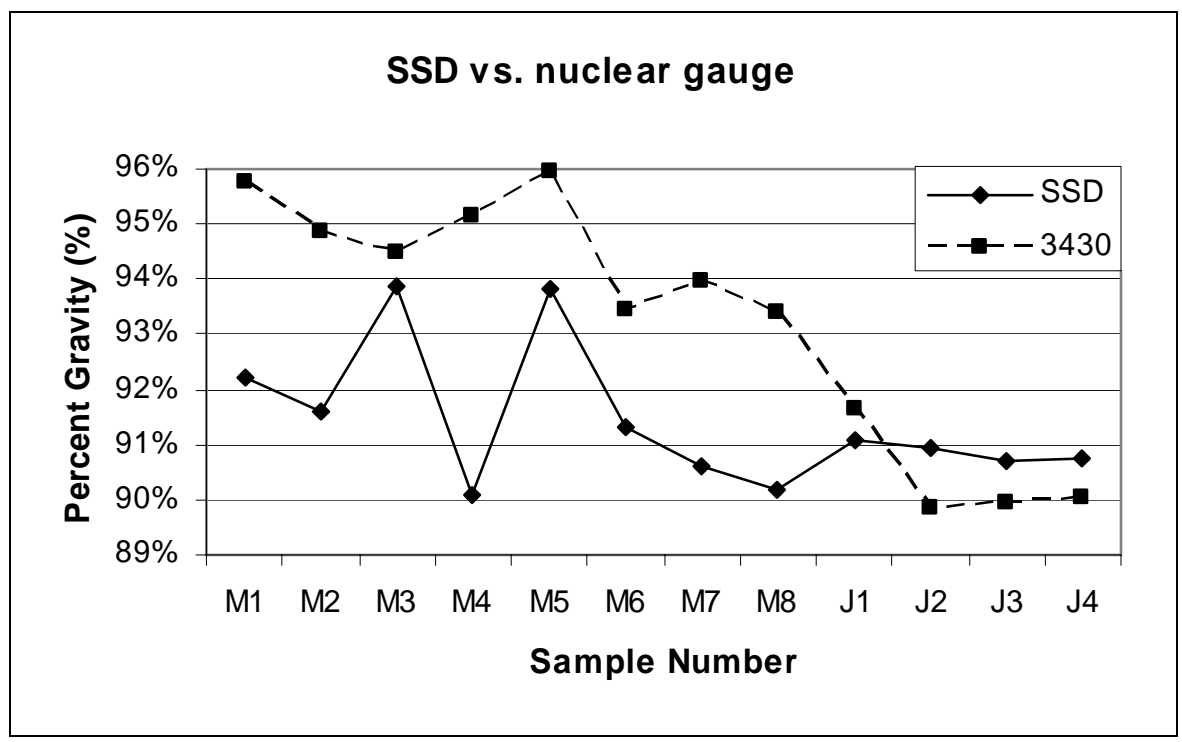

Figure 4.32: SSD and Nuclear Gauge Data for US-60 Project

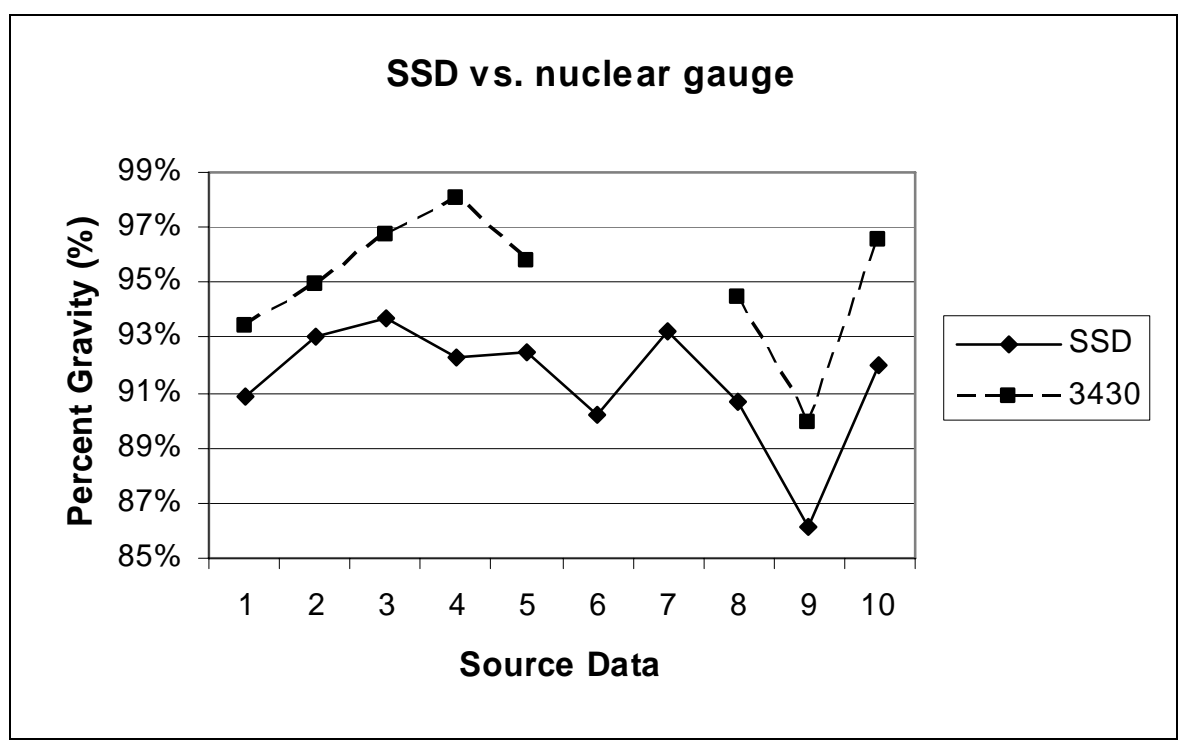

Figure 4.33: SSD and Nuclear Gauge Data for WV-622 Project

Figures 4.34, 4.35, and 4.36 for projects WV-34, WV-16, and WV-114, respectively show the data for the corrected nuclear density gauge readings and the SSD results. The t-test, Table 4.13, shows the hypothesis of equal means was rejected for projects WV 34 and WV 114. The corrected nuclear density gauge results were greater than the SSD results in both cases. There was insufficient data to reject the hypothesis for project WV 16. The SSD results were greater than the corrected nuclear density gauge results. 
Table 4.12: t-Test Comparing SSD and Nuclear Density Gauge Data

\begin{tabular}{|c|c|c|c|c|c|c|}
\hline & \multicolumn{2}{|c|}{$1-64$} & \multicolumn{2}{|c|}{ I-79 (Big Otter) } & \multicolumn{2}{|c|}{ CR-39 } \\
\hline & SSD & 3430 & SSD & 3430 & SSD & 3430 \\
\hline Mean & 2.139 & 2.166 & 2.180 & 2.196 & 2.208 & 2.232 \\
\hline Variance & 0.00500 & 0.01085 & 0.00479 & 0.00991 & 0.00488 & 0.00168 \\
\hline Observations & 20 & 20 & 8 & 8 & 10 & 10 \\
\hline Pearson Correlation & 0.87420 & & 0.94408 & & 0.26599 & \\
\hline Hypothesized Mean Difference & 0 & & 0 & & 0 & \\
\hline df & 19 & & 7 & & 9 & \\
\hline t Stat & -2.165 & & -1.100 & & -1.047 & \\
\hline $\mathrm{P}(\mathrm{T}<=\mathrm{t})$ two-tail & 0.043 & & 0.308 & & 0.322 & \\
\hline t Critical two-tail & 2.093 & & 2.365 & & 2.262 & \\
\hline & US & & WV- & 622 & & \\
\hline & SSD & 3430 & SSD & 3430 & & \\
\hline Mean & 2.195 & 2.238 & 2.195 & 2.280 & & \\
\hline Variance & 0.00093 & 0.00300 & 0.00318 & 0.00359 & & \\
\hline Observations & 12 & 12 & 8 & 8 & & \\
\hline Pearson Correlation & 0.47635 & & 0.87842 & & & \\
\hline Hypothesized Mean Difference & 0 & & 0 & & & \\
\hline $\mathrm{df}$ & 11 & & 7 & & & \\
\hline t Stat & -3.073 & & -8.400 & & & \\
\hline $\mathrm{P}(\mathrm{T}<=\mathrm{t})$ two-tail & 0.011 & & 0.000 & & & \\
\hline t Critical two-tail & 2.201 & & 2.365 & & & \\
\hline
\end{tabular}

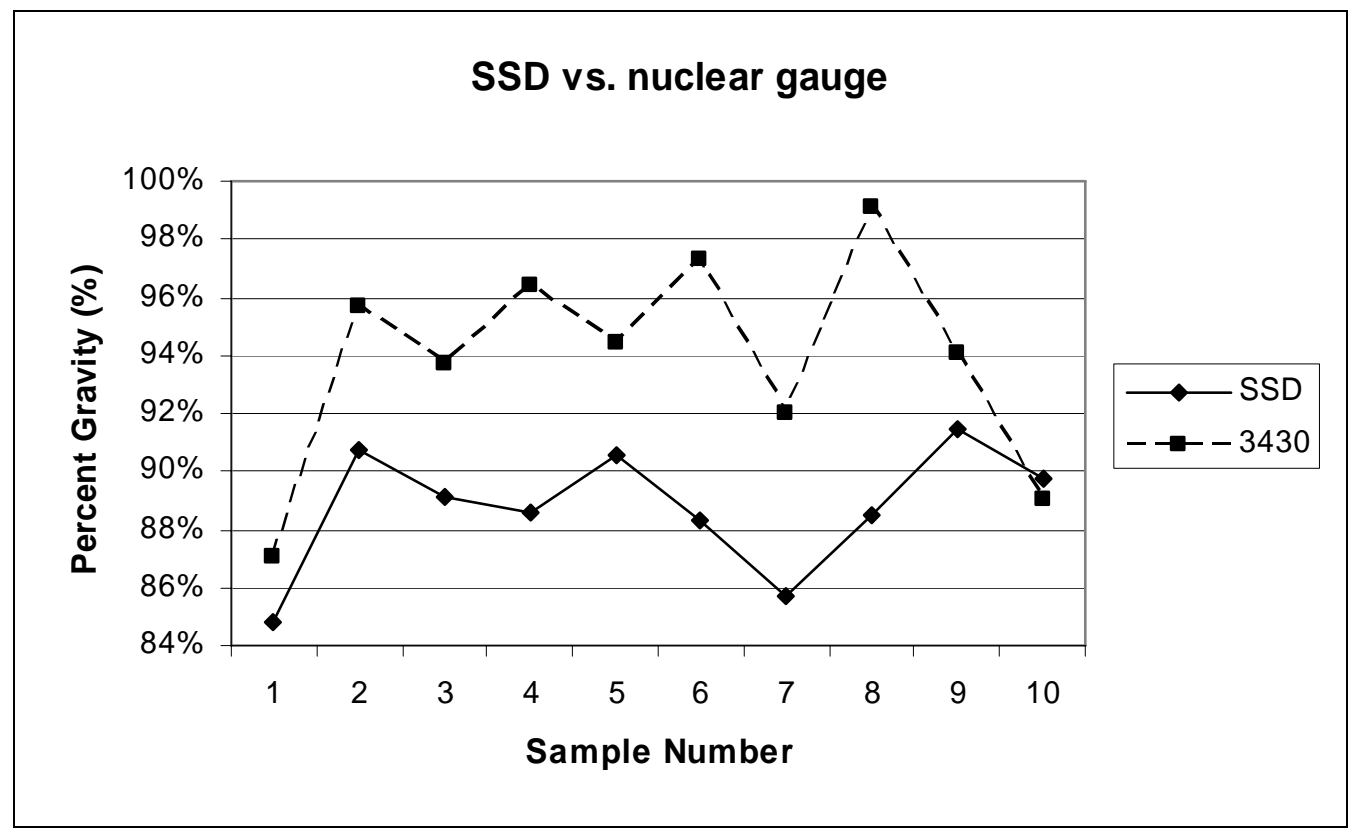

Figure 4.34: SSD and Adjusted Nuclear Gauge Data for the WV-34 Project 


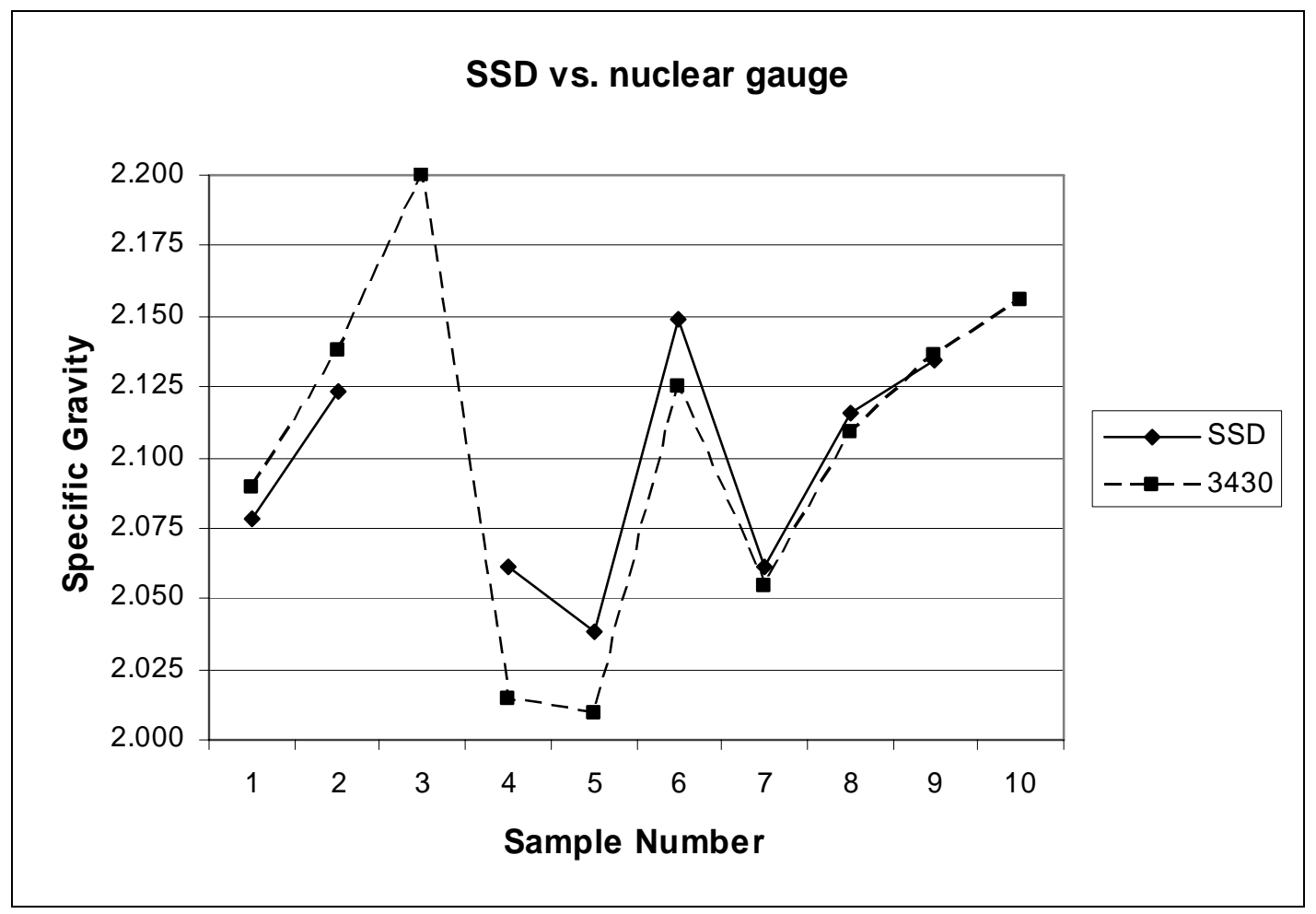

Figure 4.35: SSD and Adjusted Nuclear Gauge Data for the WV-16 Project

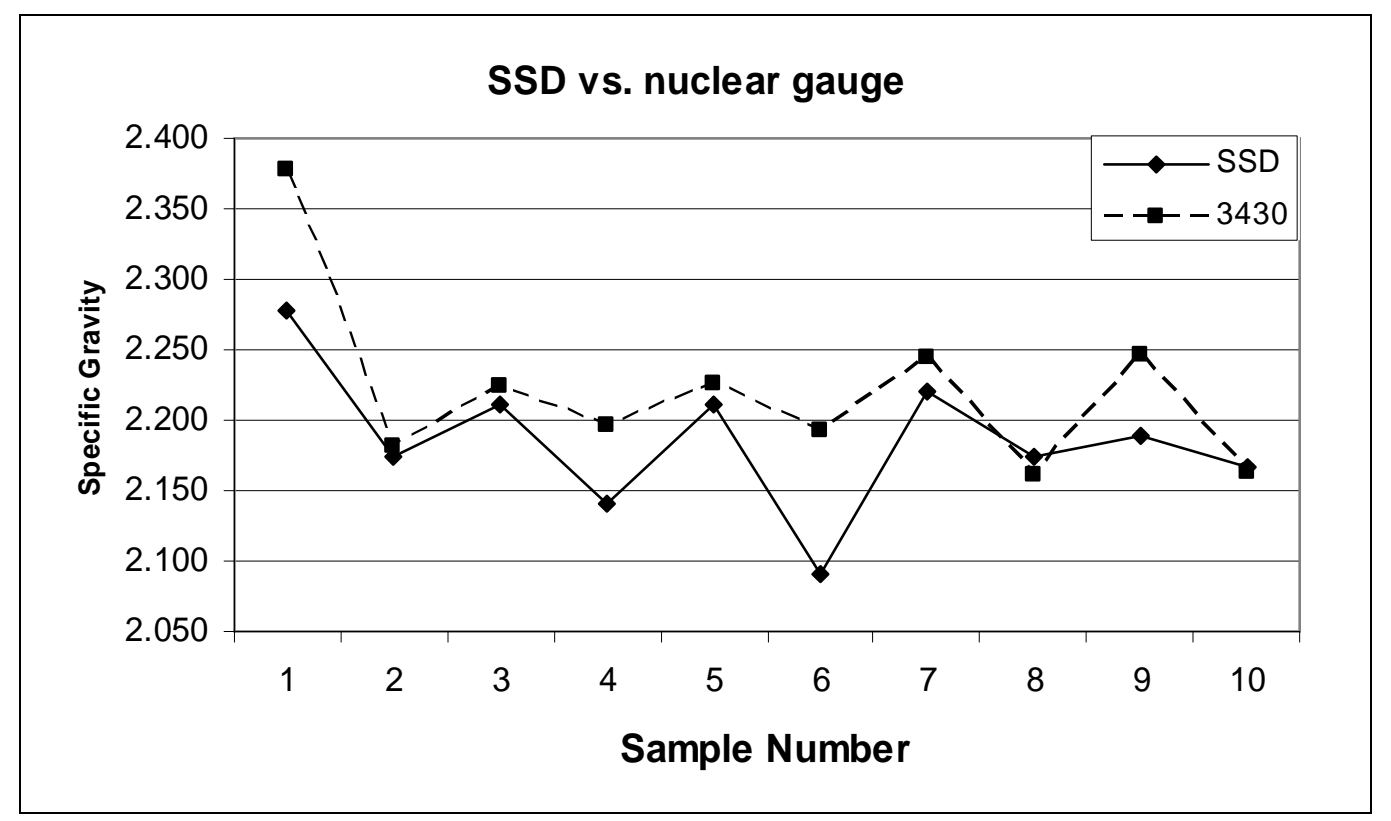

Figure 4.36: SSD and Adjusted Nuclear Gauge Data for the WV-114 Project 
Table 4.13: t-test Comparing SSD Data to Adjusted Nuclear Density Gauge Data

\begin{tabular}{|l|r|r|r|r|r|r|}
\hline & \multicolumn{2}{|c|}{ WV-34 } & \multicolumn{2}{c|}{ WV-16 } & \multicolumn{2}{c|}{ WV-114 } \\
\hline & $S S D$ & 3430 & $S S D$ & 3430 & SSD & 3430 \\
\hline \hline Mean & 2.125 & 2.247 & 2.095 & 2.085 & 2.186 & 2.221 \\
\hline Variance & 0.00259 & 0.00779 & 0.00164 & 0.00274 & 0.00249 & 0.00399 \\
\hline Observations & 10 & 10 & 8 & 8 & 10 & 10 \\
\hline Pearson Correlation & 0.41301 & & 0.92916 & & 0.76046 & \\
\hline Hypothesized Mean Difference & 0 & & 0 & & 0 & \\
\hline df & 9 & & 7 & & 9 & \\
\hline t Stat & -4.742 & & 1.430 & & -2.754 & \\
\hline P(T<=t) two-tail & 0.001 & & 0.196 & & 0.022 & \\
\hline $\mathrm{t}$ Critical two-tail & 2.262 & & 2.365 & & 2.262 & \\
\hline
\end{tabular}

\subsubsection{Comparing the Thin lift Gauge to the Paraffin Method}

The WV-622 and US-60 project data are shown in Figures 4.37 and 4.38, respectively. The t-test, Table 4.14, indicates there is insufficient data to reject the hypothesis of equal means for both projects.

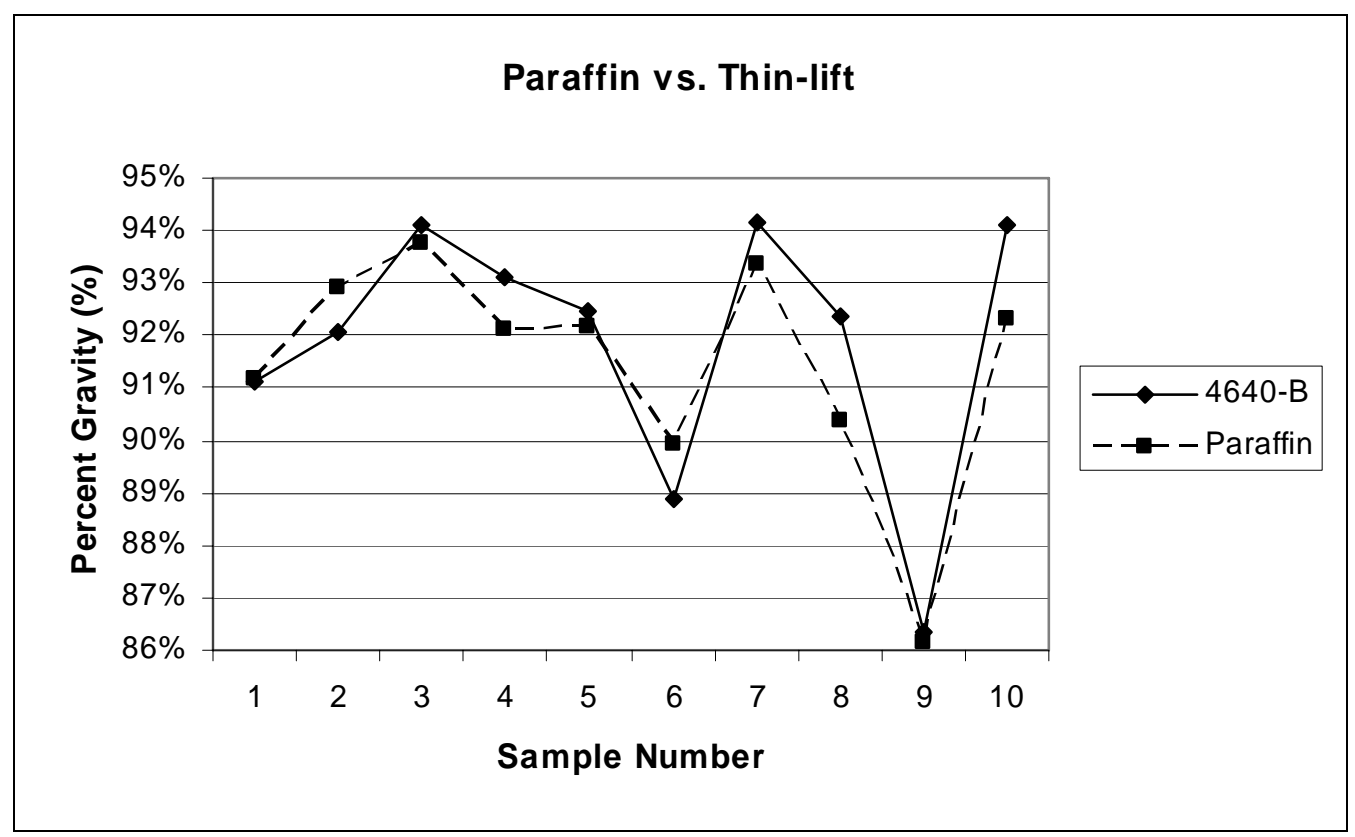

Figure 4.37: Thin-lift Gauge and Paraffin Data for the WV-622 Project 


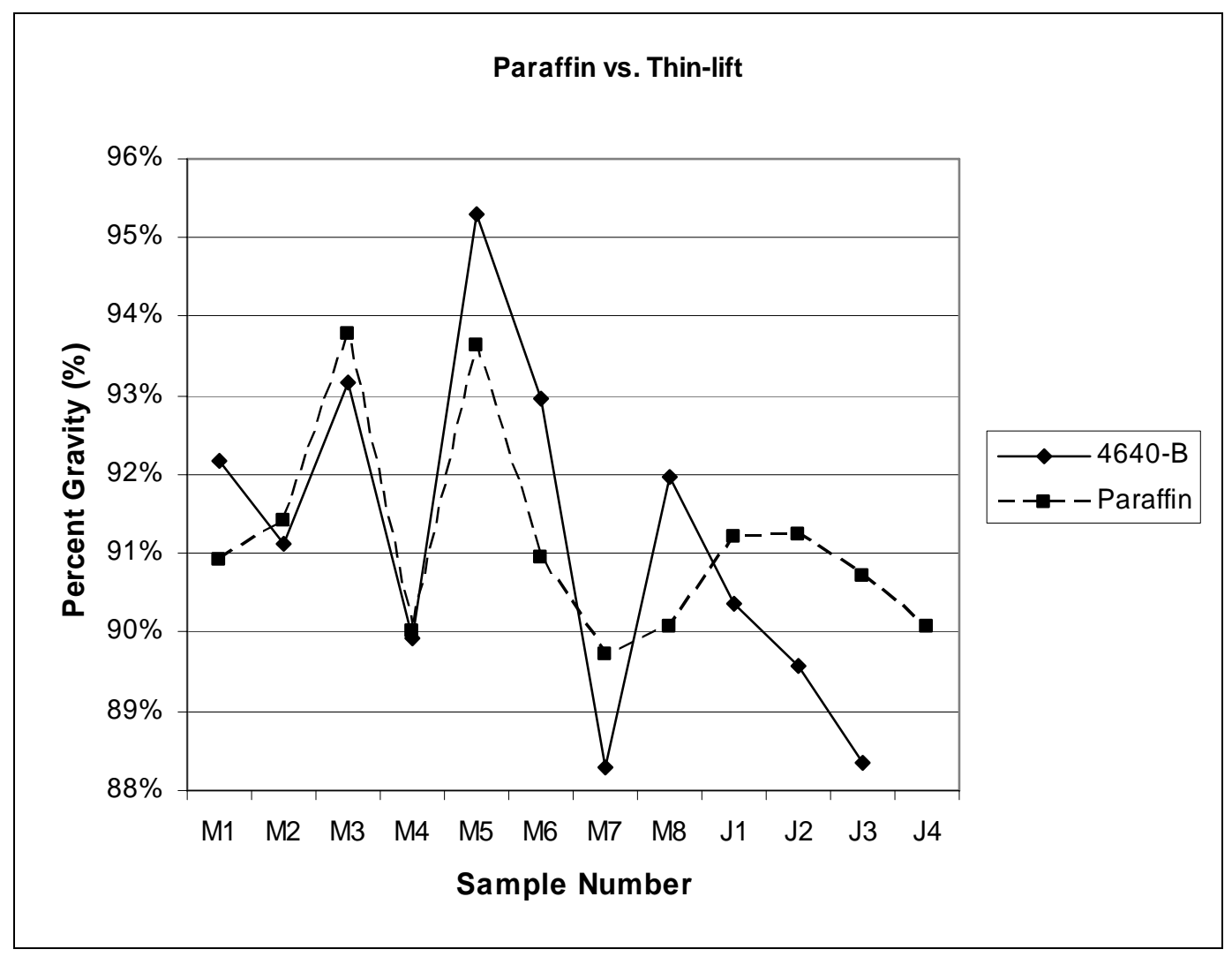

Figure 4.38: Thin-lift Gauge and Paraffin Data for the US-60 Project

Table 4.14: t-Test Comparing Paraffin and Thin-lift Gauge Data

\begin{tabular}{|l|r|r|r|r|}
\hline & \multicolumn{2}{|c|}{ WV-622 } & \multicolumn{2}{c|}{ US-60 } \\
\hline & Paraffin & $4640-B$ & Paraffin & $4640-B$ \\
\hline \hline Mean & 2.195 & 2.206 & 2.191 & 2.190 \\
\hline Variance & 0.00285 & 0.00368 & 0.00103 & 0.00270 \\
\hline Observations & 10 & 10 & 11 & 11 \\
\hline Pearson Correlation & 0.91942 & & 0.71312 & \\
\hline Hypothesized Mean Difference & 0 & & 0 & \\
\hline df & 9 & & 10 & \\
\hline t Stat & -1.425 & & 0.098 & \\
\hline P(T<=t) two-tail & 0.188 & & 0.923 & \\
\hline t Critical two-tail & 2.262 & & 2.228 & \\
\hline
\end{tabular}




\section{CHAPTER 5: CONCLUSIONS AND RECOMMENDATIONS}

\subsection{CONCLUSIONS}

The average density from samples collected from areas of longitudinal joints with a good and poor appearance did not show a statistically significant difference. This is a counter intuitive observation. There were not sufficient data to develop a hypothesis to explain this result.

The average density of samples collected from joints was statistically significantly less than the mat density for two of five projects. For the other three projects, there were insufficient data to reject the hypothesis of equal means.

The average densities of the rollerpass and lot quality control projects were not statistically significantly different. Both sets of data showed an average percent of maximum theoretical specific gravity of between 90 and 91 percent. Since these values are less than the specification minimum of 92 percent these projects may not be representative of the expectations for asphalt pavement construction.

Table 5.1 summarizes the results of the comparison of the different methods for determining density for each project. The paired two sample t-test was used to determine the projects where the hypothesis of equal means was rejected $(\mathbf{R})$ and which projects had insufficient evidence to reject the hypothesis $(\mathbf{N})$.

Table 5.15: Results of Comparison Between Testing Methods

\begin{tabular}{|c|c|c|c|c|c|c|}
\hline & $\begin{array}{c}\text { SSD } \\
\text { to } \\
\text { Paraffin }\end{array}$ & $\begin{array}{c}4640-B \\
\text { to } \\
3430 \\
\end{array}$ & $\begin{array}{c}\text { Paraffin } \\
\text { to } \\
3430 \\
\end{array}$ & $\begin{array}{c}\text { SSD } \\
\text { to } \\
3430 \\
\end{array}$ & $\begin{array}{c}\text { Paraffin } \\
\text { to } \\
4640-B\end{array}$ & $\begin{array}{c}\text { SSD } \\
\text { to } \\
4640-B \\
\end{array}$ \\
\hline 164 & & & & $\mathbf{R}$ & & \\
\hline I 77 & $\mathbf{R}$ & & & & & \\
\hline 179 & $\mathbf{R}$ & & & & & \\
\hline 179 & & & & $\mathbf{N}$ & & \\
\hline US 60 & $\mathbf{N}$ & $\mathbf{R}$ & $\mathbf{R}$ & $\mathbf{R}$ & $\mathbf{N}$ & $\mathbf{N}$ \\
\hline WV 622 & $\mathbf{N}$ & $\mathbf{R}$ & $\mathbf{R}$ & $\mathbf{R}$ & $\mathbf{N}$ & $\mathbf{N}$ \\
\hline WV $34(1)^{a}$ & $\mathbf{N}$ & & $\mathbf{R}$ & $\mathbf{R}$ & & \\
\hline CR 39 & $\mathbf{R}$ & & $\mathbf{N}$ & $\mathbf{N}$ & & \\
\hline WV $16^{\mathrm{a}}$ & & & & $\mathbf{N}$ & & \\
\hline$W V 114^{\mathrm{a}}$ & $\mathbf{N}$ & & $\mathbf{R}$ & $\mathbf{R}$ & & \\
\hline
\end{tabular}


The comparisons of the two laboratory methods showed inconsistent results. The hypothesis of equal means was rejected for three of the seven projects where both tests were performed. The reason for the discrepancy was not evaluated during this research. However, it is speculated that the differences could be attributed to absorption of water into the cut faces of the cores.

Densities measured with the standard nuclear gauge, model 3430, did not compare favorably with the densities measured either in the laboratory or with the thinlift gauge.

- The hypothesis of equal means was rejected for four of the five projects when compared to the density measured with the paraffin method.

- The hypothesis of equal means was rejected for five of the eight projects when compared to the density measured with the SSD method.

- Both projects comparing the standard and thin-lift (model 4640-B) gauges found statistically significant differences in the measured densities.

In all but one case, the average density for the project determined from the standard nuclear gauge was higher than the average density determined by the other methods. The correction process for the standard gauge did not reliably improve the comparison. For two of the projects with corrected readings, the hypothesis of equal means was rejected for the comparisons to both the SSD and paraffin-measured densities. Only one project showed a favorable comparison when the corrected standard nuclear gauge density was compared to the SSD results.

On the other hand, the thin-lift gauge was in agreement with the results of both the SSD and paraffin lab methods for the two projects evaluated.

\subsection{RECOMMENDATIONS}

Although the data set examined in this research was limited it showed that the standard nuclear gauge does not match measurements from either the lab or from a thinlift gauge. Correcting the density from the standard gauge for the density of the underlying material did not produce acceptable results. The continued use of the standard nuclear gauge should be researched carefully to either validate its continued use or to find 
a suitable alternative. The projects evaluated during this research indicated that the thinlift gauge shows promise for making reliable measurements. However, recent technology for evaluating density based on the dielectric principle shows promise as demonstrated by research in Ohio (Sargand, 2005).

Which ever field density measurement is implemented, the reference standard for determining mat density is coring and lab measurements. The current practice is to use the SSD method. However, the limited data set available at this time indicates that there may be moisture absorption issues with the SSD method. Further research is recommended to examine this problem.

All of the bordering states have specifications concerning longitudinal joint density. West Virginia should develop similar specifications and do a trial implementation to determine if longitudinal joint densities are improved. The evaluation of the joint performance would start with an initial assessment of the density of the joints versus the mat. However, a long-term evaluation should be conducted to factually establish the effect of improved joint density on the performance of the pavements.

Compaction of the pavement to the required density may be done more efficiently by incorporating new technology into the compaction process. The oscillatory roller shows promise in being able to compact the pavement more efficiently. Joint placement techniques may help obtain higher densities at the longitudinal joint. However, research on joint construction methods has not achieved a consensus on a single best practice for consistently constructing quality joints. It may be beneficial for the WVDOH to work with the construction industry to research and document a "best practices" procedure for the construction of longitudinal joints.

The projects used to compare the rollerpass and lot compaction specifications did not indicate a difference in the average density of the projects. This supports the continued use of the rollerpass specification. The review of this specification indicates the potential need for reestablishing the roller requirements if conditions change during a project. However, there is not a clear definition of what constitutes a change in conditions. Research should be performed to better define the terminology in the specification. 


\section{REFERENCES}

Akpinar M.V., Hossain M. Longitudinal Joint Construction for Hot Mix Asphalt Pavements. Kansas State University. Manhattan, KA. March 2004

Briaud J.L., Seo J. Intelligent Compaction: Overview and Research Needs. Texas A\&M University. College Station TX. December 2003

Brown, E.R. "Density of Asphalt Concrete - How Much is Needed." Transportation Research Board Record No. 1282, Transportation Research Board National Research Council, 1990. Washington DC.

Caterpillar. Caterpillar Compaction Manual. Caterpillar Inc. East Peoria IL. (June 2006) <http://www.specialtysalesllc.com/nutra-bond_compaction.htm>

Delaware Department of Transportation. DAPA/DelDot Density Gauge Evaluation. Delaware Department of Transportation. Dover, DE. November 1999

Fleckenstein J.L., Allen D.L., Schultz D.B. Compaction at the Longitudinal Construction Joint in Asphalt Pavements. Kentucky Transportation Center. Lexington, KY. May 2002

Foster, C.R., Hudson, S.B., Nelson, R.S. Constructing Longitudinal Joints in Hot Mix Asphalt Pavements. HRB Research Record 51, Highway Research Board, 1964. Washington D.C.

Kandhal P.S., Mallick R.B. Longitudinal Joint Construction Techniques for Asphalt Pavement. National Center for Asphalt Technology. Auburn, AL. August 1997

Kandhal P.S., Ramirez T.L., Ingram P.M. Evaluation of Eight Longitudinal Joint Construction Techniques for Asphalt Pavements in Pennsylvania. Pennsylvania Department of Transportation. Harrisburg PA. July 2001

KDOT KDOT Standard Specifications. Kentucky Department of Transportation. Frankfort KY. 2004

MDSHA Construction Manual. Maryland State Highway Administration. Baltimore MD. 2002

North Carolina Department of Transportation. Roadway Paving Operations. HMA/QMS Online Manual. 2004. Raleigh NC. (June 2006). $<$ http://www.ncdot.org/doh/Operations/dp_chief_eng/constructionunit/paveconst/ Asphalt_Mgmt/qms_manual/2004/default.htm>

ODOT Construction and Materials Specifications. Ohio Department of Transportation. Columbus OH. 2005 
PennDOT PennDOT Specifications. Pennsylvania Department of Transportation. Harrisburg PA. 2003

Roberts F.L., Kandhal P.S., Brown E.R., Lee D.Y., Kennedy T.W. Hot Mix Asphalt Materials, Mixture Design, and Construction. National Center for Asphalt Technology. $2^{\text {nd }}$ ed. 1996. Lanham MD.

Romero P. Field Evaluation of the PQI Model 300. University of Utah. Salt Lake City, UT. June 2001

Sargand, S. M., Kim, S, and Farrington, S.P., A Working Review of Available NonNuclear Equipment for Determining In Place Density of Asphalt, Ohio University. FHWA Report No. FHWA/OH-2005/18. December 2005. Athens OH.

Toepel A. Evaluation of Techniques for Asphaltic Pavement Longitudinal Joint Construction. Wisconsin Department of Transportation. Madison WI. November 2003

Troxler Labs. Thin Overlay Density Measurement. Troxler Electronic Labortories Inc. Research Triangle Park NC. August 1998

VDOT Road and Bridge Specification Manual. Virginia Department of Transportation. Richmond VA. 2002

WVDOH Standard Specifications for Roads and Bridges. West Virginia Division of Highways Charleston WV. 2003 


\section{APPENDIX}

Table A.1: I-64

\begin{tabular}{|c|c|c|}
\hline \multirow{2}{*}{ Station } & \multicolumn{2}{|c|}{ Specific Gravity } \\
\cline { 2 - 3 } & 3430 & SSD \\
\hline \hline $2+50$ & 2.249 & 2.207 \\
\hline $3+50$ & 2.292 & 2.233 \\
\hline $4+50$ & 2.275 & 2.232 \\
\hline $5+50$ & 2.281 & 2.247 \\
\hline $6+50$ & 2.257 & 2.063 \\
\hline $7+50$ & 2.251 & 2.193 \\
\hline $8+50$ & 2.276 & 2.218 \\
\hline $9+50$ & 2.210 & 2.164 \\
\hline $10+50$ & 2.290 & 2.217 \\
\hline $11+50$ & 2.261 & 2.199 \\
\hline $2+50$ & 2.071 & 2.050 \\
\hline $3+50$ & 2.033 & 2.075 \\
\hline $4+50$ & 2.085 & 2.097 \\
\hline $5+50$ & 2.085 & 2.086 \\
\hline $6+50$ & 2.083 & 2.110 \\
\hline $7+50$ & 2.022 & 2.068 \\
\hline $8+50$ & 2.057 & 2.069 \\
\hline $9+50$ & 2.046 & 2.077 \\
\hline $10+50$ & 2.114 & 2.100 \\
\hline $11+50$ & 2.077 & 2.082 \\
\hline
\end{tabular}

Table A.2: I-77

\begin{tabular}{|l|c|c|c|}
\hline \multicolumn{1}{|c|}{ Sample Source I77 } & Sample & \multicolumn{2}{c|}{ Specific Gravity } \\
\cline { 3 - 4 } & Number & SSD & Paraffin \\
\hline \hline NB, MP127.21 CL & 1A & 2.103 & 2.044 \\
\hline NB, MP127.21 CL & 1B & 2.127 & 2.089 \\
\hline NB, MP127.21, FL 6'L CL & 2 & 2.211 & 2.192 \\
\hline NB, MP127.52 CL & 3A & 2.238 & 2.167 \\
\hline NB, MP127.52 CL & 3B & 2.136 & 2.114 \\
\hline NB, MP127.52, FL 6'L CL & $4 A$ & 2.177 & 2.178 \\
\hline NB, MP127.52, FL 6'L CL & 4B & 2.235 & 2.204 \\
\hline NB, MP127.52, FL 6'L CL & $4 C$ & 2.306 & 2.287 \\
\hline NB, MP127.52, FL 6'L CL & $4 \mathrm{D}$ & 2.210 & 2.148 \\
\hline NB, MP128.14 CL & 5 & 2.094 & 2.030 \\
\hline NB, MP128.14, 6'L CL & $6 A$ & 2.189 & 2.137 \\
\hline NB, MP128.14, 6'L CL & $6 B$ & 2.261 & 2.247 \\
\hline NB, MP128.5 CL & 7 & 2.059 & 2.003 \\
\hline NB, MP128.5, FL 6'L CL & 8 & 2.144 & 2.117 \\
\hline SB, MP128.58, CL & 9 & 2.063 & 2.005 \\
\hline SB, MP128.58, FL 6'L CL & $10 A$ & 2.150 & 2.170 \\
\hline SB, MP128.58, FL 6'L CL & $10 B$ & 2.204 & 2.175 \\
\hline SB, MP128.58, FL 6'L CL & $10 C$ & 2.273 & 2.274 \\
\hline SB, MP128.23 CL & 11 & 2.107 & 2.071 \\
\hline SB, MP128.23, FL 6'L CL & 12 & 2.148 & 2.116 \\
\hline SB, MP127.85, CL & $13 A$ & 2.158 & 2.113 \\
\hline SB, MP127.85, CL & $13 B$ & 2.082 & 2.031 \\
\hline SB, MP127.85, FL 6'L CL & $14 A$ & 2.134 & 2.135 \\
\hline SB, MP127.85, FL 6'L CL & $14 B$ & 2.161 & 2.135 \\
\hline SB, MP127.85, FL 6'L CL & $14 C$ & 2.261 & 2.257 \\
\hline
\end{tabular}


Table A.3: I-79 (Elkview)

\begin{tabular}{|l|c|c|c|}
\hline \multicolumn{1}{|c|}{ Sample Source I79 } & Sample & \multicolumn{2}{c|}{ Specific Gravity } \\
\cline { 3 - 4 } & Number & SSD & Paraffin \\
\hline \hline NB, MP 14.34, FL 4'L CL & 1 & 2.265 & 2.253 \\
\hline NB, MP 14.34, CL & $2 A$ & 2.163 & 2.138 \\
\hline NB, MP 14.355, FL 6'L CL & $3 A$ & 2.172 & 2.151 \\
\hline NB, MP 14.355, CL & $4 A$ & 2.112 & 2.068 \\
\hline NB, MP 16.11, FL 6'L CL & 5 & 2.219 & 2.205 \\
\hline NB, MP 16.11, CL & $6 A$ & 2.136 & 2.099 \\
\hline SB, MP 16.00, CL & 7 & 2.174 & 2.139 \\
\hline SB, MP 16.00, FL 6'L CL & $8 A$ & 2.286 & 2.262 \\
\hline SB, MP 15.44, CL & 9 & 2.139 & 2.088 \\
\hline SB, MP 15.44, FL 6'L CL & $10 A$ & 2.222 & 2.206 \\
\hline SB, MP 14.20, CL & 11 & 2.077 & 2.044 \\
\hline SB, MP 14.20, FL 6'L CL & $12 A$ & 2.197 & 2.197 \\
\hline
\end{tabular}

Table A.4: I-79 (Big Otter)

\begin{tabular}{|c|c|c|}
\hline \multirow{2}{*}{$\begin{array}{c}\text { Sample } \\
\text { Location }\end{array}$} & \multicolumn{2}{|c|}{ Specific Gravity } \\
\cline { 2 - 3 } & 3430 & SSD \\
\hline \hline 1 Mat & 2.262 & 2.272 \\
\hline 1 Joint & 2.038 & 2.066 \\
\hline 2 Mat & 2.256 & 2.199 \\
\hline 2 Joint & 2.101 & 2.118 \\
\hline 3 Mat & 2.299 & 2.222 \\
\hline 3 Joint & 2.195 & 2.178 \\
\hline 4 Mat & 2.298 & 2.245 \\
\hline 4 Joint & 2.116 & 2.137 \\
\hline
\end{tabular}

Table A.5: US-60

\begin{tabular}{|c|c|c|c|c|}
\hline \multirow{2}{*}{$\begin{array}{c}\text { Sample } \\
\text { Number }\end{array}$} & \multicolumn{4}{|c|}{ Specific Gravity } \\
\cline { 2 - 5 } & SSD & Paraffin & 3430 & $4640-\mathrm{B}$ \\
\hline \hline M1 & 2.214 & 2.183 & 2.299 & 2.213 \\
\hline M2 & 2.199 & 2.195 & 2.278 & 2.188 \\
\hline M3 & 2.254 & 2.252 & 2.269 & 2.237 \\
\hline M4 & 2.163 & 2.161 & 2.285 & 2.159 \\
\hline M5 & 2.253 & 2.248 & 2.304 & 2.288 \\
\hline M6 & 2.192 & 2.184 & 2.244 & 2.232 \\
\hline M7 & 2.176 & 2.154 & 2.256 & 2.120 \\
\hline M8 & 2.165 & 2.163 & 2.243 & 2.208 \\
\hline J1 & 2.187 & 2.190 & 2.201 & 2.170 \\
\hline J2 & 2.183 & 2.191 & 2.157 & 2.151 \\
\hline J3 & 2.178 & 2.178 & 2.160 & 2.121 \\
\hline J4 & 2.179 & 2.163 & 2.162 & \\
\hline
\end{tabular}


Table A.6: WV-622

\begin{tabular}{|c|c|c|c|c|}
\hline \multirow{2}{*}{$\begin{array}{c}\text { Sample } \\
\text { Number }\end{array}$} & \multicolumn{4}{|c|}{ Specific Gravity } \\
\cline { 2 - 5 } & SSD & Paraffin & 3430 & $4640-\mathrm{B}$ \\
\hline \hline 1 & 2.181 & 2.189 & 2.243 & 2.188 \\
\hline 2 & 2.235 & 2.231 & 2.280 & 2.210 \\
\hline 3 & 2.250 & 2.251 & 2.322 & 2.259 \\
\hline 4 & 2.215 & 2.212 & 2.354 & 2.236 \\
\hline 5 & 2.220 & 2.213 & 2.299 & 2.220 \\
\hline 6 & 2.166 & 2.159 & & 2.134 \\
\hline 7 & 2.238 & 2.241 & & 2.261 \\
\hline 8 & 2.177 & 2.170 & 2.268 & 2.218 \\
\hline 9 & 2.069 & 2.068 & 2.159 & 2.073 \\
\hline 10 & 2.209 & 2.216 & 2.317 & 2.259 \\
\hline
\end{tabular}

Table A.7: US-250

\begin{tabular}{|c|c|c|c|c|}
\hline \multirow{2}{*}{$\begin{array}{c}\text { Surface } \\
\text { Density }\end{array}$} & \multicolumn{2}{|c|}{ Scratch } & \multicolumn{2}{c|}{ Corrected } \\
\cline { 2 - 5 } & Density & $\%$ mix & Density & $\%$ mix \\
\hline \hline 142.5 & 141.5 & $91.7 \%$ & 143.0 & $92.7 \%$ \\
\hline 145.0 & 141.5 & $91.7 \%$ & 148.5 & $96.2 \%$ \\
\hline 143.0 & 141.5 & $91.7 \%$ & 144.0 & $93.3 \%$ \\
\hline 142.0 & 141.5 & $91.7 \%$ & 142.5 & $92.4 \%$ \\
\hline 142.5 & 135.5 & $87.8 \%$ & 148.5 & $96.2 \%$ \\
\hline 142.5 & 141.0 & $91.4 \%$ & 144.0 & $93.3 \%$ \\
\hline 143.0 & 142.5 & $92.4 \%$ & 143.5 & $93.0 \%$ \\
\hline 141.0 & 142.5 & $92.4 \%$ & 139.5 & $90.4 \%$ \\
\hline 141.0 & 142.5 & $92.4 \%$ & 139.5 & $90.4 \%$ \\
\hline 143.5 & 141.5 & $91.7 \%$ & 145.0 & $94.0 \%$ \\
\hline 141.0 & 139.0 & $90.1 \%$ & 142.3 & $92.2 \%$ \\
\hline 143.0 & 139.5 & $90.4 \%$ & 146.0 & $94.6 \%$ \\
\hline
\end{tabular}

Table A.8: WV-16

\begin{tabular}{|c|c|c|c|c|c|}
\hline Sample & Day & \multicolumn{4}{|c|}{ Density } \\
\cline { 3 - 6 } Number & Paved & Scratch & 3430 & Adjusted & SSD \\
\hline \hline 1 & 30 -Sep & 135.0 & 132.5 & 130.4 & 129.7 \\
\hline 2 & 30 -Sep & 131.0 & 133.0 & 133.4 & 132.5 \\
\hline 3 & $1-$ Oct & 132.8 & 135.7 & 137.3 & \\
\hline 4 & $1-$ Oct & 131.8 & 127.9 & 125.7 & 128.6 \\
\hline 5 & $5-$ Oct & 130.4 & 126.8 & 125.4 & 127.2 \\
\hline 6 & $5-$ Oct & 133.0 & 132.7 & 132.6 & 134.1 \\
\hline 7 & $1-$ Oct & 133.1 & 129.6 & 128.2 & 128.6 \\
\hline 8 & $1-$ Oct & 132.4 & 131.9 & 131.6 & 132.0 \\
\hline 9 & $30-$ Sep & 131.2 & 132.6 & 133.3 & 133.2 \\
\hline 10 & $30-$ Sep & 135.6 & 134.9 & 134.5 & \\
\hline
\end{tabular}


Table A.9: CR-39

\begin{tabular}{|c|c|c|c|}
\hline Sample & \multicolumn{3}{|c|}{ Specific Gravity } \\
\cline { 2 - 4 } Number & SSD & Paraffin & 3430 \\
\hline \hline 1 & 2.207 & 2.209 & 2.256 \\
\hline 2 & 2.166 & 2.169 & 2.301 \\
\hline 3 & 2.321 & 2.309 & 2.233 \\
\hline 4 & 2.139 & 2.101 & 2.152 \\
\hline 5 & 2.191 & 2.156 & 2.207 \\
\hline 6 & 2.195 & 2.172 & 2.204 \\
\hline 7 & 2.242 & 2.170 & 2.274 \\
\hline 8 & 2.217 & 2.212 & 2.230 \\
\hline $9 \mathrm{~A}$ & 2.096 & 2.032 & 2.222 \\
\hline $9 \mathrm{~B}$ & 2.288 & 2.322 & \\
\hline $9 \mathrm{C}$ & 1.979 & 1.945 & \\
\hline 10A & 2.310 & 2.262 & 2.240 \\
\hline 10B & 2.179 & 2.101 & \\
\hline 10C & 2.157 & 2.077 & \\
\hline 10D & 2.164 & 2.075 & \\
\hline
\end{tabular}

Table A.10: WV-34 (Teays Valley)

\begin{tabular}{|c|c|c|c|c|}
\hline Sample & Day & \multicolumn{3}{|c|}{ Density } \\
\cline { 3 - 5 } Number & Paved & Scratch & Final & Corrected \\
\hline \hline 1 & 14-Jul & 135.6 & 140.8 & 145.3 \\
\hline 2 & $14-J u l$ & 137.2 & 146.1 & 153.9 \\
\hline 3 & $14-J u l$ & 137.3 & 133.6 & 130.1 \\
\hline 4 & $14-J u l$ & 140.1 & 141.4 & 142.6 \\
\hline 5 & $14-J u l$ & 133.0 & 134.7 & 136.3 \\
\hline 6 & $14-J u l$ & 140.8 & 137.8 & 135.3 \\
\hline 7 & $14-J u l$ & 135.6 & 139.0 & 142.0 \\
\hline 8 & $14-J u l$ & 141.5 & 139.3 & 137.6 \\
\hline 9 & $14-J u l$ & 136.6 & 131.2 & 126.7 \\
\hline 10 & $14-J u l$ & 140.6 & 135.3 & 130.8 \\
\hline
\end{tabular}

Table A.11: CR-41

\begin{tabular}{|c|c|c|c|c|}
\hline Sample & Day & \multicolumn{3}{|c|}{ Density } \\
\cline { 3 - 5 } Number & Paved & Scratch & Final & Corrected \\
\hline \hline 1 & 29-Apr & 135.5 & 130.4 & 126.0 \\
\hline 2 & 29-Apr & 129.6 & 130.3 & 130.9 \\
\hline 3 & 4-May & 132.5 & 136.4 & 139.7 \\
\hline 4 & 4-May & 132.4 & 130.0 & 127.9 \\
\hline 5 & 4-May & 132.9 & 133.6 & 134.2 \\
\hline 6 & 4-May & 134.3 & 130.0 & 126.3 \\
\hline 7 & 4-May & 134.7 & 134.9 & 135.1 \\
\hline 8 & 4-May & 132.0 & 137.2 & 141.7 \\
\hline 9 & 4-May & 133.4 & 135.0 & 136.4 \\
\hline 10 & 29-Apr & 133.6 & 131.8 & 130.3 \\
\hline
\end{tabular}

Table A.12: WV-114

\begin{tabular}{|c|c|c|c|c|c|}
\hline $\begin{array}{c}\text { Sample } \\
\text { Number }\end{array}$ & \multicolumn{5}{|c|}{ Density } \\
\cline { 2 - 6 } & Scratch & Final & Corrected & SSD & Paraffin \\
\hline \hline 1 & 134.5 & 143.6 & 148.4 & 142.1 & 143.2 \\
\hline 2 & 139.9 & 137.6 & 136.1 & 135.7 & 136.5 \\
\hline 3 & 137.1 & 138.4 & 138.8 & 138.0 & 138.0 \\
\hline 4 & 137.0 & 137.0 & 137.0 & 133.6 & 134.2 \\
\hline 5 & 138.2 & 138.7 & 138.9 & 138.0 & 137.6 \\
\hline 6 & 137.3 & 137.0 & 136.8 & 130.5 & 132.5 \\
\hline 7 & 137.8 & 139.2 & 140.1 & 138.5 & 137.8 \\
\hline 8 & 139.4 & 137.0 & 134.9 & 135.7 & 136.4 \\
\hline 9 & 138.9 & 139.8 & 140.2 & 136.6 & 136.2 \\
\hline 10 & 138.5 & 136.6 & 135.0 & 135.2 & 135.5 \\
\hline
\end{tabular}


Table A.13: WV-34 (Confidence)

\begin{tabular}{|c|c|c|c|}
\hline \multirow{2}{*}{$\begin{array}{l}\text { Sample } \\
\text { Number }\end{array}$} & \multicolumn{3}{|c|}{ Specific Gravity } \\
\hline & SSD & Paraffin & 3430 \\
\hline $1 \mathrm{~A}$ & 2.031 & 2.026 & 2.083 \\
\hline $1 \mathrm{~B}$ & 2.232 & 2.226 & \\
\hline $1 \mathrm{C}$ & 2.123 & 2.101 & \\
\hline $2 \mathrm{~A}$ & 2.172 & 2.162 & 2.292 \\
\hline 2B & 2.189 & 2.164 & \\
\hline $2 \mathrm{C}$ & 2.369 & 2.372 & \\
\hline $3 A$ & 2.133 & 2.120 & 2.244 \\
\hline $3 \mathrm{~B}$ & 2.249 & 2.235 & \\
\hline $3 C$ & 2.091 & 2.023 & \\
\hline $4 \mathrm{~A}$ & 2.121 & 2.105 & 2.308 \\
\hline $4 \mathrm{~B}$ & 2.187 & 2.146 & \\
\hline $4 C$ & 2.322 & 2.295 & \\
\hline $5 A$ & 2.168 & 2.165 & 2.260 \\
\hline $5 B$ & 2.233 & 2.215 & \\
\hline $5 C$ & 2.100 & 2.094 & \\
\hline $6 \mathrm{~A}$ & 2.114 & 2.065 & 2.329 \\
\hline $6 \mathrm{~B}$ & 2.212 & 2.208 & \\
\hline $7 \mathrm{~A}$ & 2.052 & 1.967 & 2.204 \\
\hline $7 \mathrm{~B}$ & 2.163 & 2.116 & \\
\hline $7 \mathrm{C}$ & 2.293 & 2.259 & \\
\hline $8 \mathrm{~A}$ & 2.118 & 2.111 & 2.372 \\
\hline $8 \mathrm{~B}$ & 2.167 & 2.162 & \\
\hline $8 C$ & 2.344 & 2.295 & \\
\hline $8 D$ & 2.283 & 2.259 & \\
\hline $9 \mathrm{~A}$ & 2.190 & 2.195 & 2.252 \\
\hline $9 \mathrm{~B}$ & 2.170 & 2.163 & \\
\hline $9 \mathrm{C}$ & 2.270 & 2.269 & \\
\hline $10 \mathrm{~A}$ & 2.149 & 2.145 & 2.131 \\
\hline $10 \mathrm{~B}$ & 2.224 & 2.213 & \\
\hline $10 \mathrm{C}$ & 2.097 & 2.090 & \\
\hline JC1-A & 2.097 & 2.114 & \\
\hline JC1-B & 2.127 & 2.103 & \\
\hline JC1-C & 2.282 & 2.284 & \\
\hline JC2-A & 2.141 & 2.129 & \\
\hline JC2-B & 2.152 & 2.091 & \\
\hline
\end{tabular}

